\title{
First Annual Progress Report on Radiation Tolerance of Controlled Fusion Welds in High Temperature Oxidation Resistant FeCrAl Alloys
}

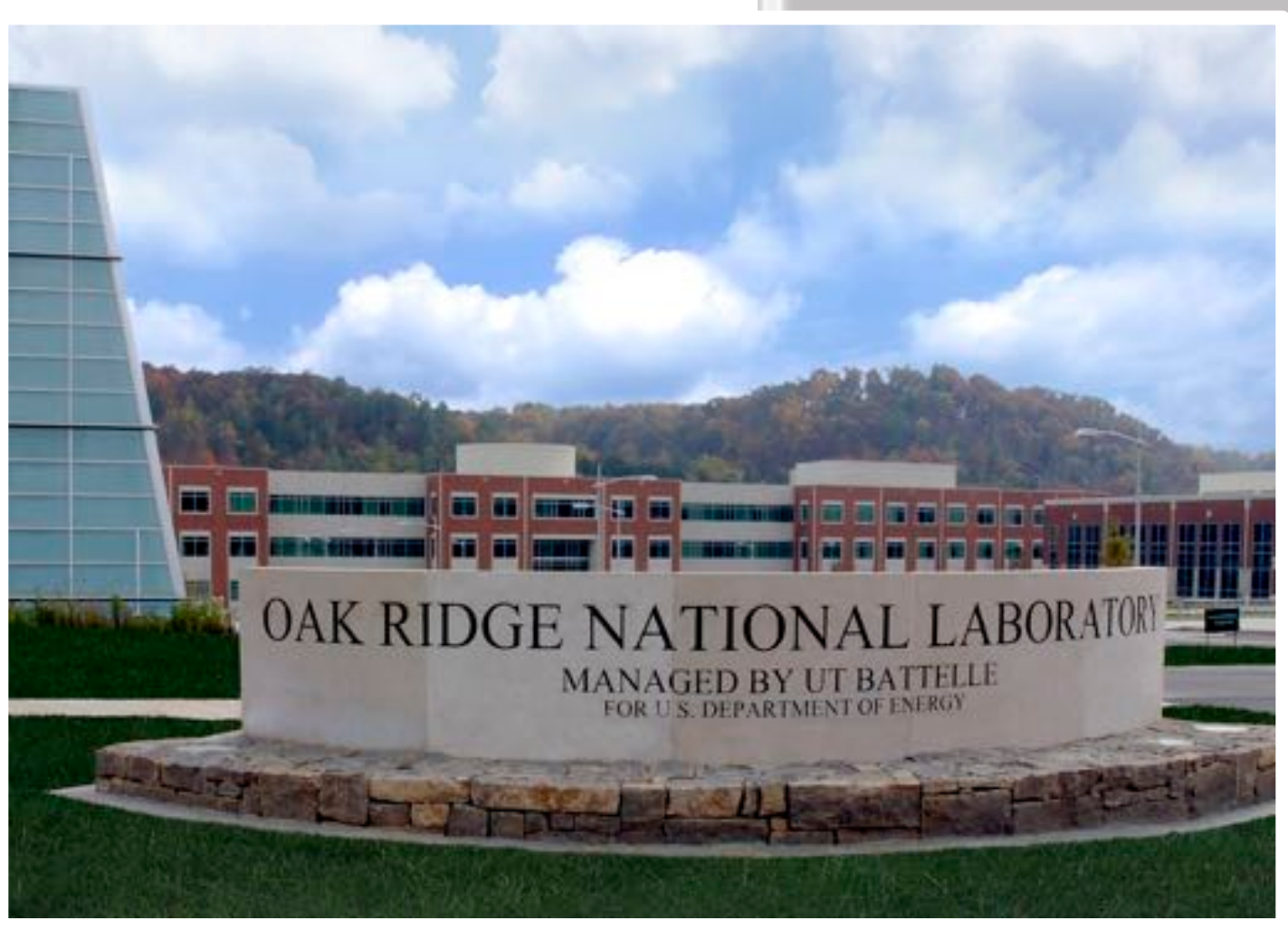

Approved for public release. Distribution is unlimited.
Kevin G. Field Maxim N. Gussev Xunxiang $\mathrm{Hu}$ Yukinori Yamamoto Richard Howard

December 30, 2015 


\section{DOCUMENT AVAILABILITY}

Reports produced after January 1, 1996, are generally available free via US Department of Energy (DOE) SciTech Connect.

Website http://www.osti.gov/scitech/

Reports produced before January 1, 1996, may be purchased by members of the public from the following source:

National Technical Information Service

5285 Port Royal Road

Springfield, VA 22161

Telephone 703-605-6000 (1-800-553-6847)

TDD 703-487-4639

Fax 703-605-6900

E-mail info@ntis.gov

Website http://www.ntis.gov/help/ordermethods.aspx

Reports are available to DOE employees, DOE contractors, Energy Technology Data Exchange representatives, and International Nuclear Information System representatives from the following source:

Office of Scientific and Technical Information

PO Box 62

Oak Ridge, TN 37831

Telephone 865-576-8401

Fax 865-576-5728

E-mail reports@osti.gov

Website http://www.osti.gov/contact.html

This report was prepared as an account of work sponsored by an agency of the United States Government. Neither the United States Government nor any agency thereof, nor any of their employees, makes any warranty, express or implied, or assumes any legal liability or responsibility for the accuracy, completeness, or usefulness of any information, apparatus, product, or process disclosed, or represents that its use would not infringe privately owned rights. Reference herein to any specific commercial product, process, or service by trade name, trademark, manufacturer, or otherwise, does not necessarily constitute or imply its endorsement, recommendation, or favoring by the United States Government or any agency thereof. The views and opinions of authors expressed herein do not necessarily state or reflect those of the United States Government or any agency thereof. 
ORNL/TM-2015/770

M2CA-14OR0404025

Nuclear Energy Enabling Technologies (NEET): Reactor Materials

\section{First Annual Progress Report on Radiation Tolerance of Controlled Fusion Welds in High Temperature Oxidation Resistant FeCrAl Alloys}

Kevin G. Field, Maxim N. Gussev, Xunxiang Hu, Yukinori Yamamoto, and Richard Howard

Date Published: December $30^{\text {th }}, 2015$

Prepared by

OAK RIDGE NATIONAL LABORATORY

Oak Ridge, Tennessee 37831-6283

managed by

UT-BATTELLE, LLC

for the

US DEPARTMENT OF ENERGY

under contract DE-AC05-00OR22725 



\section{CONTENTS}

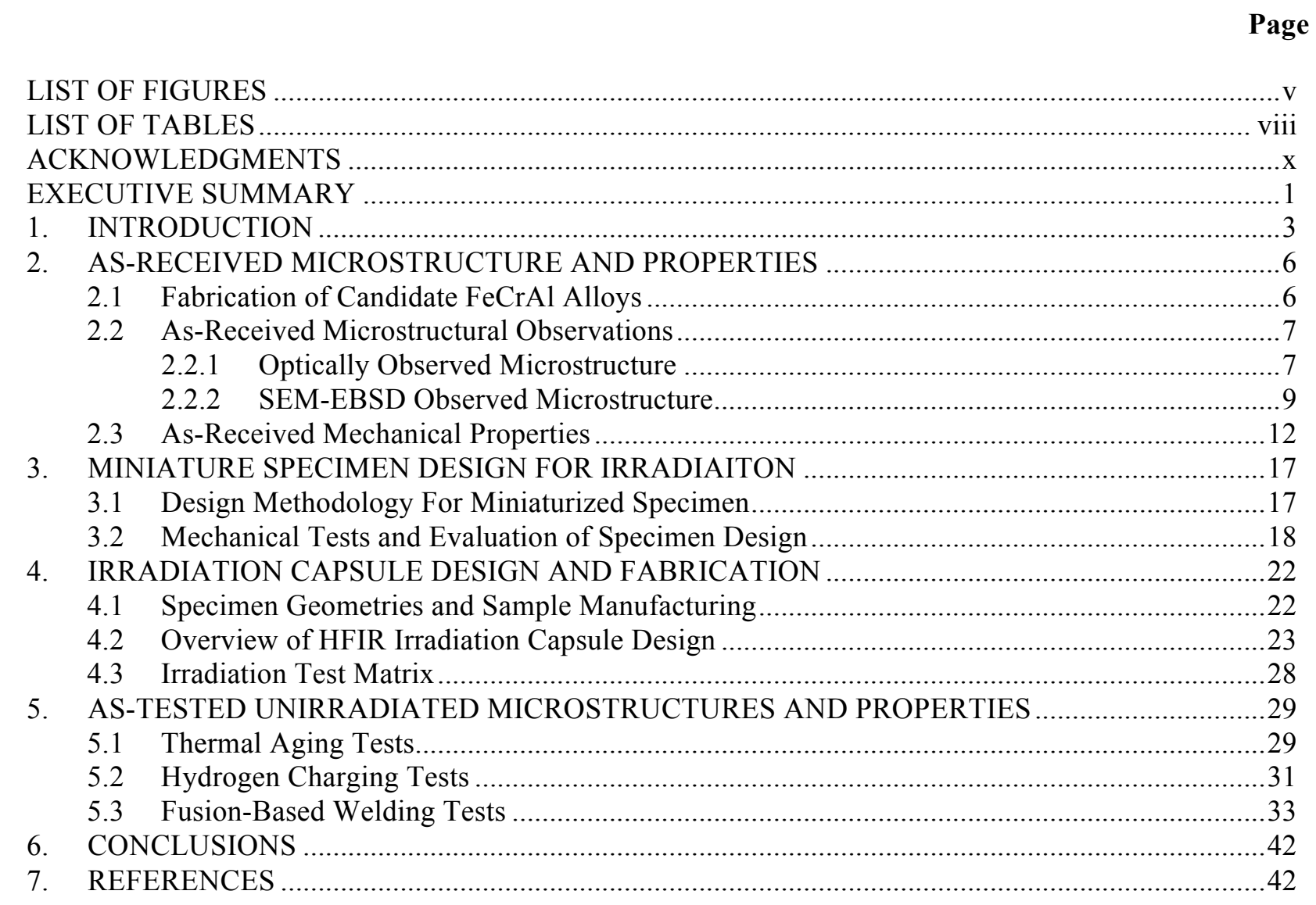





\section{LIST OF FIGURES}

Figure

Page

Figure 1: Optical micrographs of Fe-10Al-5Cr alloys welded in pure $\mathrm{Ar}$ (a) and $\mathrm{Ar}+5 \% \mathrm{H}$ (b) reproduced from Ref. [6]. Figure shows the susceptibility of FeCrAl alloys to hydrogen cracking during welding.

Figure 2: Composition effect on the weldability of $\mathrm{FeCrAl}$ alloys after gas tungsten arc welding (GTAW). Reproduced from Ref. [8]...

Figure 3: Scattered intensities and best-fit model of $\mathrm{FeCrAl}$ specimens obtained from SANS after irradiation in the HFIR at $382^{\circ} \mathrm{C}$ to a dose of $1.8 \mathrm{dpa}$. Higher scattering intensities in the range of $\sim 1 \mathrm{Q}$ is indicative of higher $\alpha^{\prime}$ volume fraction. Reproduced from [17].

Figure 4: Optical micrographs of candidate $\mathrm{FeCrAl}$ alloys for welding and irradiation testing; (a) C35M, (b) C36M, (c) C37M, (d) C35MN, (e) C35M01 TC, (f) C35M03TC, and (g) C35M10TC. Rolling direction is left to right in all images. .

Figure 5: Typical SEM-EBSD determined microstructure of the (a) C35M alloy and (b) C37M alloy. Black dashed ovals show non-recrystallized areas. Black arrow shows elongated defect ("stringer").

Figure 6: The as-received texture of the C35M alloy. Grains are strongly orientated close to the [101] pole.

Figure 7: Typical SEM-EBSD determined microstructure of the (a) C35M01TC alloy, (b) C35M03TC, and (c) C35M10TC alloy.

Figure 8. Typical engineering diagrams for the tested specimens of SS-J geometry.

Figure 9: An example of DIC (digital image correlation) data for one of the as-received C35MT10alloy specimens.

Figure 10: Fracture surface images of (a) C35M, (b) C36M, and (c) C37M FeCrAl alloys. .15

Figure 11: The typical fracture surface of the C35M10TC alloy specimen, (a) at low SEM magnification and (b) at higher SEM magnification.

Figure 12: C35M01TC alloy specimen: general view of the fracture surface and a location with specific cube-shaped particles located in the dimples, (a) at low SEM magnification and (b) at higher SEM magnification.

Figure 13: Preliminary geometries.

Figure 14: Simplified schematic of the tensile specimen geometries for weld and irradiation testing. Figure not to scale.

Figure 15: Images of a C35M specimen (Type 1E-0.4) tested using "natural contrast" conditions; high-angle lighting was employed to increase surface variation contrast. a) The specimen loaded at $\sim 40 \%$ yield stress; b) Image taken at the ultimate stress point; c) Image taken close to the fracture point. Black arrows point local plastic strain in the head area. "D" shows a "digital extensometer" tracking two selected points at the specimen surface. Insertions at the left show the engineering load-displacement diagram with a red arrow pointing displacement and load values for the corresponding image.

Figure 16: True stress-true strain curves obtained for the tested specimens for the (a) uniform elongation and (b) for the neck area using the DIC data. Red: Type-1 specimens in Table 2, all types; blue: Type-2 specimens in Table 2, all types; green: SS-J type.

Figure 17: Image of laser engraving positions on the specimens; (a) SS-J type and (b) SS-2E.................23

Figure 18: Cross-section through HFIR illustrating the primary experimental sites (left) and a picture of the reactor core (right)

Figure 19: Flux trap irradiation positions 
Figure 20: HFIR irradiation capsule design showing the versatile use of both SS-J type and SS-2E specimens in the same irradiation campaign

Figure 21: Images of representative specimens and subassemblies. From left to right: $\mathrm{SiC}$ thermometry, chevron and coffin assemblies, SS-J type and SS-2E specimens, tensile specimens in holders, and sub-holder assembly and roll pin.

Figure 22: Specimen temperature contours for (a) $200^{\circ} \mathrm{C}$ PTT5 FCAT design, (b) $330^{\circ} \mathrm{C}$ PTT6 FCAT design, and (c) $550^{\circ} \mathrm{C}$ PTT5 FCAT design.

Figure 23: The effect of $\mathrm{Cr}$ and $\mathrm{Al}$ addition on the change in micro hardness in candidate $\mathrm{FeCrAl}$ as a function of time at (a) $400^{\circ} \mathrm{C}$ and (b) $475^{\circ} \mathrm{C}$. Data points are based on averaging greater than 5 individual measurements, standard deviations were on average 4-5 HV 0.3 30

Figure 24: Proposed FeCrAl phase diagram at $475^{\circ} \mathrm{C}$. Adapted for use from Ref. [11].....

Figure 25: Comparison of tensile testing results for as-received C37M (green), low hydrogen loading sample (blue), and high hydrogen loading sample (red)....

Figure 26: Image of cross-welds performed using laser welding techniques on the C37M alloy; (a) as imaged, (b) with overlays of SS-J type and SS-2E sample geometries to show where samples were fabricated from.

Figure 27: SEM-EBSD determined IPF maps showing weldment structure in the (a) C35M, (b) C37M, (c) C35M01TC, (d) C35M03TC, and (e) C35M10TC candidate alloys. .35

Figure 28: Cross weld hardness maps (Hv 0.3) taken at $100 \mu \mathrm{m} \times 100 \mu \mathrm{m}$ spacing of (a) C35M, (b) C37M, (c) C35M01TC, and (d) C35M03TC. Color scale is the same for each map. ..............36

Figure 29: Engineering tensile curves for the C35M10TC alloy before and after welding. .......................37

Figure 30: Strain distribution at the surface of the C35M10TC welded specimen. ...................................38

Figure 31: The local mechanical behavior of the weldment (C35M10TC alloy)......................................38

Figure 32: Fractography analysis of the C35MTC10 alloy prior (left) and after (right) welding. ...............39

Figure 33: The typical fracture surface of the welded C35MTC01 alloy specimen..................................40

Figure 34: The impact of the laser welding on the C37M alloy fracture mechanism (a - lower magnification image and $b$ ) higher magnification image). The fracture surface of the asreceived (c) specimen is shown at the bottom to underline the degree of changes. 



\section{LIST OF TABLES}

\section{Table}

Page

Table 1: Candidate FeCrAl alloys processing routes and composition in weight percent analyzed by

Table 2: Mechanical properties of the tested as-received specimens.

Table 3: Mechanical properties of the C35M3 alloy determined using different tensile specimen

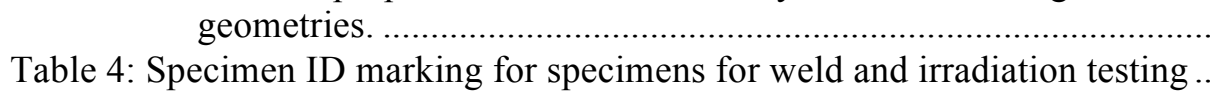

Table 5: Design performance of the modular tensile design demonstrating thermal equivalence of

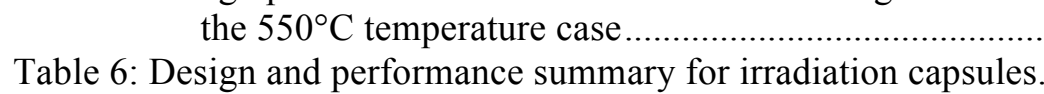

Table 7: Irradiation test matrix and single rabbit loading list by alloy type, specimen type, and configuration. Alloys ODS FeCrAl and C06M are FeCrAl alloys currently of interest in other irradiation programs.

Table 8: Oxygen and hydrogen contents after cathodic charging. The oxygen and hydrogen of asreceived samples are also listed for comparison.

Table 9: Summary of the tensile properties for C37M with different hydrogen contents

Table 10: Mechanical properties of the welded specimens in comparison with the as-received material. 



\section{ACKNOWLEDGMENTS}

This research was sponsored by the U.S. Department of Energy, Office of Nuclear Energy, for the Nuclear Energy Enabling Technologies (NEET) program for the Reactor Materials effort. This report was authored by UT-Battelle, LLC under Contract No. DE-AC05-00OR22725 with the U.S. Department of Energy. The assistance of Zach Thomas and Jay Ferriday on the thermal aging studies is graciously acknowledged. 


\section{EXECUTIVE SUMMARY}

The present report summarizes and discusses the first year efforts towards developing a modern, nuclear grade $\mathrm{FeCrAl}$ alloy designed to have enhanced radiation tolerance and weldability under the Department of Energy (DOE) Nuclear Energy Enabling Technologies (NEET) program. Significant efforts have been made within the first year of this project including the fabrication of seven candidate FeCrAl alloys with well controlled chemistry and microstructure, the microstructural characterization of these alloys using standardized and advanced techniques, mechanical properties testing and evaluation of base alloys, the completion of welding trials and production of weldments for subsequent testing, the design of novel tensile specimen geometry to increase the number of samples that can be irradiated in a single capsule and also shorten the time of their assessment after irradiation, the development of testing procedures for controlled hydrogen ingress studies, and a detailed mechanical and microstructural assessment of weldments prior to irradiation or hydrogen charging. These efforts and research results have shown promise for the $\mathrm{FeCrAl}$ alloy class as a new nuclear grade alloy class.

Chapter 1 provides a brief overview of the FeCrAl alloy class as nuclear technology including their hypothesized benefits as well as where potential knowledge gaps exist. Specifically, FeCrAl alloys are an attractive alloy class due to their excellent environmental compatibility including aqueous corrosion, heavy metal compatibility, and oxidation resistance in high temperature steam [1-4]. Given this, their weldability and radiation tolerance under specific radiation environments including light water reactor (LWR) environments could limit their overall application. Hence, in Chapter 2 a set of seven alloys were developed to assess different compositions and microstructures, which could increase the radiation tolerance of the alloys while decreasing their cracking susceptibility during welding. These modern FeCrAl alloys are all based on a Fe-13Cr-5Al-2Mo-0.2Si-0.05Y (in wt.\%) FeCrAl alloy. This alloy is designated within the program as $\mathrm{C} 35 \mathrm{M}$. The other six alloys produced included alloys with $\mathrm{TiC}$ and Laves phase distributions and alloys with varying $\mathrm{Al}$ content. The $\mathrm{C} 35 \mathrm{M}$ alloy was used as the master alloy for all alloys. These alloys were assessed using optical microscopy, electron microscopy, and mechanical testing techniques. Further details on these assessments are discussed in Chapter 2.

One issue with current research and development programs with limited timeframes but interested in mechanical testing of specimens irradiated in materials test reactors is the large volume of current specimen sizes prevents them to be brought into low-radiological threat facilities immediately following irradiation. This pushes out post-irradiation examination (PIE) timelines. Furthermore, many hot cell facilities do not provide robust in-situ techniques or the ability to determine true stress-strain curves, limiting the information gained from valuable (both in cost and potential knowledge gained) samples. Hence, in Chapter 3 a miniature uniaxial tensile test specimen was developed. Several different geometries were evaluated and it was determined the SS-2E geometry provided the best repeatable results towards other sub-sized tensile specimens typically used in materials test reactors. The SS-2E geometry reduces the volume nearly five times over the smallest sample currently in deployment. This volume reduction in-turn reduces the radiological threat of specimens allowing the specimens to be brought into facilities with proper in-situ experimental techniques such as Oak Ridge National Laboratory's (ORNL) Low Activation Materials Development and Analysis (LAMDA) facility.

The new SS-2E geometry developed in Chapter 3 and the new alloys developed in Chapter 2 will be evaluated under intense neutron irradiation in the High Flux Isotope Reactor (HFIR) housed at ORNL. Chapter 4 discusses the irradiation campaign to accomplish this including the development of a modular irradiation capsule or "rabbit" which can house standard sub-sized tensile specimens as well as the new SS-2E tensile specimen geometry in the same rabbit. These two different geometries can be interspersed within the rabbit allowing for a high degree of flexibility in the irradiation campaign. The irradiation program for the $\mathrm{FeCrAl}$ alloys will evaluate three different temperatures, $200^{\circ} \mathrm{C}, 330^{\circ} \mathrm{C}$, and $550^{\circ} \mathrm{C}$ at 
three different nominal doses, $2 \mathrm{dpa}, 8 \mathrm{dpa}$, and $15 \mathrm{dpa}$. This dose and temperature range spans a wide range of conditions used in nuclear reactors and hence will provide initial insight on the radiation tolerance of the seven different FeCrAl alloys including welded specimens. Both SS-2E geometries and standard sub-sized specimens will be irradiated allowing for the first direct comparison between the new specimen geometry developed and the more typically used specimen geometries on irradiated specimens. The first specimens are expected to be evaluated in early fiscal year 2016 (FY16).

Chapter 5 presents results on different testing and evaluation programs to provide a sound foundation on the understanding of the FeCrAl alloys prior to irradiation. Three major thrusts have been completed. These are thermal aging, hydrogen charging, and fusion-based weldability assessment. The seven alloys have been used in these three thrusts. Section 5.1 showed a possibility for phase instabilities in the alloys at temperatures of $400^{\circ} \mathrm{C}$ and $475^{\circ} \mathrm{C}$, although some promise on minimizing this effect through composition refinement was found. Section 5.2 presents results on hydrogen charging, and it was found that in the short term goals of this program that cathodic hydrogen charging provided the best process for introducing hydrogen into the alloys. Initial tensile testing of hydrogen loaded specimens shows that these samples can have significantly different tensile responses compared to their unloaded counterparts. Finally, Section 5.3 presents the optimized welding trials including microstructural and mechanical property evaluations. Initial results show the addition of $\mathrm{TiC}$ in the base alloy could modify the microstructure in the weldments, which might lead to better overall weldability of the FeCrAl alloy class.

The results and discussion presented in the following report provide a brief overview of the program currently in place focused on optimizing both the microstructure and chemistry of the FeCrAl alloy class to obtain the necessary properties and performance for nuclear power applications including weldability, thermal stability, and radiation tolerance. 


\section{INTRODUCTION}

Modern $\mathrm{FeCrAl}$ alloys with a potential for optimized chemistry and microstructure are an attractive class of materials for nuclear power production applications. Studies on the modern FeCrAl alloys class have indicated their capability to have excellent environmental compatibility including aqueous corrosion, heavy metal compatibility, and oxidation resistance in high-temperature steam [1-4]. These inherent properties lead the $\mathrm{FeCrAl}$ alloy class to be conceptualized for use in a range of nuclear reactor materials deployments including as cladding materials with enhanced accident tolerance for light water reactors (LWRs), in the dual-coolant lead-lithium (DCLL) blanket concept for fusion reactor technologies, and as structural components for advanced fast reactor designs. The FeCrAl alloy class is also an attractive class for nuclear applications as it has a rich history in other energy generation and industrial applications including the fossil fuel and automotive industry. Hence, materials development programs for FeCrAl alloys centered on nuclear power production can leverage this pre-existing materials database and use it as an initial starting point for further alloy optimization for nuclear specific applications.

Use of $\mathrm{FeCrAl}$ alloys outside the nuclear energy realm have indicated that $\mathrm{FeCrAl}$ alloys are susceptible to cracking during welding, particularly during fusion-based welding where hydrogen or water might be present [5-8]. For example, Dupont et al. showed that hydrogen impurities can lead to significant cracking in $\mathrm{FeCrAl}$ alloys, Figure 1 [7]. Figure 1 shows that the presence of 5\% hydrogen impurity in the cover gas during welding can lead to significant cracking but such effect is not observed in welding with cover gasses absent of hydrogen. Furthermore, the studies of Regina et al. have shown the cracking susceptibility under welding is composition dependent, with high-Cr and/or high-Al additions leading to cracking in the fusion zone, Figure 2 [8]. The cracking in these alloys has been linked to the free hydrogen interacting with the microstructure and has been hypothesized that water vapor interacts with the $\mathrm{Cr}$ and $\mathrm{Al}$ during welding to produce this detrimental free hydrogen. The possibility and assessment of cracking during welding needs to be evaluated for $\mathrm{FeCrAl}$ alloys deemed to be relevant towards nuclear applications.
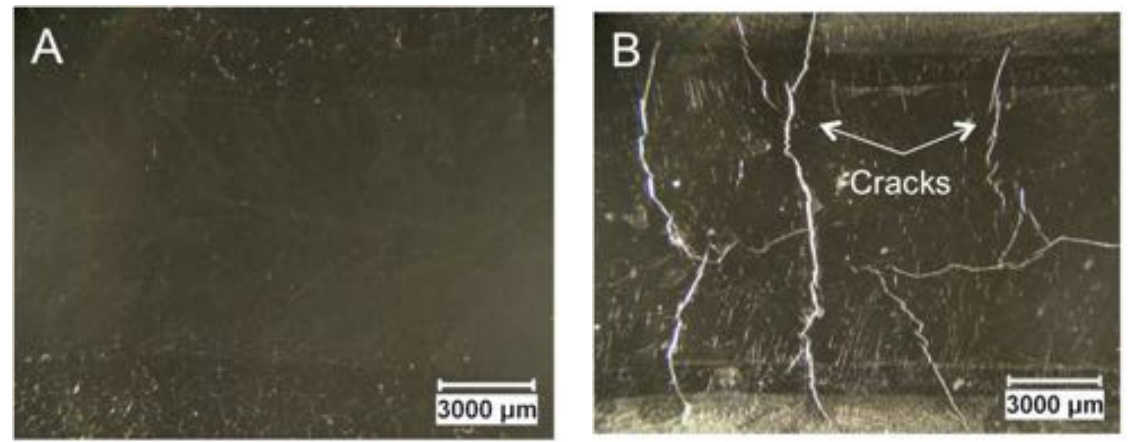

Figure 1: Optical micrographs of Fe-10Al-5Cr alloys welded in pure $\mathrm{Ar}$ (a) and $\mathrm{Ar}+5 \% \mathrm{H}$ (b) reproduced from Ref. [6]. Figure shows the susceptibility of FeCrAl alloys to hydrogen cracking during welding.

Fusion based welding techniques, the primary welding technology for several nuclear applications $[9,10]$, can also have detrimental secondary impacts for nuclear applications. Of primary concern is the destruction of highly controlled base microstructures due to the high heat input that leads to melting in the fusion zone and significant temperature increases surrounding the fusion zone leading to the wellestablished heat-affected zone (HAZ) in the weldments. These effects lead to a loss of the controlled microstructure in the fusion zone and HAZ. These important microstructural aspects, such as grain size, dislocation networks, and precipitate dispersions that can be lost as the result of welding, are primary defect sinks under irradiation leading to the material increased (or decreased) radiation tolerance. Clearly, 
delicate microstructural control is needed in the base metal, HAZ, and fusion zone to maintain any predetermined requirements for radiation tolerance towards a components end-of-life.

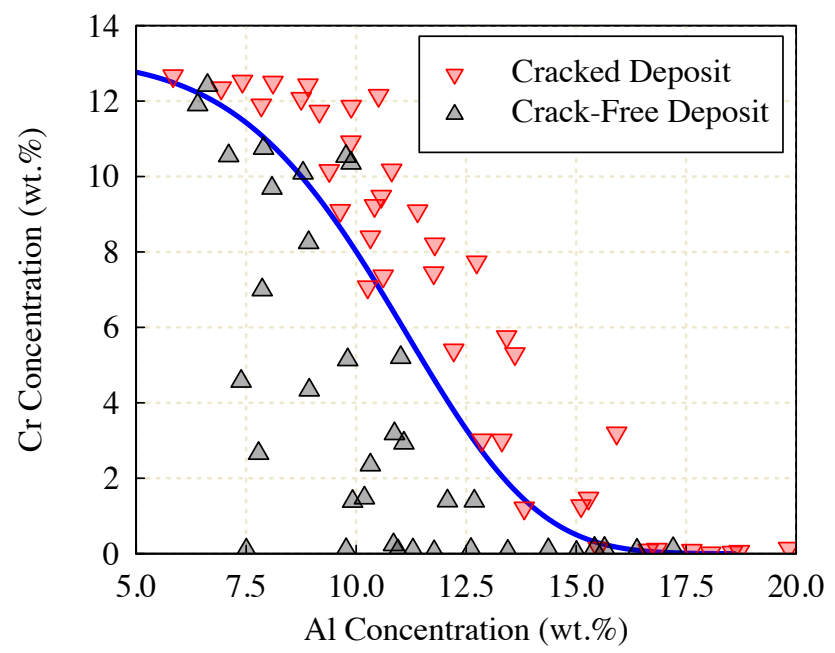

Figure 2: Composition effect on the weldability of $\mathrm{FeCrAl}$ alloys after gas tungsten arc welding (GTAW). Reproduced from Ref. [8].

Another key aspect of the radiation tolerance of $\mathrm{FeCrAl}$ alloys is phase stability under irradiation. The work of Kobayashi and Takasugi [11] laid the ground work for showing that specific FeCrAl compositions, particularly those with high-Cr and low-Al content, can have a phase instability leading to the formation of the Cr-rich $\alpha^{\prime}$ phase. This phase is well known and has been studied in detail for $\mathrm{FeCr}$ alloys, such as model alloys or HT-9 [12-16]. Generally, in the compositions relevant to nuclear applications, the Cr-rich $\alpha^{\prime}$ phase precipitates out as small, nanometer-sized spherical precipitates at number densities well in excess of $10^{23} \mathrm{~m}^{-3}$ [16]. Although these small precipitates have been generally demonstrated to be a weak barrier to dislocation motion [17,18], their large number density and fairly homogenous distribution in the matrix can significantly impact the mechanical properties including both the tensile and fracture properties of $\mathrm{FeCr}$ alloys. Recently, the work of Field et al. [11,19] has indicated phase instability of thermally aging of $\mathrm{FeCrAl}$ alloys and under both thermal aging and neutron irradiation for $\mathrm{FeCr}$ alloys, also occurs under accelerated neutron irradiation for four model $\mathrm{FeCrAl}$ alloys using small angle neutron scattering (SANS) techniques, Figure 3 [17]. This work also showed the significant impact $\alpha^{\prime}$ can have on the tensile properties of FeCrAl alloys. Although the work of Field et al., and the many conducted for $\mathrm{FeCr}$ systems, provides some insight into the phase stability of $\mathrm{FeCrAl}$ alloys under irradiation, a more detailed and systematic study is needed to fully assess the mechanisms for $\mathrm{FeCrAl}$ alloys and also the impact on that of FeCrAl weldments.

Limited systematic investigations have been conducted to individually assess the weldability and radiation tolerance as well as the confluence between the two in the FeCrAl alloys class. For example, studies were conducted in the 1960's at General Electric and supporting contractors under the HighTemperature Materials Program on FeCrAl alloys but the studies were generally limited towards hightemperature applications $\left(>500^{\circ} \mathrm{C}\right)$ for fuel compatibility tests and limited irradiation studies conducted at very low temperatures $\left(<120^{\circ} \mathrm{C}\right)$ [20-22]. To the authors knowledge, based on the output of the HighTemperature Materials Program, no studies were specifically focused on looking at the radiation tolerance of weldments or techniques/tactics for successful fusion based welds of their experimental alloys. Furthermore, the aforementioned work of Field et al. [17] was solely focused on model FeCrAl alloys in an unwelded state. 


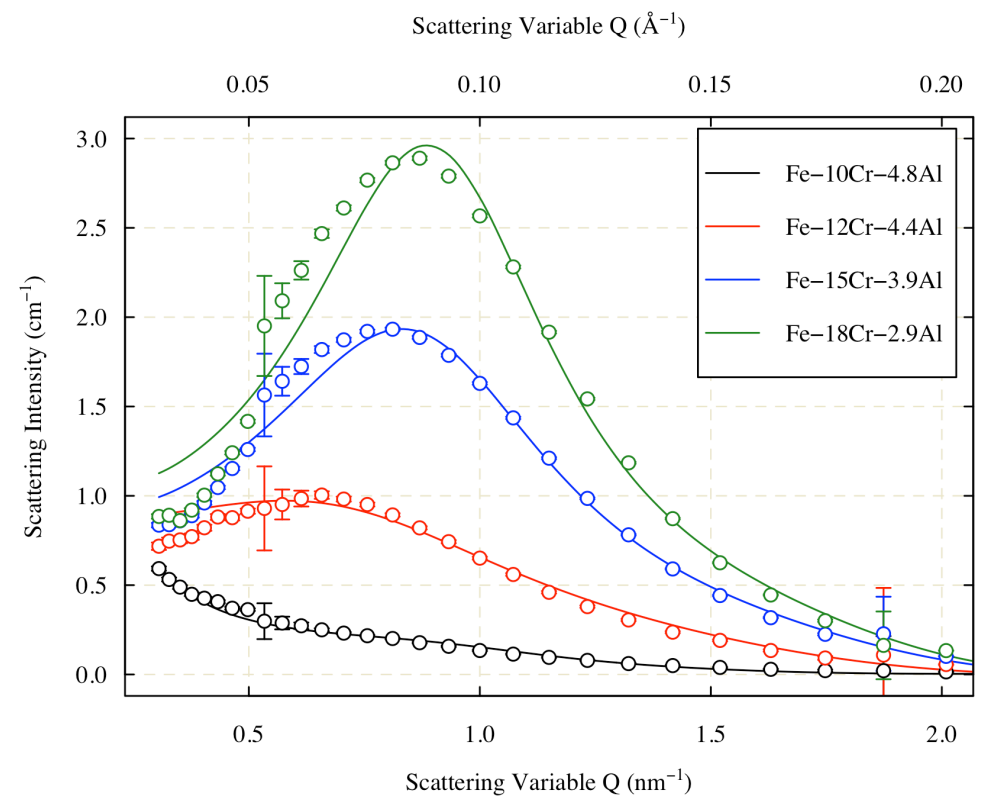

Figure 3: Scattered intensities and best-fit model of FeCrAl specimens obtained from SANS after irradiation in the HFIR at $382^{\circ} \mathrm{C}$ to a dose of $1.8 \mathrm{dpa}$. Higher scattering intensities in the range of $\sim 1 \mathrm{Q}$ is indicative of higher $\alpha^{\prime}$ volume fraction. Reproduced from [17].

The limited information in literature in regards to radiation tolerance and weldability presents a challenge for designers and engineers who wish to exploit the marked benefits of $\mathrm{FeCrAl}$ alloys as an accurate extrapolation of FeCrAl's performance throughout a life cycle in a reactor concept cannot be completed. To provide critical data and analysis, a research and development program centralized on the use of candidate $\mathrm{FeCrAl}$ alloys to assess the fusion-based weldability and radiation tolerance of these alloys has been initiated. This program was initiated in the United States 2015 fiscal calendar year under the Department of Energy (DOE) Nuclear Energy Enabling Technologies (NEET) program.

The FeCrAl alloys development program under the DOE NEET program is focused on studying two main possibilities for the advancement of FeCrAl alloy development: (1) use of hydrogen trapping sites as a mitigation strategy for susceptibility to cracking during fusion-based welding and (2) refined microstructural and composition control for increased phase stability and hence radiation tolerance under neutron irradiation. These two thrusts are based on initial successes shown outside of the nuclear field. Primarily, recent work on introducing benign hydrogen trapping sites such as fine precipitate dispersion has shown to reduce the crack susceptibility of $\mathrm{FeCrAl}$ alloys during fusion-based welding in the presence of hydrogen [7]. Also, the work of Kobayashi and Takasugi [11], mentioned previously, have indicated that increasing the $\mathrm{Al}$ content greater than $\sim 5 \mathrm{wt} . \%$ can push the phase boundary for $\alpha^{\prime}$ precipitation under thermal aging to higher $\mathrm{Cr}$ contents. By shifting the phase boundary, the volume fraction of $\alpha^{\prime}$ demonstrated by Field et al. [17] could be greatly reduced or completely eliminated under irradiation. Both research thrusts, and hence significant findings, can then be coupled to generate a FeCrAl alloy with fully optimized chemistry and microstructure that is both easily weldable and radiation tolerant for extended nuclear power service times.

During the first year of this research and development program, several significant activities and findings have been completed. This includes the fabrication of seven candidate FeCrAl alloys with well-controlled chemistry and microstructure, the microstructural characterization of these alloys using standardized and advanced techniques, mechanical properties testing and evaluation of base alloys, the completion of welding trails and production of weldments for subsequent testing, the design of novel tensile specimen geometry to increase the number of samples that can be irradiated in a single capsule and also shorten the 
time of their assessment after irradiation, the development of testing procedures for controlled hydrogen ingress studies, and a detailed mechanical and microstructural assessment of weldments prior to irradiation or hydrogen charging. Many of the details of these program outputs can be found in the previously published milestone reports for this program [23-25]. As a vehicle to provide a concise and consolidated repository of information on this research, the following report briefly describes the highlights from the program on Radiation Tolerance of Controlled Fusion Welds in High Temperature Oxidation Resistant FeCrAl Alloys completed in the first fiscal year of execution, FY2015.

\section{AS-RECEIVED MICROSTRUCTURE AND PROPERTIES}

\subsection{Fabrication of Candidate FeCrAl Alloys}

Three different sub-alloy classes within the FeCrAl alloy class was conceptualized, fabricated, and assessed for use within this research and development program. The three sub-classes are: FeCrAl alloys with high-Al additions (6-7 wt.\% Al, designated as C36M and C37M), FeCrAl alloys with Laves precipitate dispersions (designated as $\mathrm{C} 35 \mathrm{MN}$ ), and $\mathrm{FeCrAl}$ alloys with $\mathrm{TiC}$ precipitate dispersions (designated as C35M01TC, C35M03TC, C35M10TC). The alloys generated in these sub-alloy classes were all derivations of a primary candidate alloy designated as $\mathrm{C} 35 \mathrm{M}$. The $\mathrm{C} 35 \mathrm{M}$ alloy is a $\mathrm{FeCrAl}$ alloy with a nominal target composition of $\mathrm{Fe}-13 \mathrm{Cr}-5 \mathrm{Al}-2 \mathrm{Mo}-0.2 \mathrm{Si}-0.05 \mathrm{Y}$ with a ferritic matrix with grain sizes on the order of 5-10 $\mu \mathrm{m}$. The base alloy content of $13 \mathrm{wt} . \% \mathrm{Cr}$ and $5 \mathrm{wt} \% \mathrm{Al}$ was selected based on initial findings on composition dependencies for radiation tolerance, oxidation resistance, and property developments of $\mathrm{FeCrAl}$ alloys $[4,17,26]$. Mo and $\mathrm{Si}$ are included as solid-solution strengtheners. The alloy derivations where developed as the addition of increased $\mathrm{Al}$ in the matrix is suspected to push the phase boundary for Cr-rich $\alpha^{\prime}$ formation resulting in a reduction or elimination of $\alpha^{\prime}$ formation under irradiation and the precipitate dispersions composed of either Laves phase or TiC are hypothesized to act as benign hydrogen trapping sites thereby reducing the diffusible hydrogen under fusion-welding. By reducing the diffusible hydrogen, the hope is to decrease the cracking susceptibly of the alloy under fusion welding in a hydrogenated and/or water environment.

Two different processing routes were utilized to produce different sub-alloy classes. The first is vacuum induction melting (VIM) while the second is arc melting with drop-casting. Due to the limited complexity needed for the fabrication of C35M, C36M, C37M, and C35MN, a commercial vendor was used for the VIM production of feedstock for the program. The resulting feedstock was VIM ingots of $\sim 18 \mathrm{~kg}$ and a size of $81 \mathrm{~mm}$ diameter by $300 \mathrm{~mm}$ length. The VIM ingots were homogenized at $1200^{\circ} \mathrm{C}$ in an argon gas atmosphere for $4 \mathrm{~h}$, followed by air-cooling and water-quenching. The ingots were sectioned into small pieces, hot forged at $800^{\circ} \mathrm{C}$ with total $50 \%$ thickness reduction to make plate-shaped samples. The plates were hot-rolled at $800^{\circ} \mathrm{C}$ with an additional $40 \%$ reduction and then annealed at $800^{\circ} \mathrm{C}$ in laboratory air for $1 \mathrm{~h}$. The resulting total thickness reduction was $70 \%$ after this step. The plates were then warm-rolled at $300^{\circ} \mathrm{C}$ with an $80-90 \%$ total thickness reduction from the hot-rolled plates and then annealed at $650^{\circ} \mathrm{C}$ for $1 \mathrm{~h}$ in air.

Arc melting with drop casting at Oak Ridge National Laboratory (ORNL) was used as the fabrication route for the C35M01TC, C35M03TC, and C35M10TC as the lab-scaled heat production allowed for precise chemistry and microstructure control. The ingots were $13 \mathrm{~mm} \times 25 \mathrm{~mm} \times 125 \mathrm{~mm}$. Commercial TiC powder with nominal $0.1,0.3$, and $1.0 \mathrm{wt} \%$ were mixed with $\mathrm{C} 35 \mathrm{M} 3$ (in Table 1, used as a master alloy) by arc-melting. The TiC powder was placed on the bottom of the water-cooled copper hearth in the arc-melt furnace, and then the master alloy was set on the powder. The first arc-melt was conducted on melting only the master alloy to cover all powder by the molten master alloy. Because of the surface tension of the $\mathrm{TiC}$ powder, the first melt typically resulted in only embedding the non-melted TiC powder at the bottom of the button ingot. The ingot was then flipped to make the embedded TiC powder lay on 
the top of the ingot, and then the second arc-melt was conducted to melt the TiC powder first. The melted TiC tended not to be miscible with the molten master alloy but flow on the top of the liquid during arcmelting. The flipping and arc-melting were repeated several times until the melted $\mathrm{TiC}$ was completely miscible in the liquid. Once the mixing was completed, the ingot was drop-cast in the mold with a size described above. Finished ingots were homogenized at $1200^{\circ} \mathrm{C}$ in an argon gas for $1 \mathrm{~h}$, followed by aircooling and water-quenching. The ingots were hot-forged and hot-rolled at $800^{\circ} \mathrm{C}$, then warm-rolled at $300^{\circ} \mathrm{C}$, and then annealed at $1 \mathrm{~h}$ in air.

All ingots were sent out to a commercial vendor to verify chemistry. Table 1 provides the resulting analyzed compositions and summarizes the processing route (VIM or arc melt) for each alloy. It should be noted that based on the weldability map in Figure 2, the alloys of interest lie on the crack - crack-free deposit boundary for gas tungsten arc welding (GTAW) and similar compositions have shown cracking when exposed to a hydrogenated environment during GTAW.

Table 1: Candidate FeCrAl alloys processing routes and composition in weight percent.

\begin{tabular}{|c|c|c|c|c|c|c|c|c|c|c|c|c|c|}
\hline Alloy & $\mathbf{F e}$ & $\mathrm{Cr}$ & Al & $\mathbf{Y}$ & Mo & Si & $\mathbf{N b}$ & $\mathrm{C}$ & $\mathbf{S}$ & $\mathbf{O}$ & $\mathbf{N}$ & $\mathbf{P}$ & $\mathbf{T i}$ \\
\hline $\mathrm{C} 35 \mathrm{M}^{1}$ & 79.43 & 13.06 & 5.31 & 0.053 & 2 & 0.13 & $<0.01$ & 0.001 & $<0.0003$ & 0.0012 & 0.0003 & 0.007 & $<0.01$ \\
\hline $\mathrm{C} 6 \mathrm{M}^{1}$ & 78.8 & 12.98 & 6 & 0.04 & 1.98 & 0.18 & $<0.01$ & 0.003 & $<0.0003$ & 0.0016 & 0.0002 & $<0.002$ & 0.01 \\
\hline C37 $M^{1}$ & 77.49 & 13.01 & 7.22 & 0.081 & 1.99 & 0.19 & $<0.01$ & 0.001 & $<0.0003$ & 0.0026 & 0.0002 & 0.004 & $<0.01$ \\
\hline $\mathrm{C}_{35} \mathrm{MN}^{1}$ & 78.7 & 13 & 5.11 & 0.044 & 1.99 & 0.18 & 0.96 & 0.005 & 0.0003 & 0.0014 & 0.0002 & $<0.002$ & - \\
\hline C35M01TC $^{2}$ & 79.51 & 13 & 5.2 & 0.04 & 1.98 & 0.15 & $<0.01$ & 0.024 & $<0.0003$ & 0.0009 & 0.0004 & 0.002 & 0.08 \\
\hline $\mathrm{C35M03TC}^{2}$ & 79.34 & 13.03 & 5.17 & 0.04 & 1.97 & 0.15 & $<0.01$ & 0.058 & $<0.0003$ & 0.0009 & 0.0003 & 0.003 & 0.22 \\
\hline C35M10TC $^{2}$ & 78.82 & 12.95 & 5.14 & 0.01 & 1.96 & 0.2 & $<0.01$ & 0.18 & $<0.0003$ & 0.0012 & 0.0007 & $<0.002$ & 0.71 \\
\hline
\end{tabular}

\subsection{As-Received Microstructural Observations}

\subsubsection{Optically Observed Microstructure}

As all alloys were designed to show similar microstructures, all alloys showed a fully-ferritic microstructure under optical microscopy, but the average nominal grain size and secondary phase dispersions varied depended on the investigated alloy. Figure 4 shows the optical micrographs of each alloy. Microstructures were controlled to keep generally good room-temperature ductility without reducing the tensile properties significantly from the as-rolled condition. The high Al-variants, C36M and $\mathrm{C} 37 \mathrm{M}$, as well as the base variant, $\mathrm{C} 35 \mathrm{M}$, had elongated grains along the rolling direction (left to right in Figure 4) with dispersions of partially recrystallized grains on the order of $5 \mu \mathrm{m}$. The band-like structure is due to the deformation caused during the hot-rolling process. The final annealing at $650^{\circ} \mathrm{C}$ resulted in the formation of partial recrystallization along the slip bands. Figure $4 \mathrm{~d}$ shows a successful dispersion of Laves phase (the dark contrast particles) in the base ferrite microstructure. Similarly, the TiC alloys (C35M01TC, C35M03TC, and C35M10TC) showed successful dispersions of TiC (the dark contrast particles) within a fully recrystallized ferritic matrix. Generally, the grain sizes for the TiC alloys was on the order of $10 \mu \mathrm{m}$. Figure $4 \mathrm{e}-\mathrm{g}$ shows the volume fraction of the TiC dispersion increased with increasing the nominal $\mathrm{TiC}$ contents of the alloys, although full quantitative assessment of the volume fraction remains to be determined. 
(a)

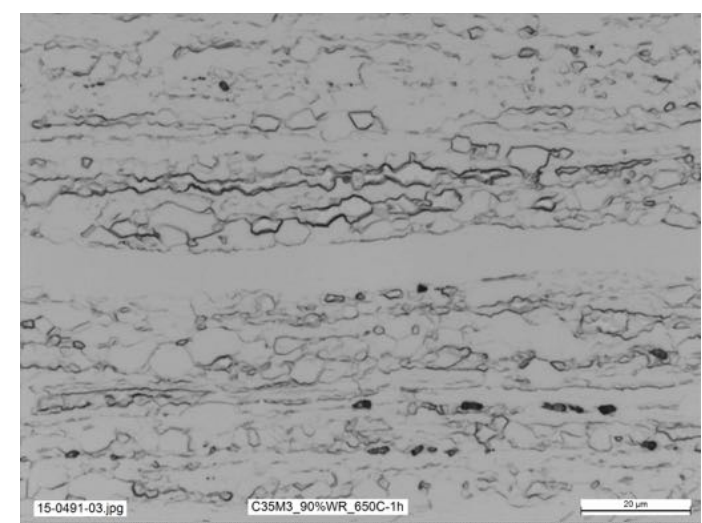

(c)

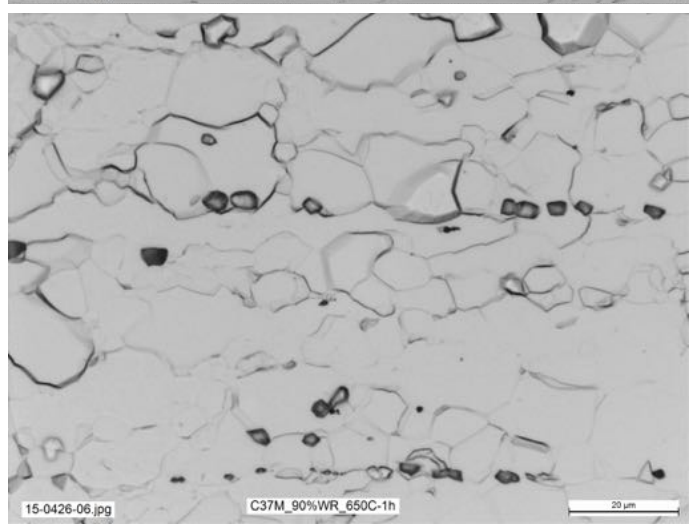

(e)

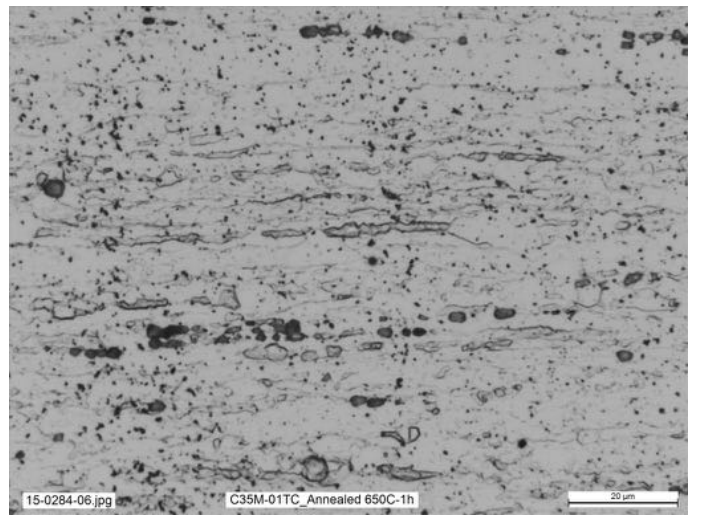

(g)

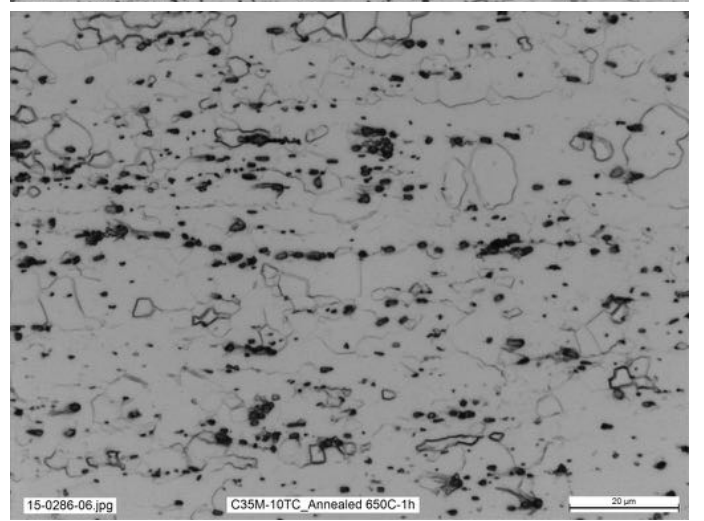

(b)

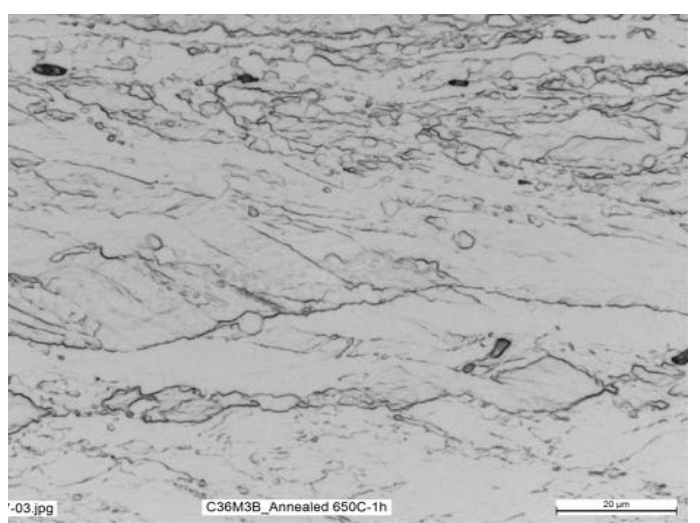

(d)

(f)
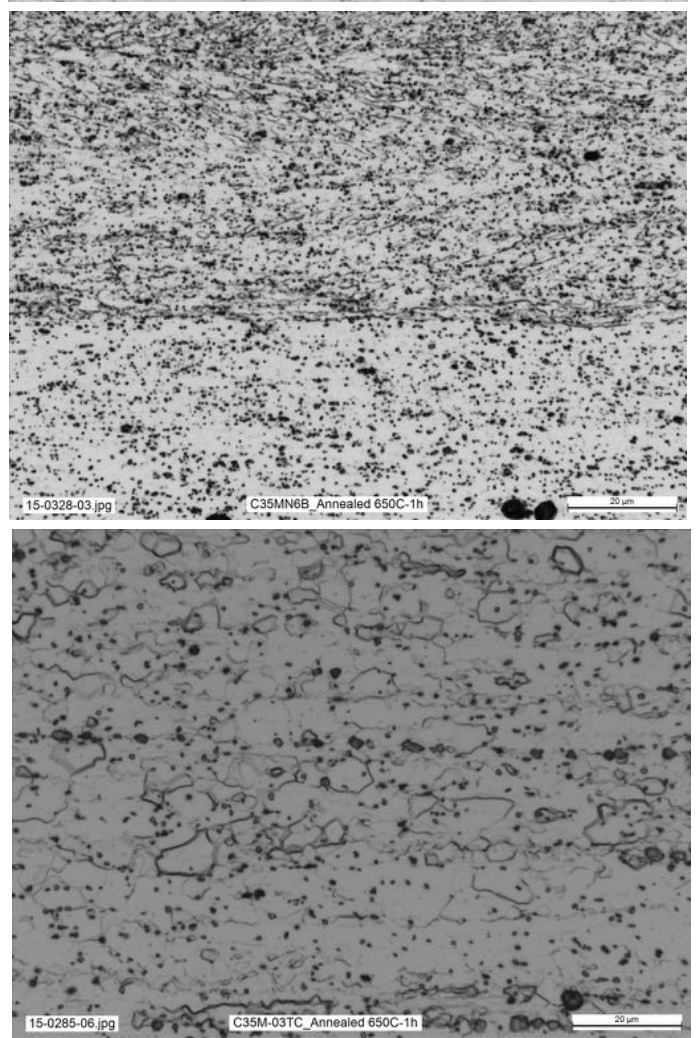

Figure 4: Optical micrographs of candidate $\mathrm{FeCrAl}$ alloys for welding and irradiation testing; (a) C35M, (b) C36M, (c) C37M, (d) C35MN, (e) C35M01TC, (f) C35M03TC, and (g) C35M10TC. Rolling direction is left to right in all images. 


\subsubsection{SEM-EBSD Observed Microstructure}

Optical microscopy efforts were complemented by the use of scanning electron microscopy coupled with electron backscattered diffraction (SEM-EBSD). SEM-EBSD can provide more robust measurements including good statistics on the grain size, texture (orientation), and grain shape compared to more traditional optical microscopy. Preliminary studies were conducted using a JEOL JSM 6500F SEM with a field emission gun (FEG) equipped with an EDAX EBSD system housed at ORNL. The accelerating voltage for investigations was $20 \mathrm{kV}$ while the working distance was held between 12 to $17 \mathrm{~mm}$. The step size of EBSD maps varied depending on the resolution needed for microstructural assessment but was generally 0.5 to $3.0 \mu \mathrm{m}$. Camera operation was done in a $2 \times 2$ binning mode at $\sim 90-100$ frames per second (fps). All inverse pole figure (IPF) maps were colored with respect to the rolling direction during the final warm-rolling step. All samples for investigation were carefully polished using standard metallography practices to produce a defect free, mirror-like surface. Due to the unavailability of the C36M and C35MN alloys at the time of initial EBSD studies they were not investigated, although future work will include characterizing these materials with EBSD.

The C35M and C37M alloy showed similar microstructures by SEM-EBSD when compared to the optical microscopy images, Figure 5. Both alloys showed a microstructure consistent with a warm-rolled material where a subset of grains were elongated with pronounced texturing and another population of grains that appeared to be recrystallized with a generally small size and round morphology. The recrystallized grains formed specific chains elongated in the rolling direction and the repetition of recrystallized and nonrecrystallized grains resulted in a pronounced band-like microstructure similar to the ones observed optically in Figure $4 \mathrm{a}$ and 4c. Both alloys exhibited strong texturing near the [101] corner of the IPF as shown for the C35M alloy in Figure 6, consistent with the warm-rolled condition of these alloys. The C35M alloy also showed small inclusions which could not be identified optically or using SEM-EBSD, further work would be needed to identify these inclusions if they are deemed significant towards the weldability and/or radiation tolerance of the alloy. Inclusions were also observed in the C37M alloy. These inclusions tended to be elongated in the rolling direction and resembled stringers common for alloys with the processing routes described earlier. 
a)

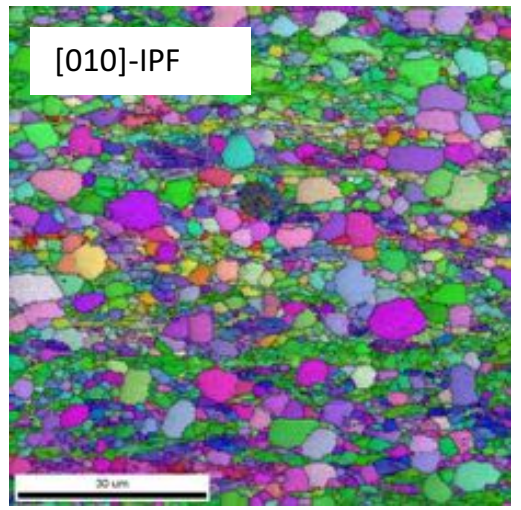

b)

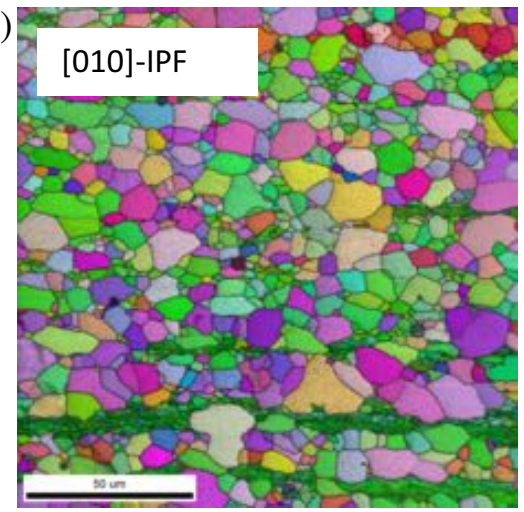

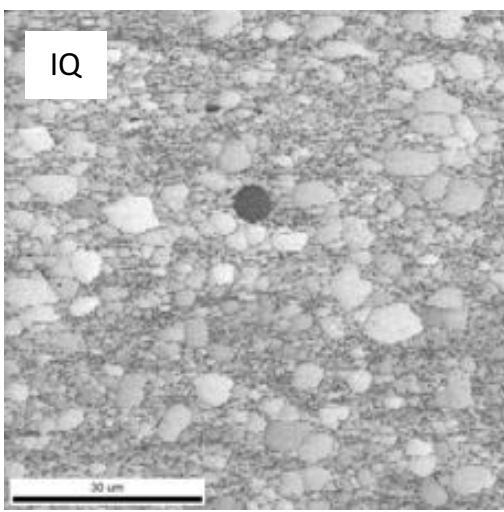

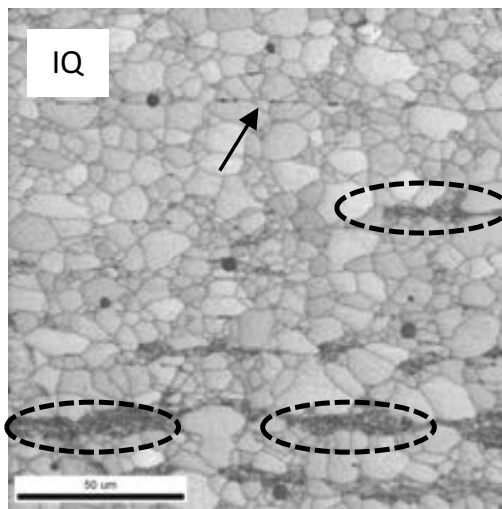

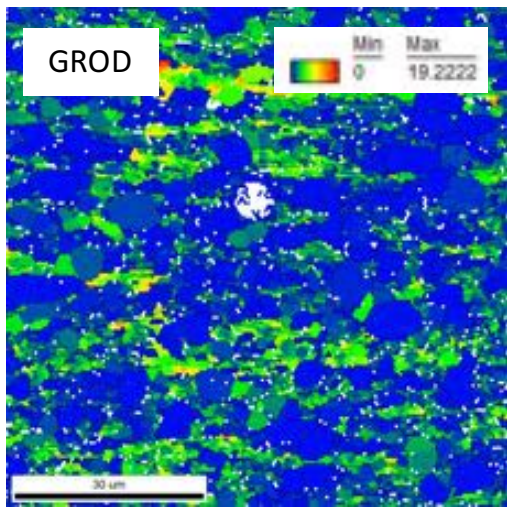

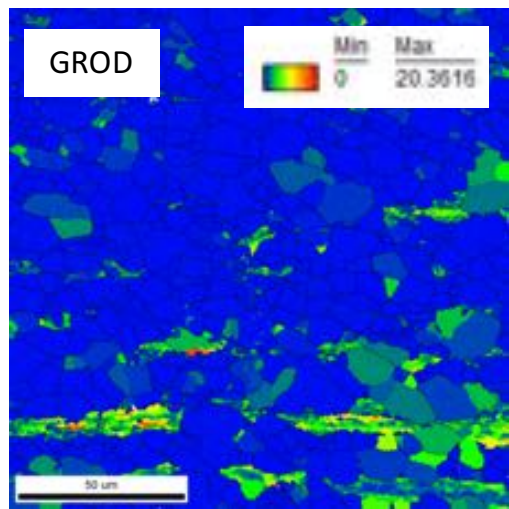

Figure 5: Typical SEM-EBSD determined microstructure of the (a) C35M alloy and (b) C37M alloy. Black dashed ovals show non-recrystallized areas. Black arrow shows elongated defect ("stringer"). Image on the left is the inverse pole figure map (IPF), middle is the image quality map (IQ) and on the right is the grain reference orientation deviation map (GROD).

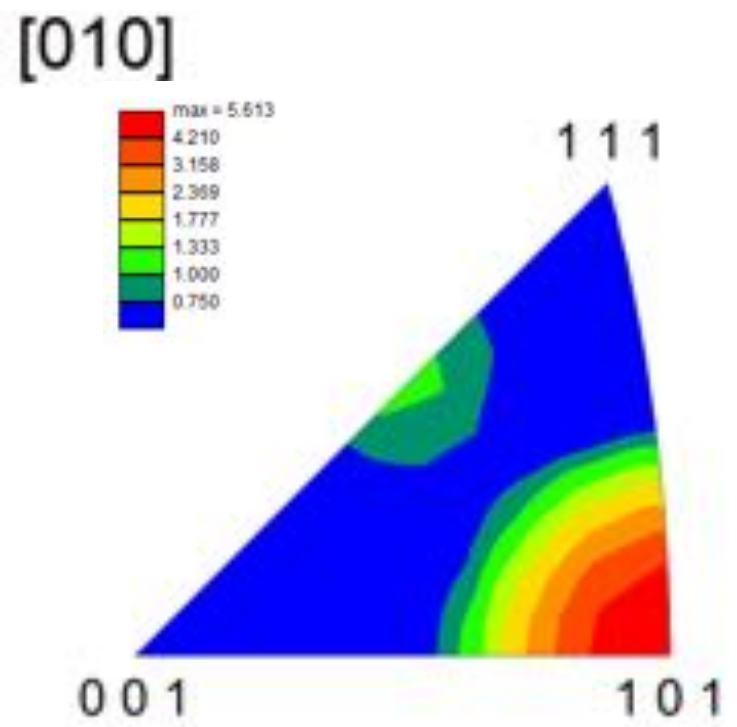

Figure 6: The as-received texture of the C35M alloy. Grains are strongly orientated close to the [101] pole. 
The C35M01TC, C35M03TC, and C35M10TC alloys all showed similar microstructures under SEMEBSD observation. Generally, the microstructures consisted of recrystallized and non-recrystallized grains, Figure 7. The size of the recrystallized grains was on the order of the $\mathrm{C} 35 \mathrm{M}$ alloy shown in Figure 5a. The SEM-EBSD observations suggest that the nominal addition of up to $1 \mathrm{wt} \% \mathrm{TiC}$ does not significantly impact the general warm-rolled microstructure of the now standard processing route for the other $\mathrm{FeCrAl}$ alloys under investigation in this study.

a)
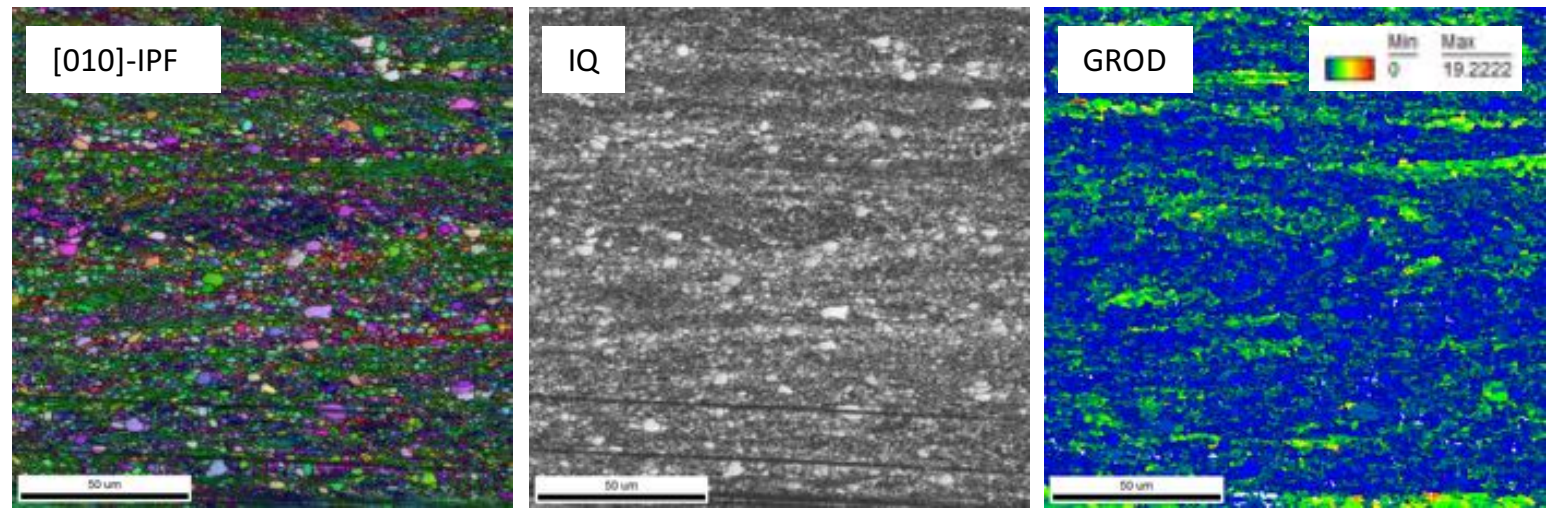

b)
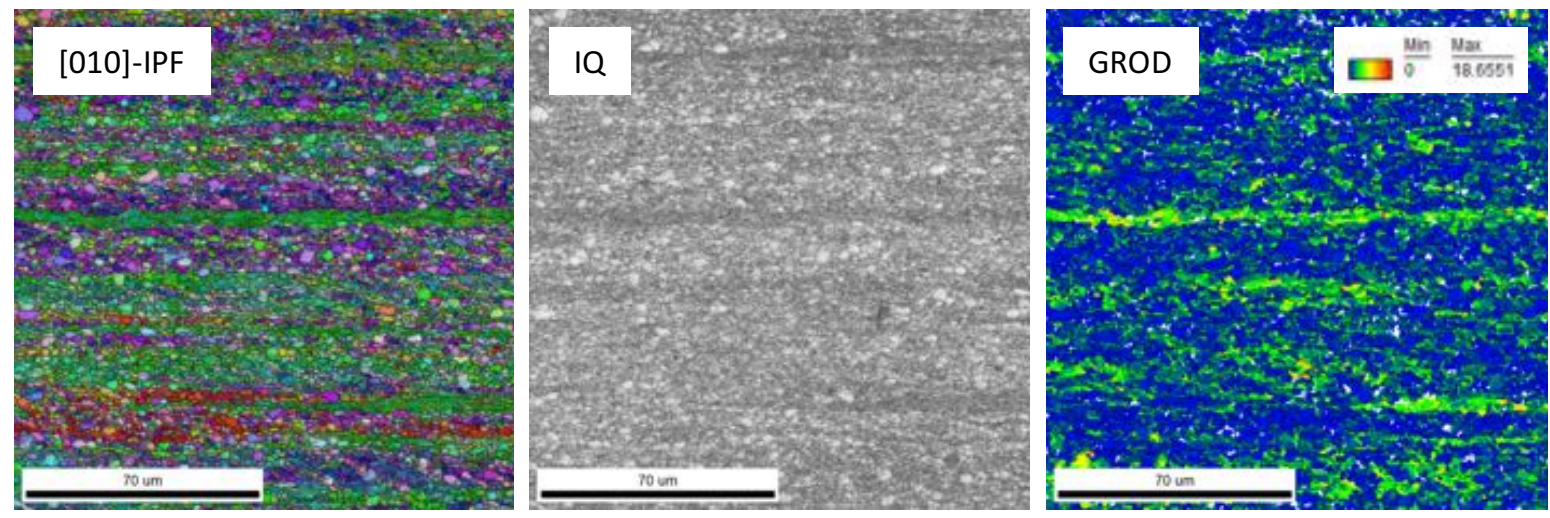

c)
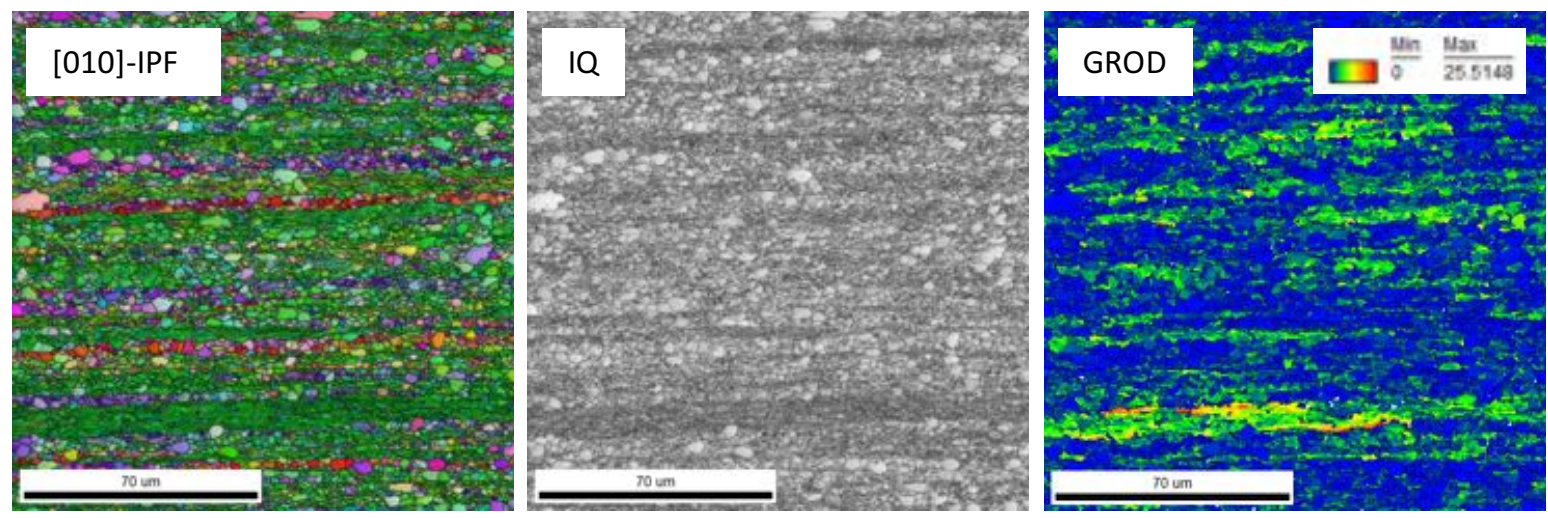

Figure 7: Typical SEM-EBSD determined microstructure of the (a) C35M01TC alloy, (b)

C35M03TC, and (c) C35M10TC alloy. Image on the left is the inverse pole figure map (IPF), middle is the image quality map (IQ) and on the right is the grain reference orientation deviation map (GROD). 


\subsection{As-Received Mechanical Properties}

Tensile tests were performed on an MTS Insight 2-52 one-column tensile screw machine. All tensile specimens were shoulder loaded and tested at room temperature. Before the tensile tests, a subset of specimens was painted with a random speckle pattern. Several specimens were tested without speckle patterns to characterize deformation relief development; in this case, side white light of controlled intensity was used to provide contrast details on the specimen surface. Surface speckle patterns allow for optical, non-contact strain measurements during tensile testing [27]. High-resolution Allied Vision GT6600 and GX3300 cameras were used in the experiments; the lenses employed provided the resolution $\sim 10-15$ and $\sim 5 \mu \mathrm{m}$ per pixel for SS-J type and miniature specimens (discussed in later Sections), respectively. Strain fields and true stress - true strain curves were calculated using VIC-2D commercial software and a custom program utilizing common digital image correlation algorithms (DIC). DIC is a modern method allowing for non-contact strain measurements, visualization of deformation bands, analysis of necking, etc. The details, peculiarities, and limitations of the DIC are widely discussed in the literature [27].

Table 2 shows the mechanical properties of the as-received alloys. At the moment, the testing is still in progress, and full data is not available for all materials. At least three specimens were successfully tested per point providing acceptable statistics; specimens with defects (thickness gradients, internal cracks formed during cold-rolling, etc.) were excluded from the results. As follows from the table, modification of the parent material by alloying (changes in $\mathrm{Cr}$-content, or Nb-addition) led to some variations in the yield stress; the ultimate stress value for the modified alloys is higher compared to the parent material (except C37M). Ductility level depends on the alloying scheme with a general tendency for some decrease compared to the $\mathrm{C} 35 \mathrm{M}$ alloy. The largest ductility drop was observed for the material with $\mathrm{Nb}$ addition $(\mathrm{C} 35 \mathrm{MN})$ with known Laves phase dispersions.

Table 2: Mechanical properties of the tested as-received specimens.

\begin{tabular}{|c|c|c|c|c|c|}
\hline Alloy & $\begin{array}{c}\text { Specimen } \\
\text { geometry }\end{array}$ & $\begin{array}{c}\text { Yield stress, } \\
\text { MPa }\end{array}$ & $\begin{array}{c}\text { Ultimate } \\
\text { stress, MPa }\end{array}$ & $\begin{array}{c}\text { Uniform } \\
\text { elongation, \% }\end{array}$ & $\begin{array}{c}\text { Total } \\
\text { elongation, } \%\end{array}$ \\
\hline \hline \multicolumn{7}{|c|}{ Parent alloy } \\
\hline C35M & SS-2E & 616 & 732.8 & 12.2 & 22.6 \\
\hline \multicolumn{7}{|c|}{ Materials modified by alloying } \\
\hline C35MN & SS-2E & 830.3 & 888.8 & 4.0 & 8.8 \\
\hline C36M & SS-J & 814.7 & 869.1 & 6.8 & 15.1 \\
\hline C37M & SS-J & 587.2 & 720.9 & 10.8 & 20.4 \\
\hline \multicolumn{7}{|c|}{ Materials with TiC } \\
\hline C35M01TC & SS-2E & 638.1 & 737.4 & 11.1 & 21.3 \\
\hline C35M10TC & SS-J & 581.6 & 707.5 & 14.6 & 23.0 \\
\hline
\end{tabular}

Materials with TiC (Table 2) demonstrated very weak changes in the yield and ultimate stress levels, compared to the parent C35M alloy. Surprisingly, ductility level also remained practically unchanged. Unfortunately, at the moment, there is no possibility to recover "pure alloying effects" (e.g., MPa per 1\% of alloying element addition) since all materials have complex thermomechanical treatment history leading to the difference in the recrystallization degree, texture degree, and grain size. 
Figure 8 shows some typical engineering tensile diagrams in coordinates "plastic strain vs. engineering stress"; to exclude the possibility of specimen geometry contribution, only SS-J type specimen data are shown. One can see the strong difference in the strength level and ductility depending on the material composition. Interestingly, all materials demonstrated well-developed neck and high local ductility, Figure 9. According to the DIC data, local plastic strain level in the neck may reach to 0.5 (Hencky strain definition was employed, also known as true or logarithmic strain), Figure 9.

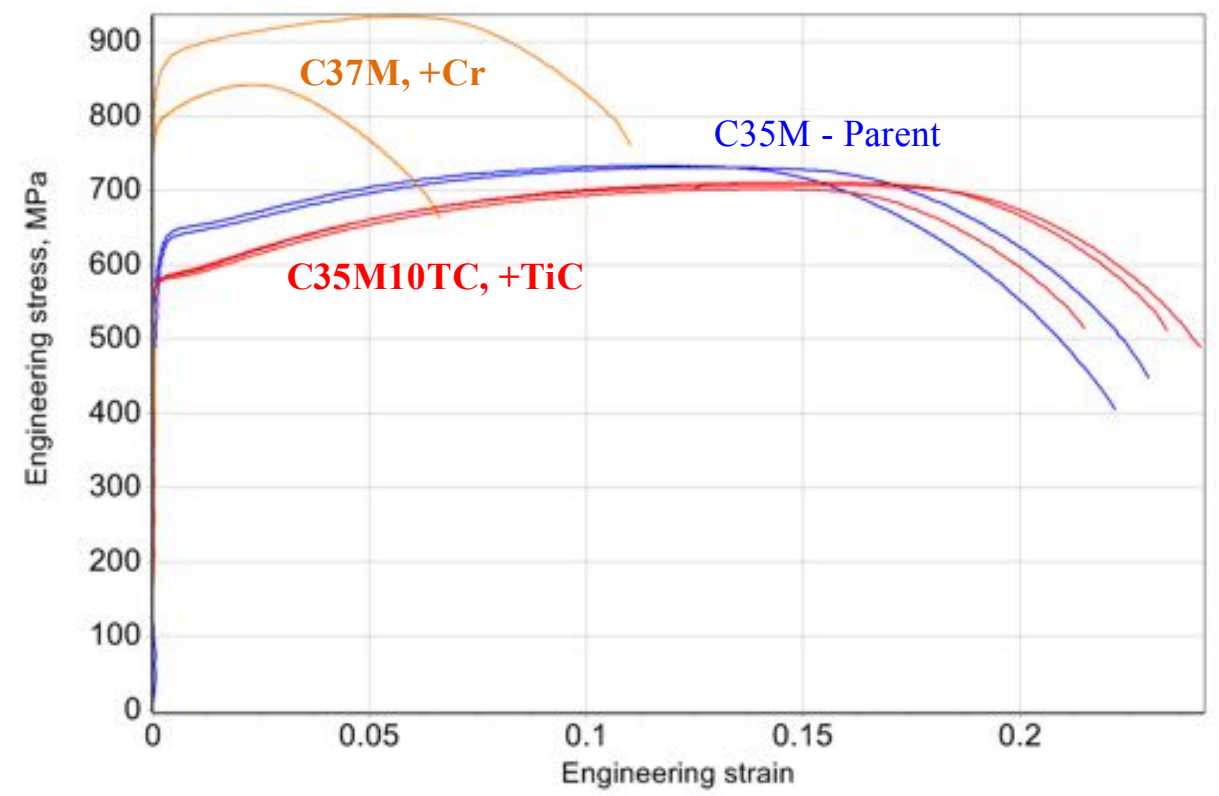

Figure 8. Typical engineering diagrams for the tested specimens of SS-J geometry. 


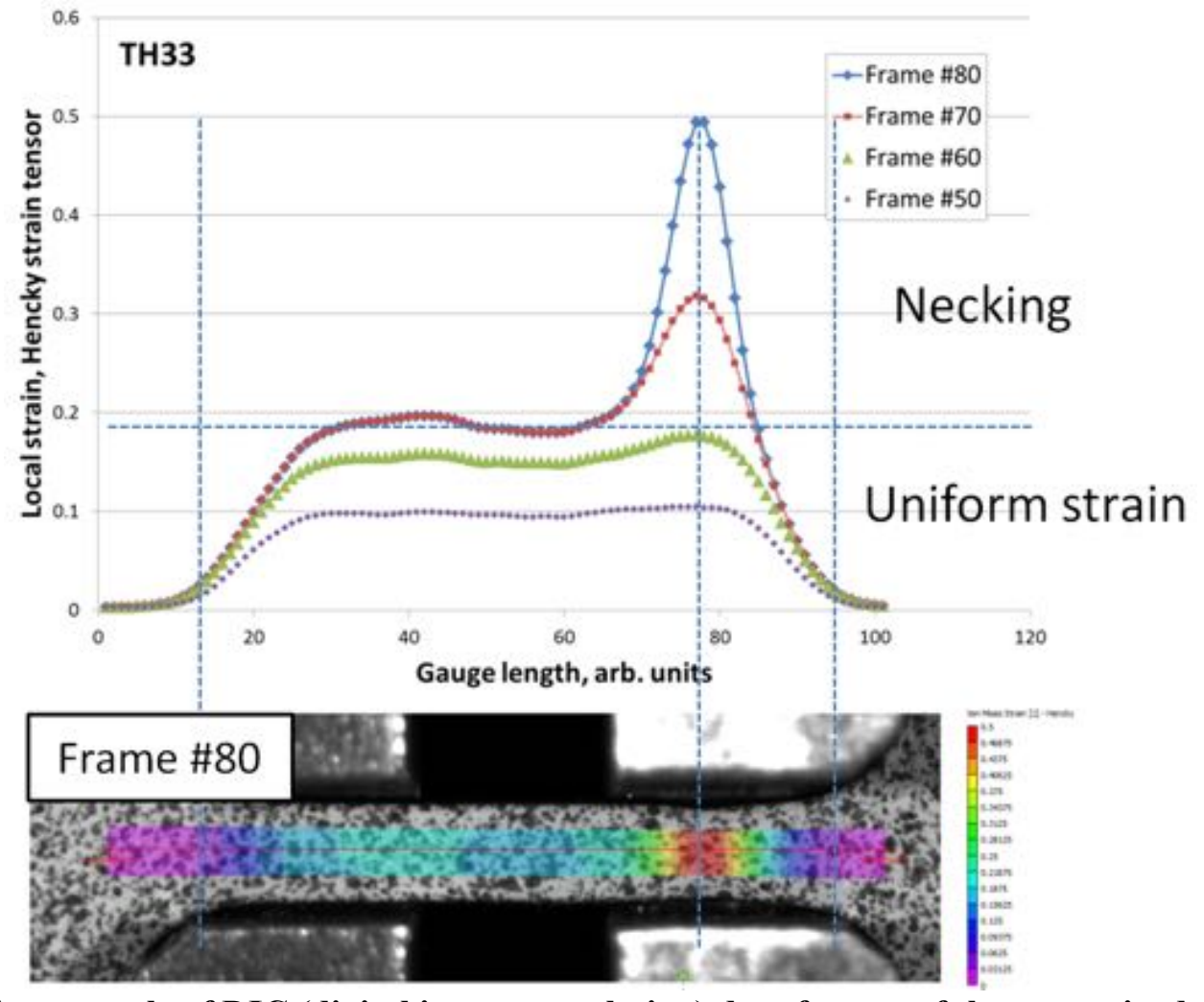

Figure 9: An example of DIC (digital image correlation) data for one of the as-received C35MT10alloy specimens.

The as-received $\mathrm{C} 35 \mathrm{M}$ alloy demonstrated ductile fracture mechanism. Numerous, well-developed dimples were observed at the fracture surface, Figure 10. Modified alloys also demonstrated ductile behavior with the formation of deep, multiple dimples, Figure 10 and Figure 11. Some signs of delayering were observed (for instance, Figure 10, C36M-alloy); however, these might be just pre-existing defects, not a strain-induced feature. 
a)

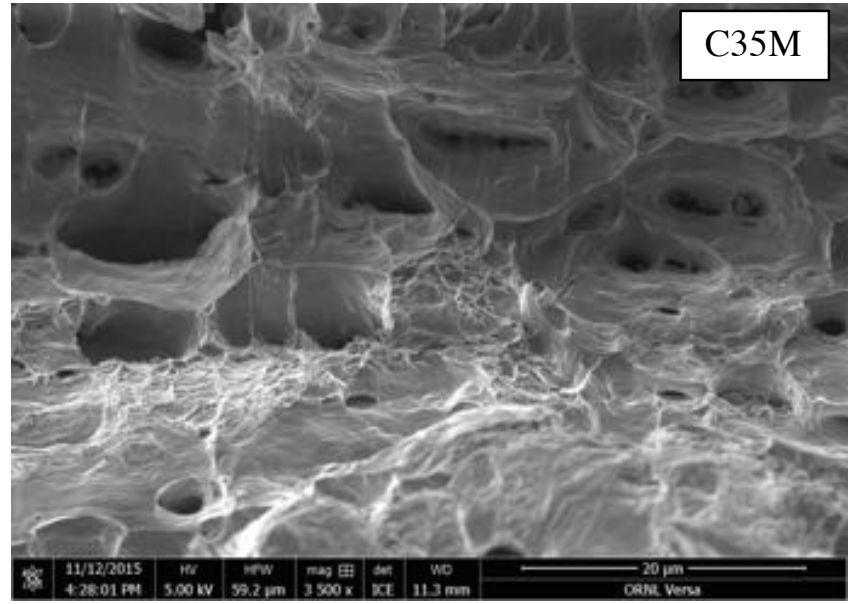

b)

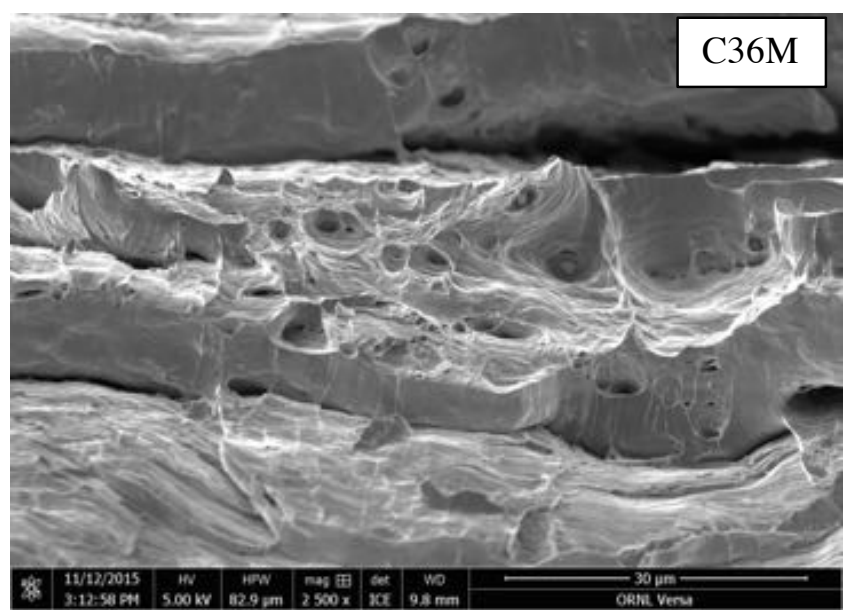

c)

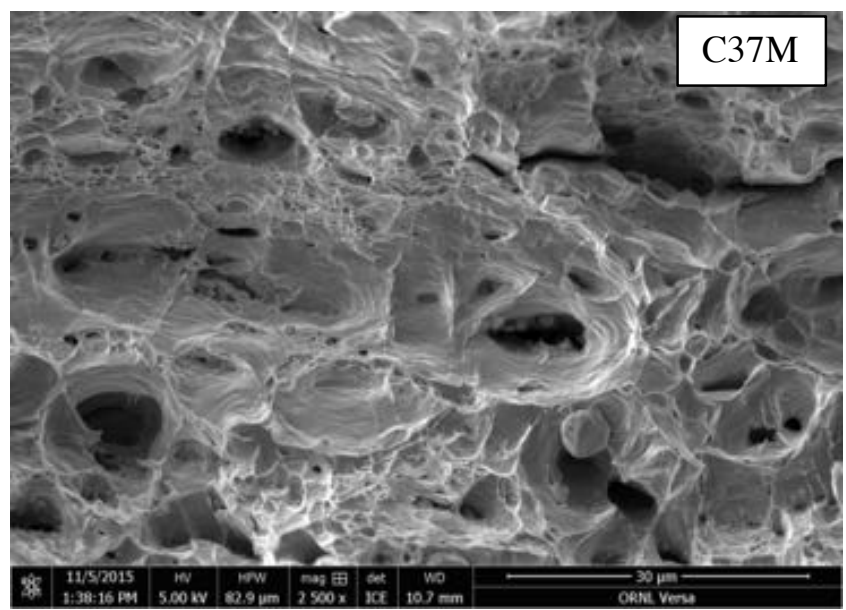

Figure 10: Fracture surface images of (a) C35M, (b) C36M, and (c) C37M FeCrAl alloys. 

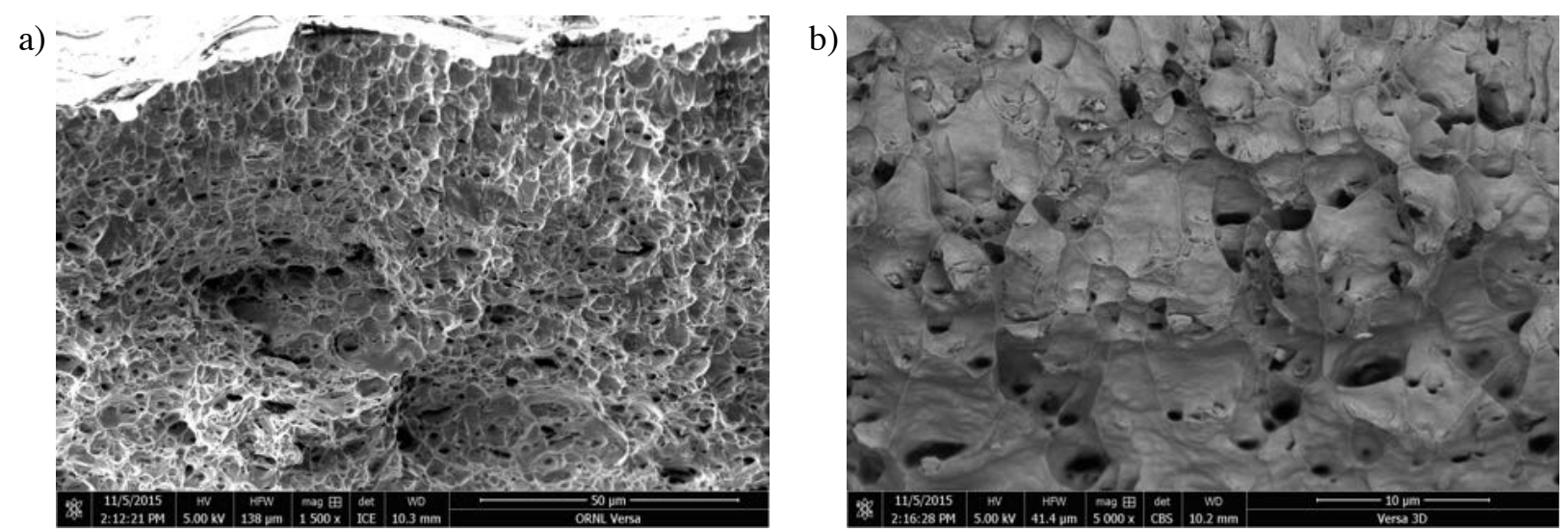

Figure 11: The typical fracture surface of the C35M10TC alloy specimen, (a) at low SEM magnification and (b) at higher SEM magnification.

Materials with TiC-addition demonstrated an interesting peculiarity. At some locations, dimples contained small well-shaped cubic or rectangular particles, Figure 12.

a)

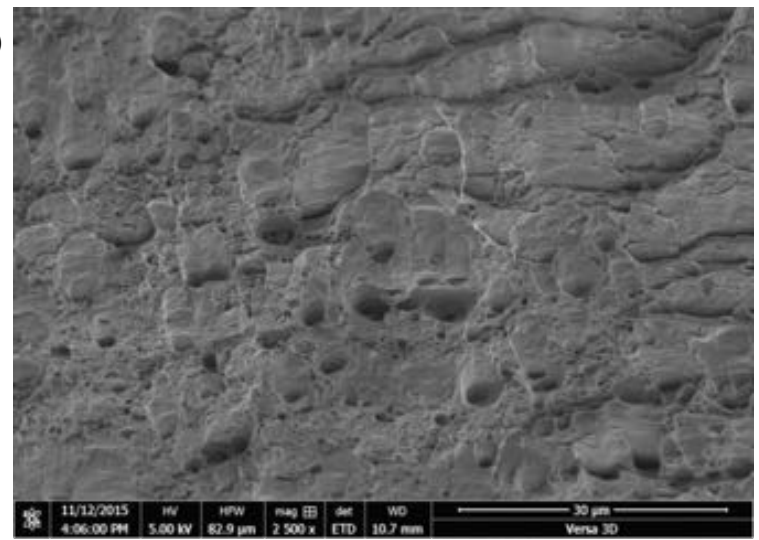

b)

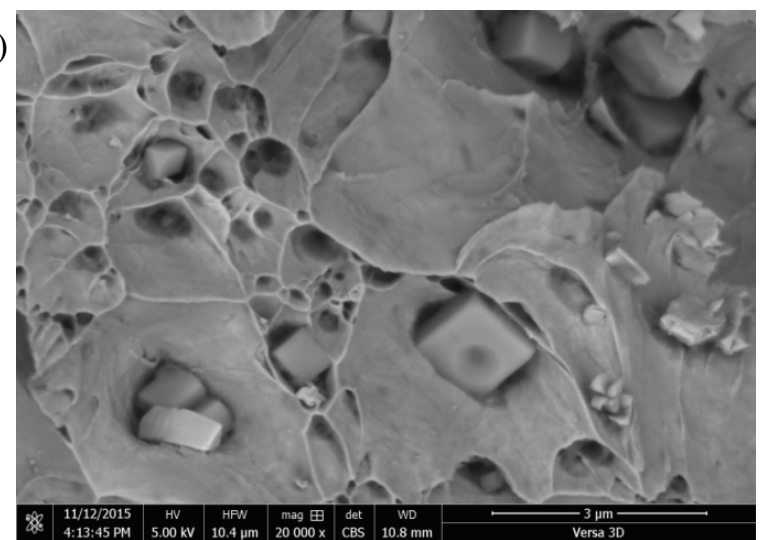

Figure 12: C35M01TC alloy specimen: general view of the fracture surface and a location with specific cube-shaped particles located in the dimples, (a) at low SEM magnification and (b) at higher SEM magnification.

Based on the results present, it can be concluded that alloying did not compromise the mechanical strength of the advanced materials offered in the present project. For all studied alloys, local ductility is high enough, and no tendency towards embrittlement was observed. This is reinforced based on the observation of fracture surfaces following tensile testing where all studied alloys demonstrated ductile facture mechanisms with well-pronounced, deep dimples. 


\section{MINIATURE SPECIMEN DESIGN FOR IRRADIAITON}

\subsection{Design Methodology for Miniaturized Specimen}

There is a constant and growing interest in the mechanical testing of small specimens and analyzing material behavior at small scales. In general materials science, this interest is being driven by introducing smaller devices and exploring the micro- and nano-mechanics areas [28]; it is important to analyze the properties and performance of micro-parts and components. At the same time, the nuclear industry often has a different goal [29,30]: miniature samples that have reduced radiological activity taken from nuclear installations should provide bulk mechanical properties or at a minimum, translatable results across different length scales of test specimens.

Additionally, the recent progress in different in-situ test methods is impressive and the next decade is likely to see a considerable rise in in-situ test techniques for general materials science and nuclear materials. For instance, micro-pillar testing, in-situ electron backscatter diffraction (EBSD), highresolution EBSD, advanced 3D structure reconstruction tools, infrared microscopy, and other techniques are quickly providing new and unique data.

It is an attractive idea to employ these methods to investigations into radiation effects of materials. Of special importance, is the deployment of these techniques on neutron irradiated materials. Significant progress has been made to use light ion and heavy ion irradiations to simulate neutron irradiation while producing samples with little or no radioactivity [31], but discrepancies in the observed microstructure and mechanical properties still exist. Furthermore, several different fabrication procedures such as welding or additive manufacturing have intrinsic length scales that exceed the typical penetration depth of ion beam irradiation systems. The result is the full-scale mechanical properties evaluation of these components cannot be completed if ion irradiations are used, but can be with neutron irradiations as the depth of penetration is not a concern. Hence, neutron irradiated data is still needed for many cases of alloy and/or technique development efforts.

Miniature sub-size specimens for post neutron radiation testing have a long story and are widely used for investigating mechanical properties and deformation-hardening behavior of metals and alloys [32,33], weldments [34], nanostructured materials, and different composites. A variety of different sizes and geometries are used in nuclear materials science $[33,35,36]$, with new geometries and testing methods being constantly developed [37]. Historically, for the irradiation at the High-Flux Isotope Reactor (HFIR) two miniature tensile specimen geometries are most often used, SS-3 and SS-J type [32,33]. For many material classes, these geometries provide acceptable mechanical properties compared to standard specimens [32]. However, the post-irradiation activity level is usually too high and limits the postirradiation testing within a hot cell facility only, especially when moderate to high damage dose (dpa) samples are of interest. Reaching the acceptable activity level to test out of the hot cell and hence with equipment possible for in-situ testing techniques may require unacceptable waiting times that exceed the lifetime of the program or project interested in such data.

In order to conduct out of hot-cell testing and enable more robust characterization techniques such as insitu testing, an effort has been initiated to develop a miniaturized tensile specimen that significantly reduces the sample activity by reducing the sample volume while still providing accurate, or at least translatable, results for tensile properties of different metals and alloys of interest. As such, the following aspects were considered during this effort:

1. The miniature specimen geometry should reproduce a polycrystalline-like behavior. To achieve this, the specimen should contain greater than five grains per the smallest dimension. Generally, if the 
thinnest area has less than 5 grains, the specimen will demonstrate reduced strength. For the most common grain size of 40-50 $\mu \mathrm{m}$, it limits the minimal thickness to $\sim 300-400 \mu \mathrm{m}$.

2. To reproduce necking and strain localization behavior accurately (or, at least, close to the SS-J types), the geometry should meet specific thickness/width and length/cross-section requirements.

3. The specimen should have limited activity after irradiation. Currently, at the ORNL's LAMDA facility (Low-Activation Materials Development Laboratory) the limit is $100 \mathrm{mR} / \mathrm{h}$ at $30 \mathrm{~cm}$ to allow for the out-of-hot cell research activity. Thus, specimen volume should be significantly reduced, especially if high dpa specimens are of interest to reduce the overall sample activity ( $\mathrm{mRem} / \mathrm{hr}$ level).

4. Sample geometry should be simple and avoid or minimize rounded shapes. This criterion will reduce the sample production price. In the future, it would be advantageous to allow for machining the same samples from irradiated materials in the hot cell facility. Thus, the simpler the geometry the more feasible it is to execute in-cell sample machining.

5. Additionally, the specimens should fit into the existing irradiation capsules eliminating the need in repeating the complex thermo-hydraulic calculations for the new geometry. The number of miniaturized specimens per capsule should be larger compared to the SS-J types. Additionally, each capsule should be able to carry both new and old specimen types and optimize the number of specimens of each type as necessary for a particular project.

After analyzing the criteria and limitations listed above, the following geometries were considered for preliminary analysis, Figure 13. Two gauge lengths were chosen: 2.55 and $3.55 \mathrm{~mm}$ (Types 1 and 2 respectively) and two head types were employed. Small heads (S) were expected and allowed to deform during the test; however these heads were strong enough to carry the load during the mechanical test. For this geometry, the head shape stability was sacrificed for reducing mass and radioactivity level. It was believed that DIC will allow for retrieving correct true stress - true strain curves for the gauge portion of the specimen, if necessary.

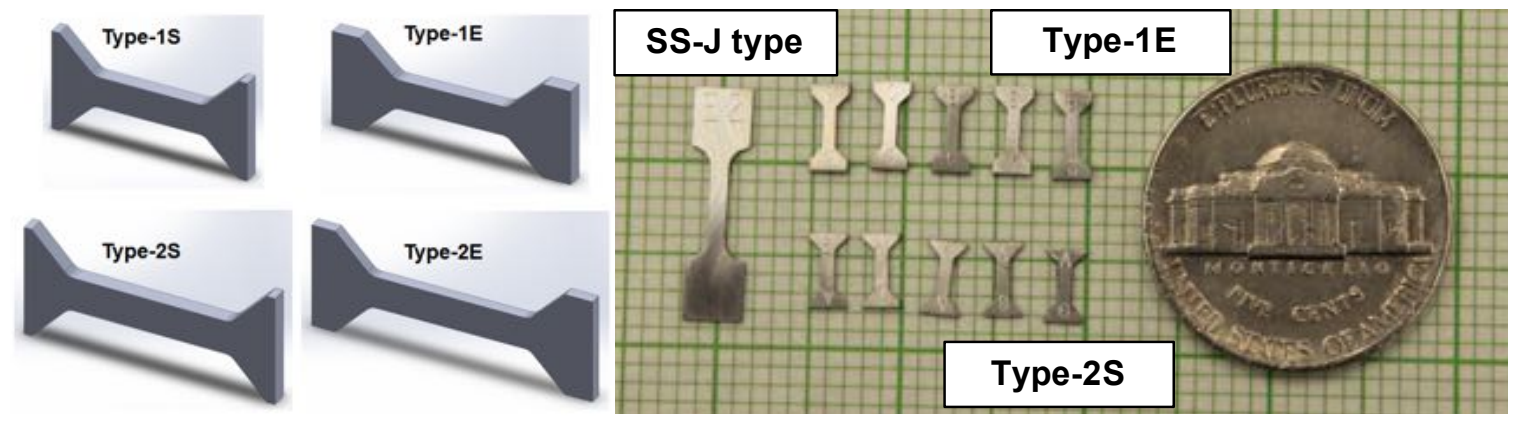

Figure 13: Preliminary geometries.

Extended heads (E) were designed to carry the load with minimum or zero plastic strain in the head. Further head size increase would eliminate the plastic strain in the heads completely, but the price paid will be the extra sample mass and radioactivity. Moreover, for each small specimen geometry (Types 1 and 2, S- and E-heads), two different specimen thicknesses $(0.4$ and $0.6 \mathrm{~mm})$ were considered. All specimens, regardless of thickness and gauge length, could be tested using the same grips.

\subsection{Mechanical Tests and Evaluation of Specimen Design}

The different specimen geometries were tested using the same procedures described in Section 2.3. SS-J type specimens with a sample thickness of $0.75 \mathrm{~mm}$ was used as a baseline for comparison. At least five specimens per geometry were tested to provide acceptable statistics. For the preliminary analysis, the base C35M alloy was selected, although to date several other different FeCrAl alloys as well as other nuclear relevant materials such as 304 stainless steel and tungsten have been tested. The mechanical test results 
obtained for the new geometries were compared with the data obtained for the SS-J type geometry. Table 3 demonstrates a typical data set for the C35M alloy.

Table 3: Mechanical properties of the C35M3 alloy determined using different tensile specimen geometries.

\begin{tabular}{|c|c|c|c|c|c|c|c|}
\hline \multirow{2}{*}{\multicolumn{3}{|c|}{ Specimen geometry }} & \multicolumn{4}{|c|}{ Mechanical properties } & \multirow[b]{2}{*}{$\begin{array}{c}\text { Geometry } \\
\text { selection } \\
\text { points }\end{array}$} \\
\hline & & & $\begin{array}{c}\text { Yield } \\
\text { stress, } \\
\text { MPa }\end{array}$ & $\begin{array}{c}\text { Ultimate } \\
\text { stress, MPa }\end{array}$ & $\begin{array}{c}\text { Uniform } \\
\text { elongation, } \\
\%\end{array}$ & $\begin{array}{c}\text { Total } \\
\text { elongation, } \\
\%\end{array}$ & \\
\hline \multicolumn{3}{|c|}{ SS-J type } & 710 & 767 & 7.9 & 14.8 & - \\
\hline \multirow{8}{*}{ SS-Mini*** } & \multirow{4}{*}{$\begin{array}{c}\text { Short } \\
(2.55 \mathrm{~mm} \\
\text { gauge })\end{array}$} & 1S-0.4 & 607 & 760 & 10.8 & 23.1 & $\bullet$ \\
\hline & & 1E-0.4 & 725 & 782 & 6.6 & 18.2 & $\bullet$ \\
\hline & & 1S-0.6 & 663 & 796 & 10.0 & 29.0 & \\
\hline & & $1 E-0.6$ & 761 & 826 & 9.0 & 28.0 & $\bullet$ \\
\hline & \multirow{4}{*}{$\begin{array}{c}\text { Long } \\
(3.55 \mathrm{~mm} \\
\text { gauge })\end{array}$} & 2S-0.4 & 708 & 821 & 9.0 & 18.0 & $\bullet$ \\
\hline & & 2E-0.4 & 705 & 761 & 7.0 & 15.0 & $\cdots$ \\
\hline & & $2 S-0.6$ & 702 & 822 & 11.0 & 25.0 & $\bullet$ \\
\hline & & $2 \mathrm{E}-0.6$ & 753 & 821 & 9.0 & 22.0 & $\bullet$ \\
\hline
\end{tabular}

* For specimen with $0.75-\mathrm{mm}$ thickness, $12 \times 3$ if a SS-J $(\mathrm{T}=0.5 \mathrm{~mm})$ type specimen is used

** Nomenclature example: the "1S-0.4" abbreviator means Type 1 (short gauge) with small (S) head and thickness of $0.4 \mathrm{~mm}$.

The summary data set allows for parametric comparison (small heads vs. large, short specimens vs. long, and thin vs. thick). It was natural to use some grade system to pick up the best shape and dimensions. First, the specimens with small heads (S) always demonstrated smaller yield stress and larger ultimate stress and ductility (especially total elongation) compared to the SS-J type. It was caused by plastic strain in the heads and its contribution in the total specimen deformation. The extended heads (E) provided much better matching of the yield stress with less than $10 \%$ difference compared to the SS-J type. In order to grade the different geometries, all E-headed specimens received one point toward the selection of the best geometry. Second, the specimens with short gauge (Type 1, $2.55 \mathrm{~mm}$ ) demonstrated slightly higher uniform elongation and much higher total elongation compared to the specimens with long gauge (Type 2, $3.55 \mathrm{~mm}$ ). Ductility values for the Type 2, in general, were closer to the SS-J type compared to the Type 1. This provided an additional selection point to the Type 2. And third, the thick specimens (0.6$\mathrm{mm}$ ) always had larger total elongation compared to the thin ones $(0.4 \mathrm{~mm})$, so the thin specimens were closer to the SS-J type (providing thus the third selection point, Table 3 ). The resulting grading indicated the SS-Mini 2E-0.4 geometry (SS-2E, for short) as the best prototype for further analysis. The dimensions of the SS-2E prototype in relation to the SS-J type is shown in Figure 14. It should be noted the exact same steps as the C35M alloy were conducted for several of the other $\mathrm{FeCrAl}$ alloys and for a 304 stainless steel with the same conclusion on SS-2E as the best geometry to mimic the SS-J type geometry. 

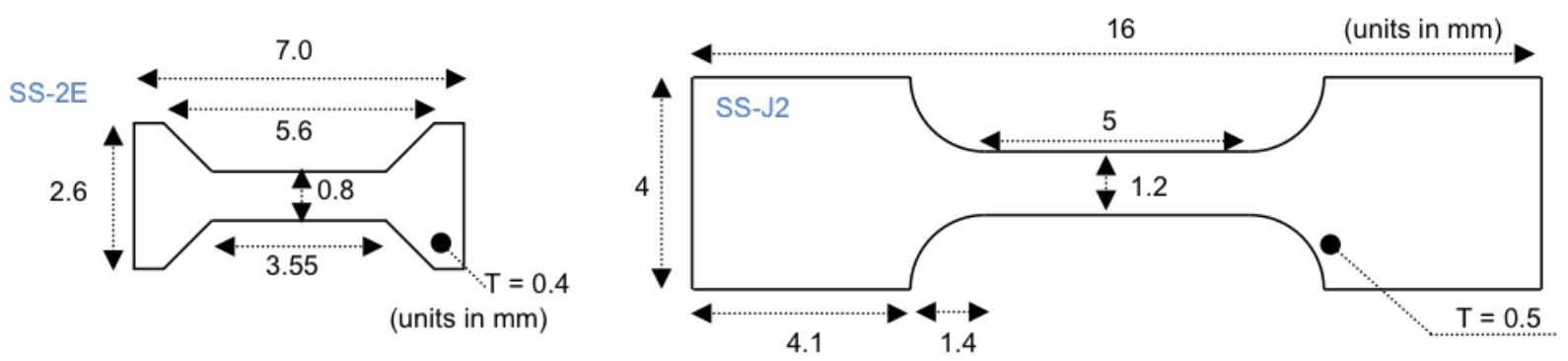

Figure 14: Simplified schematic of the tensile specimen geometries for weld and irradiation testing. Figure not to scale.

As discussed, a key aspect of the miniature specimen design was to enable the use of in-situ analysis techniques such as digital image correlation (DIC) which can provide a more robust analysis on the tensile properties of materials after irradiation. To assess the feasibility of such techniques using the SS$2 \mathrm{E}$ specimen geometry, a subset of specimens was imaged using high-angle lighting and analysis to determine the true curves for the miniature tensile specimens. Figure 15 shows several images taken insitu during a tensile test using DIC with the natural pattern via side lighting. Figure 15 shows even through the progression of the tensile test (yield, necking, and failure), the contrast in the image provides reasonable capabilities to track selected points allowing for non-contact digital extensometery to be performed such as the inset in Figure 15. This data can then be directly translated into true stress - true strain curves, Figure 16. Figure 16a shows the true curves obtained for the C35M tested specimens in the uniform elongation area for both the Type 1, Type 2 and SS-J type specimens. Compared to engineering stress-strain curves, the scatter in the data was minimized. This suggests that ability to perform in-situ analysis of specimens can greatly reduce or completely eliminate any geometry factors during the tensile test.

Figure 16b shows the true curves obtained from the same tests as Figure 16a but for the necking region of the sample for the Type 1S and SS-J type specimen. Hence, the strain is larger than those in Figure 16a. These two sample geometries showed the largest discrepancy in engineering stress-strain assessment, Table 3, but as shown in Figure 16b, the reasonable agreement can be found when using true curves and using the "constant volume criteria".

Clearly, the brief discussion on the results and analysis of the miniaturized test specimen shows that a miniaturized specimen can be used to accurately assess the mechanical properties of the $\mathrm{FeCrAl}$ alloys currently under development in this program. More importantly, it may be concluded that non-contact optic measurements, such as DIC, allowed for eliminating the geometry factor for the material of interest (modified FeCrAl alloy). Such findings provide confidence in the highest ranked specimen, the Type SS$2 \mathrm{E}$, for deployment in irradiation campaigns as a viable test specimen for testing out of the hot cell. This geometry reduces the overall specimen volume by a factor of 5 , greatly decreasing total specimen activity following irradiation while still providing acceptable mechanical property data in either the engineering stress-strain or true stress-strain regime. 
a)

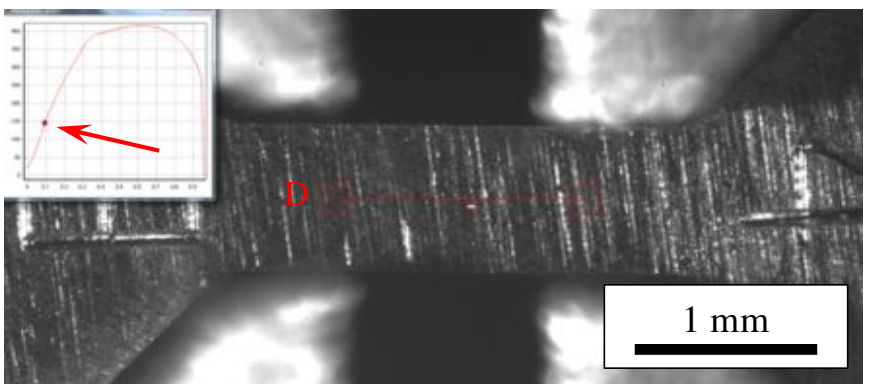

b)

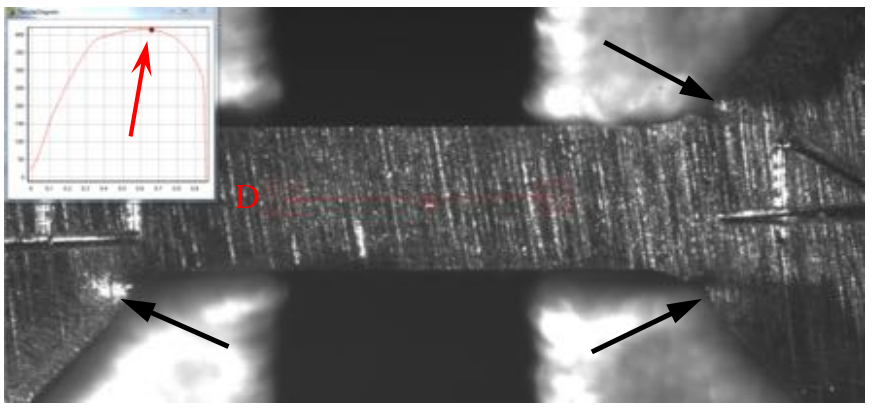

c)

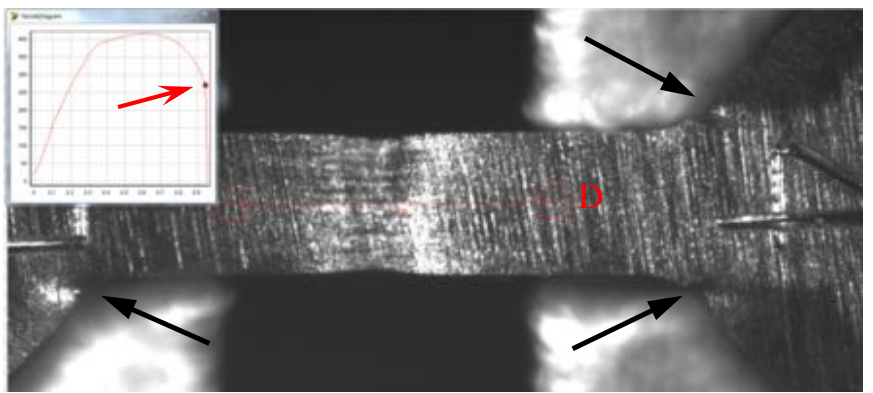

Figure 15: Images of a C35M specimen (Type 1E-0.4) tested using "natural contrast" conditions; high-angle lighting was employed to increase surface variation contrast. a) The specimen loaded at $\sim \mathbf{4 0} \%$ yield stress; b) Image taken at the ultimate stress point; c) Image taken close to the fracture point. Black arrows point local plastic strain in the head area. "D" shows a "digital extensometer" tracking two selected points at the specimen surface. Insertions at the left show the engineering load-displacement diagram with a red arrow pointing displacement and load values for the corresponding image.

a)

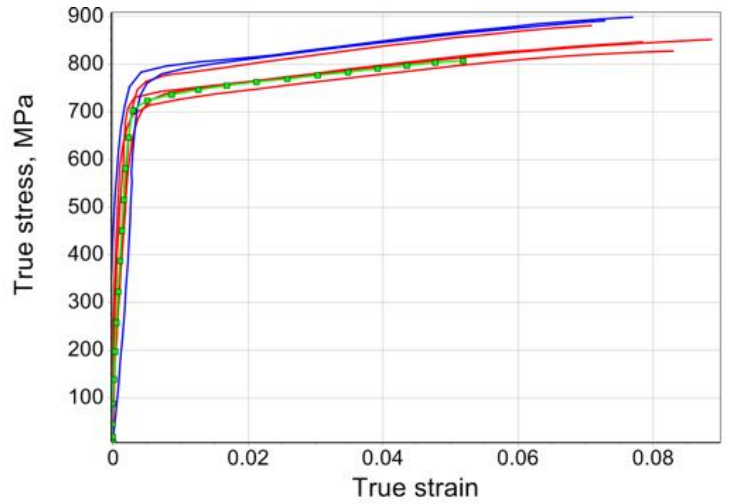

b)

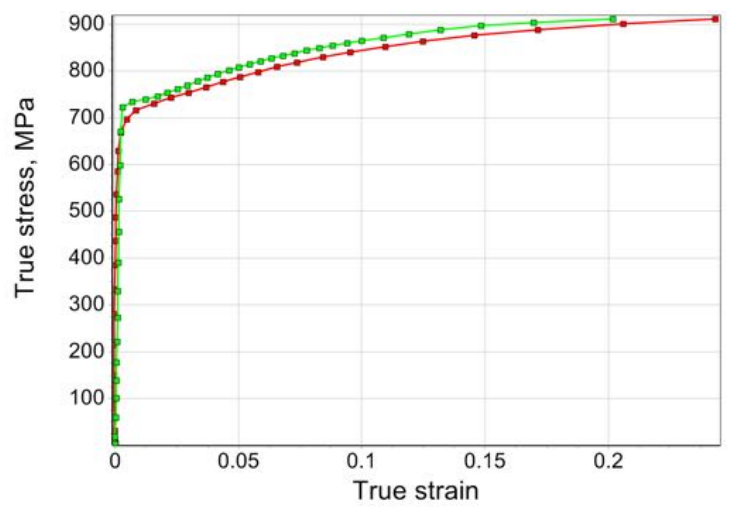

Figure 16: True stress-true strain curves obtained for the tested specimens for the (a) uniform elongation and (b) for the neck area using the DIC data. Red: Type-1 specimens in Table 2, all types; blue: Type-2 specimens in Table 2, all types; green: SS-J type. 


\section{IRRADIATION CAPSULE DESIGN AND FABRICATION}

\subsection{Specimen Geometries and Sample Manufacturing}

Two tensile specimen geometries were selected for use in irradiation testing. Tensile testing will provide the fundamental mechanical properties of the irradiated alloys and allow for direct comparison of postirradiation mechanical properties to the as-received mechanical properties provided in Section 2.3. The two sample configurations are the aforementioned SS-2E and SS-J type with a thickness of $0.5 \mathrm{~mm}$, as shown previously in Figure 14. As discussed, the SS-J type configuration has and is widely used for mechanical properties evaluation of irradiated specimens within the HFIR. Sheet-type tensile specimens were selected as it maximizes the radial space of the cylindrical irradiation capsule while still providing for efficient heat transfer across the stacked faces during elevated temperature irradiation tests. Shoulder loaded specimens, i.e. specimens without pinholes, was selected as it provides unstrained volume post tensile testing for mechanical characterization.

Both specimen geometries were fabricated by a single outside vendor. All samples were machined using an electric discharge machine (EDM) from flat sheet product. For larger features, especially in the SS-J type samples, the EDM burn layers were removed by mechanical removal techniques. Due to the small size of the SS-2E specimen geometry, the edges of most of the specimens contained small burrs and defects. These were carefully removed using a hand file. Welded samples were produced from the same welded samples discussed later in Section 5.3. Details on the welding parameters can be found in the later section. The top-weld was centered on the gauge for both the SS-2E and SS-J type specimens during sample machining. Surface grinding was used to get samples within the thickness tolerance of the irradiation capsule build. The result was the weld location could not be visually determined after machining. Hence, prior to machining each sample was photographed and samples where the fusion zone was not aligned within reason to the gauge centerline were removed from the irradiation capsule build inventory. Care was taken to maintain batch traceability during the fabrication process.

To maintain traceability prior to and after irradiation all samples were marked using laser engraving with a unique alpha-numeric sample identifier. The scheme used for the samples is provided in Table 4. Care was taken in assigning an identifier that the characters do not appear to be similar under microscopic investigation to limit ambiguity during post-irradiation sorting. Generally, the SS-2E markings were relatively small, Figure 17, resulting in a need for magnified optical inspection, especially during postirradiation examination (PIE). This will result in slower identification during hot-cell operation but is unavoidable due to the limited surface area of the tab region of the tensile specimen. After engraving, all samples were dimensionally inspected to verify their viability for use in the irradiation capsule builds. Those that did not meet the stringent dimensional requirements were removed from the irradiation capsule build inventory. 
Table 4: Specimen ID marking for specimens for weld and irradiation testing

\begin{tabular}{|c|c|c|c|}
\hline $\begin{array}{c}\text { Spec } \\
\text { ID. }\end{array}$ & $\begin{array}{c}\text { Specimen } \\
\text { Type }\end{array}$ & $\begin{array}{c}\text { Material } \\
\text { Code }\end{array}$ & Condition \\
\hline \hline MFXX & SS-J2 & C35M & non-welded \\
\hline M6XX & SS-J2 & C36M & non-welded \\
\hline MVXX & SS-J2 & C37M & non-welded \\
\hline TKXX & SS-J2 & C35MTC01 & non-welded \\
\hline TCXX & SS-J2 & C35MTC03 & non-welded \\
\hline THXX & SS-J2 & C35MTC10 & non-welded \\
\hline N5XX & SS-J2 & C35MN & non-welded \\
\hline FXX & SS-2E & C35M & non-welded \\
\hline IXX & SS-2E & C36M & non-welded \\
\hline VXX & SS-2E & C37M & non-welded \\
\hline KXX & SS-2E & C35MTC01 & non-welded \\
\hline TXX & SS-2E & C35MTC03 & non-welded \\
\hline HXX & SS-2E & C35MTC10 & non-welded \\
\hline NXX & SS-2E & C35MN & non-welded \\
\hline
\end{tabular}

\begin{tabular}{|c|c|c|c|}
\hline $\begin{array}{c}\text { Spec } \\
\text { ID. }\end{array}$ & $\begin{array}{c}\text { Specimen } \\
\text { Type }\end{array}$ & $\begin{array}{c}\text { Material } \\
\text { Code }\end{array}$ & Condition \\
\hline \hline 5WXX & SS-J2 & C35M & welded \\
\hline VWXX & SS-J2 & C37M & welded \\
\hline KWXX & SS-J2 & C35MTC01 & welded \\
\hline TWXX & SS-J2 & C35MTC03 & welded \\
\hline HWXX & SS-J2 & C35MTC10 & welded \\
\hline NWXX & SS-J2 & C35MN & welded \\
\hline AXX & SS-2E & C35M & welded \\
\hline VXX & SS-2E & C37M & welded \\
\hline LXX & SS-2E & C35MTC01 & welded \\
\hline CXX & SS-2E & C35MTC03 & welded \\
\hline OXX & SS-2E & C35MTC10 & welded \\
\hline BXX & SS-2E & C35MN & welded \\
\hline
\end{tabular}

(a)

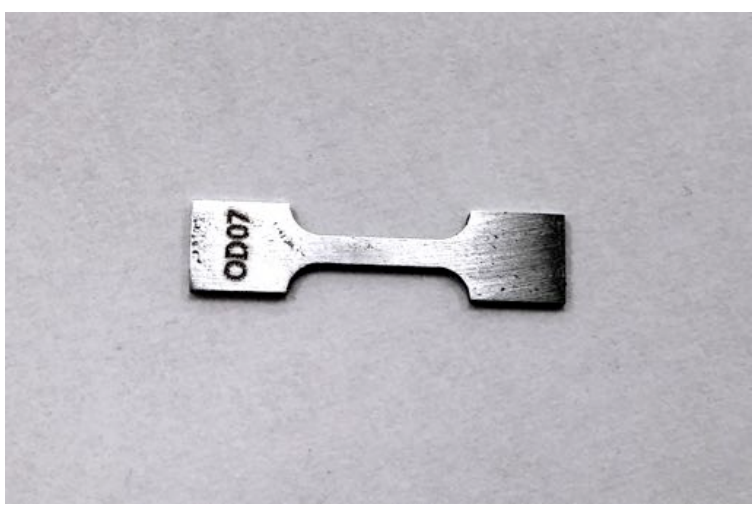

(b)

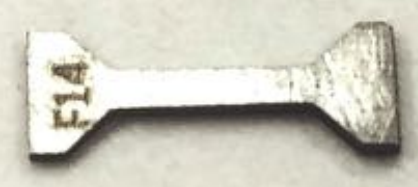

Figure 17: Image of laser engraving positions on the specimens; (a) SS-J type and (b) SS-2E.

\subsection{Overview of HFIR Irradiation Capsule Design}

HFIR is a beryllium-reflected, pressurized, light-water-cooled and moderated flux-trap-type reactor. The core consists of aluminum-clad involute-fuel plates, which currently utilizes highly enriched ${ }^{235} \mathrm{U}$ fuel at a power level of $85 \mathrm{MWt}$. The reactor core, illustrated in Figure 18, consists of two concentric annular regions, each approximately $61 \mathrm{~cm}$ in height. The flux trap is $\sim 12.7 \mathrm{~cm}$ in diameter, and the outer fueled region is $\sim 43.5 \mathrm{~cm}$ in diameter. The fuel region is surrounded by a beryllium annular reflector approximately $30.5 \mathrm{~cm}$ in thickness. The beryllium reflector is in turn backed up by a water reflector of effectively infinite thickness. In the axial direction, the reactor is reflected by water. The reactor core 
assembly is contained in a $2.44 \mathrm{~m}$ diameter pressure vessel, which is located in a $5.5 \mathrm{~m}$ cylindrical pool of water.
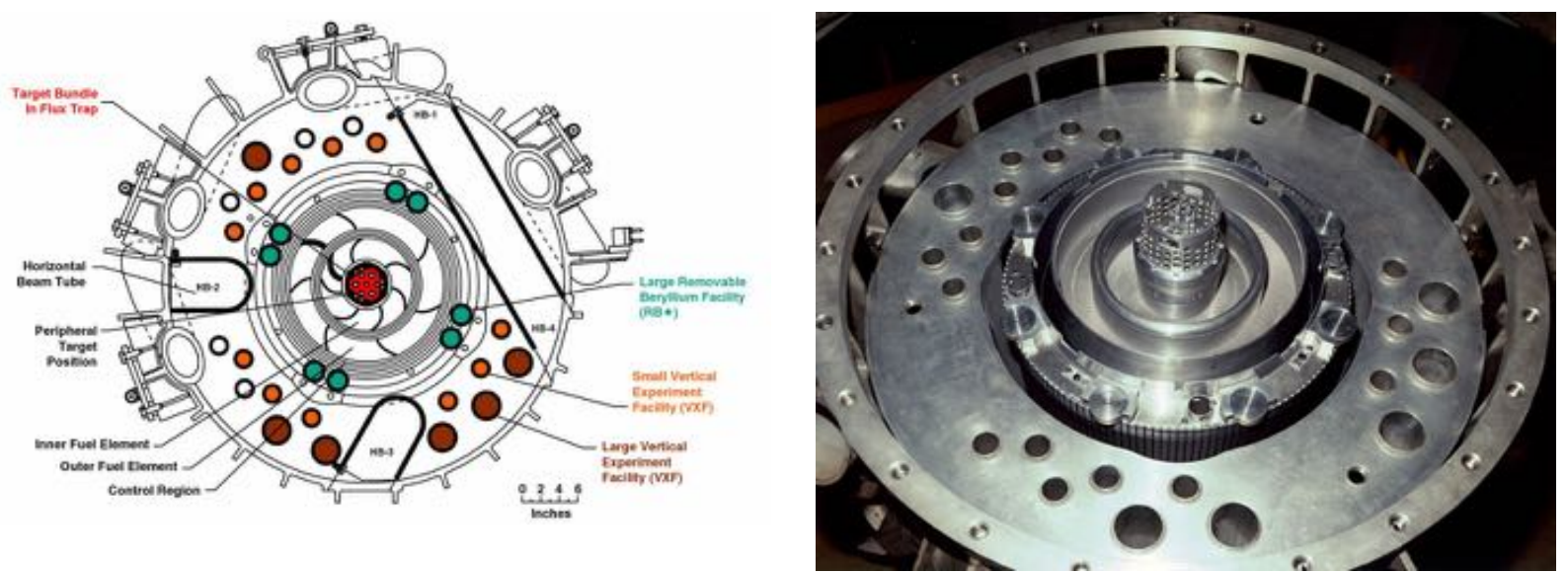

Figure 18: Cross-section through HFIR illustrating the primary experimental sites (left) and a picture of the reactor core (right)

The uniaxial tensile test irradiation capsules (capsules are commonly called rabbits) in this design will be placed in the flux trap of HFIR, either in a peripheral target tube (PTT), which is shown as red in Figure 19 , or in a target rod rabbit holder (TRRH), which is shown as green. In each of these locations, there is a tube in which up to nine rabbits can be stacked.

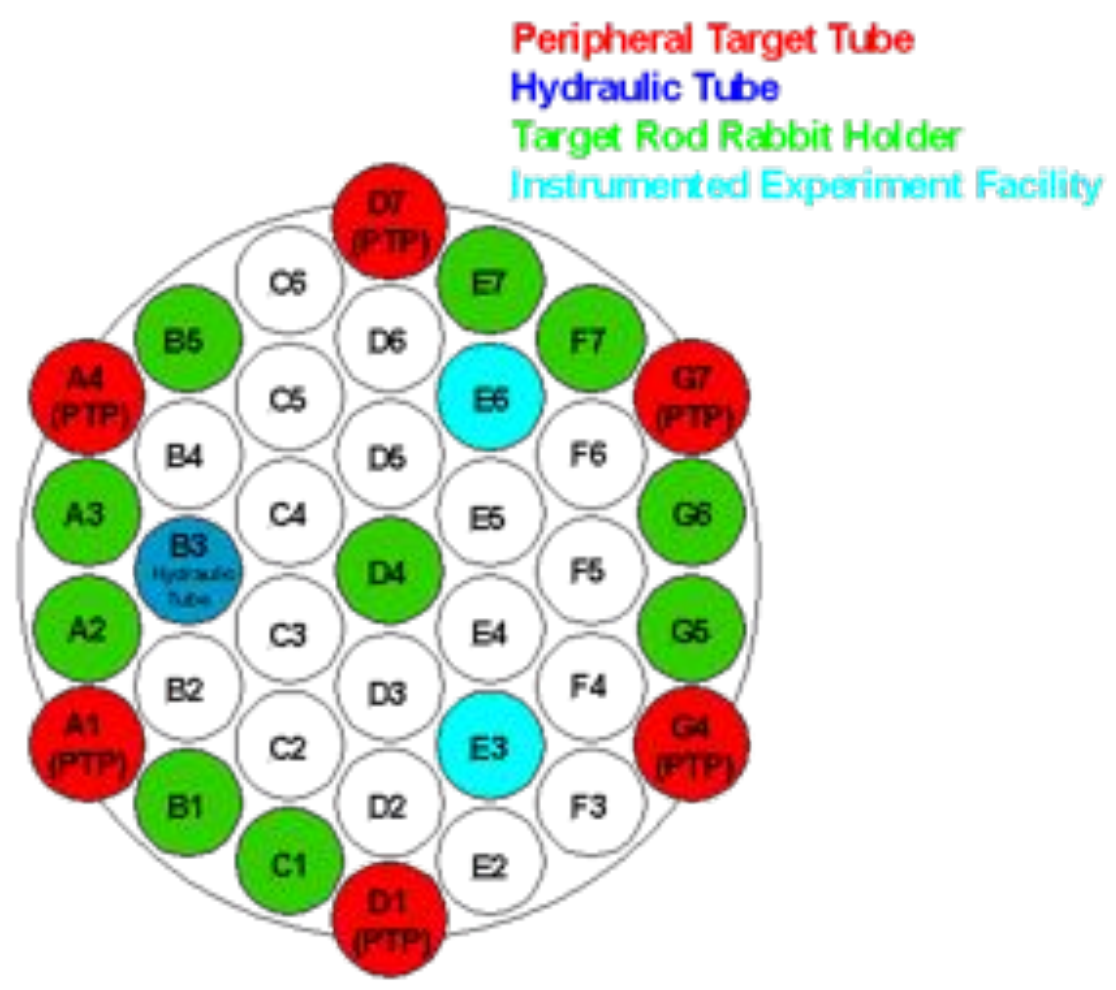

Figure 19: Flux trap irradiation positions

The HFIR rabbit capsule design for this program is tailored to contain various FeCrAl tensile specimen styles (SS-J type and SS-2E), as shown in Figure 20. This versatile modular loading configuration was developed to provide flexibility in specimen loading with a useful range of irradiation temperatures in 
support of a wide range of nuclear materials research. Each unique specimen configuration was designed to have thermal equivalency, allowing the SS-J type and SS-2E specimen configurations to be interchangeable with no impact on the design performance. This equivalency was achieved making the tensile specimens and their supporting parts (chevrons, liners, etc.) form a uniform 'coupon' with a common mass, geometry, and thermal properties. Table 5 demonstrates the performance of the thermal equivalency. The capsule design may be used in all flux trap positions available in the HFIR. Furthermore, the modular subassemblies provide inherent specimen grouping and simplify post irradiation disassembly. This feature provides valuable cost savings, given the relatively high cost of the hot cell facility usage.

The specimens are supported by steel chevrons or coffins, depending on specimen type, to equalize heat generation between the different configurations. Each holder sub-assembly contains 4 "quadrants" (specimens, chevrons [or coffins] and SiC thermometry liners). The quadrants are pressed into each of the 4 corners of the square cutout in the holders using a steel spring pin. The holders have raised 'standoff' features to center the holder assembly within the housing. Grafoil is used to separate the holder subassemblies from the cool bottom of the aluminum housing. The assembly configuration is represented in Figure 21.

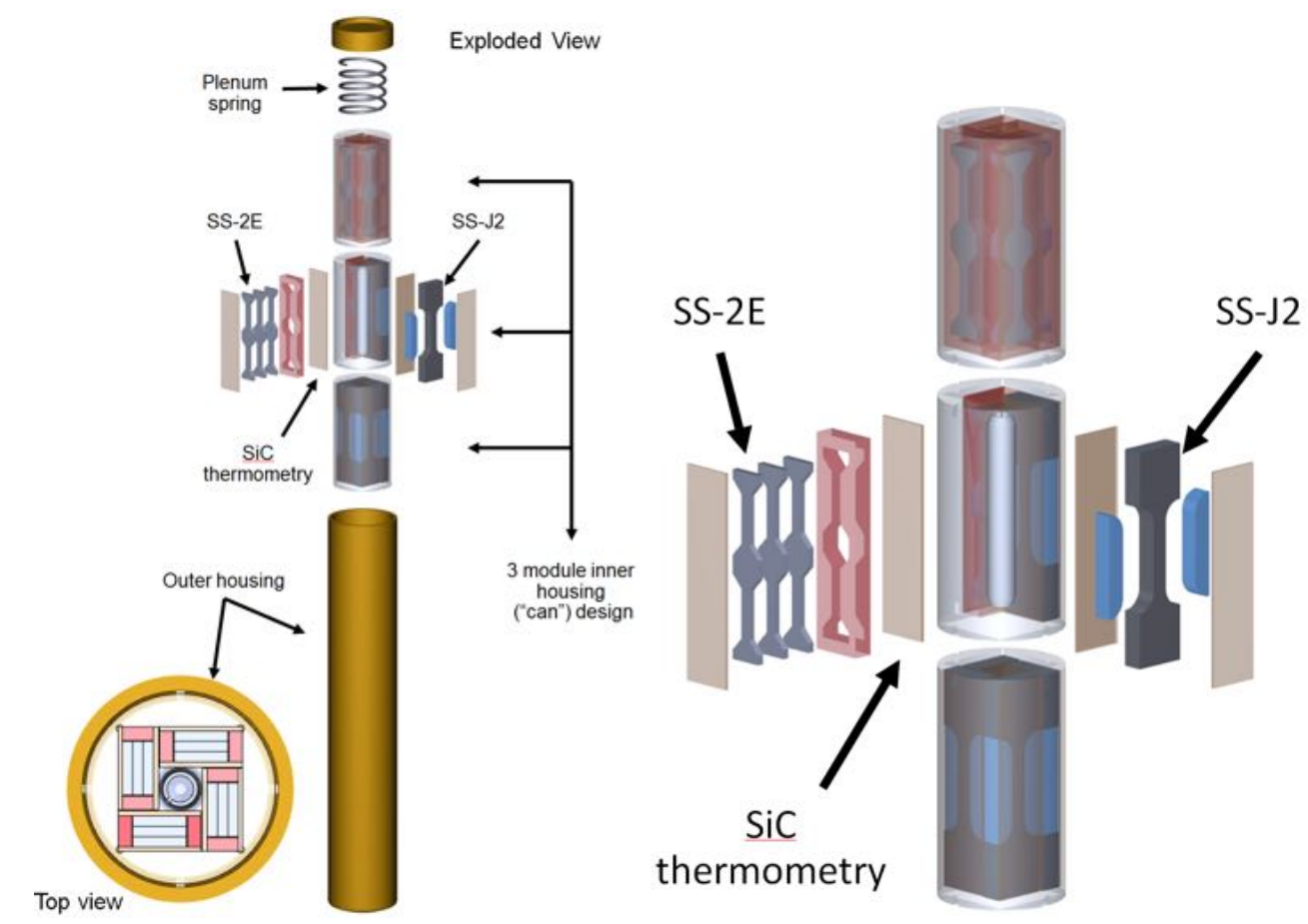

Figure 20: HFIR irradiation capsule design showing the versatile use of both SS-J type and SS-2E specimens in the same irradiation campaign. 
Table 5: Design performance of the modular tensile design demonstrating thermal equivalence of the $550^{\circ} \mathrm{C}$ temperature case

\begin{tabular}{|c|c|c|c|c|c|c|c|}
\hline \multirow[b]{2}{*}{ Assembly Type } & \multirow[b]{2}{*}{ Specimen Type } & \multirow{2}{*}{ Qty } & \multicolumn{2}{|c|}{ Mass (g) } & \multicolumn{3}{|c|}{ Temperature $\left({ }^{\circ} \mathrm{C}\right)$} \\
\hline & & & Component & Total & Avg. & Min. & Max. \\
\hline \multirow{5}{*}{ SS-2E } & \multirow{3}{*}{ SS-2E } & \multirow{3}{*}{6} & \multirow{3}{*}{0.186} & \multirow{5}{*}{0.813} & 550 & 530 & 560 \\
\hline & & & & & 540 & 536 & 547 \\
\hline & & & & & 525 & 515 & 531 \\
\hline & Liner & 1 & 0.155 & & \multirow{2}{*}{\multicolumn{3}{|c|}{ N/A }} \\
\hline & Coffin & 1 & 0.381 & & & & \\
\hline \multirow{4}{*}{ SS-J type } & \multirow{3}{*}{ SS-J type } & \multirow{3}{*}{3} & \multirow{3}{*}{0.526} & \multirow{4}{*}{0.833} & 547 & 506 & 580 \\
\hline & & & & & 536 & 502 & 570 \\
\hline & & & & & 515 & 498 & 548 \\
\hline & Chevron & 2 & 0.216 & & \multicolumn{3}{|c|}{ N/A } \\
\hline Common & Thermometry & 1 & 0.091 & N/A & 559 & 497 & 604 \\
\hline
\end{tabular}

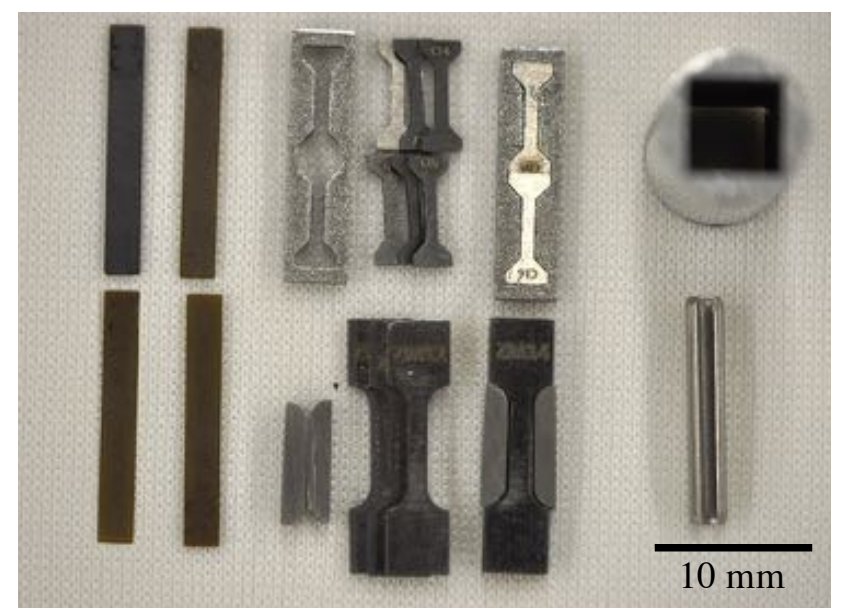

Figure 21: Images of representative specimens and subassemblies. From left to right: SiC thermometry, chevron and coffin assemblies, SS-J type and SS-2E specimens, tensile specimens in holders, and sub-holder assembly and roll pin.

For the ANSYS finite element analysis (FEA) design, a three-dimensional model of the capsule is used to estimate operating temperatures. Given the modular nature of the design, a single tensile configuration layer located at the capsule centerline was analyzed for thermal performance. Scoping analyses were performed to show that all generic configurations of SS-J type/SS-2E tensile specimens perform in the same fashion, given the virtually identical heat loading and contact gaps seen in the loading permutations. The results presented are for a basic 12 specimen loading configuration using only SS-J type specimens (thickness is $0.5 \mathrm{~mm}$ ) with chevrons.

The original rabbits were designed for average irradiation temperatures of $200^{\circ} \mathrm{C}, 330^{\circ} \mathrm{C}$, and $550^{\circ} \mathrm{C}$. Other design temperatures are achievable with little effort, but $200^{\circ} \mathrm{C}$ has been defined as the lower limit. A specific temperature is set by adjusting the holder material and the gap between the holder and the housing. Other boundary conditions such as heating rates and convective heat transfer rates are HFIR specific and assumed to be constant. 
The details for each temperature design case are summarized in Table 6. This information includes holder material, irradiation location, fill gas, and holder design diameter. Note that the $\mathrm{SiC}$ passive thermometry provides nominal irradiation temperature information. Thermometry will be analyzed during post irradiation examination and the results are compared to the predicted temperatures to understand the actual performance of the capsules. Figure 22 shows the temperature contours for the SS-J type specimens for the temperature conditions expressed in Table 6.

Table 6: Design and performance summary for irradiation capsules.

\begin{tabular}{|c|c|c|c|c|c|c|c|c|}
\hline \multirow[t]{2}{*}{ Design Temp. $\left({ }^{\circ} \mathrm{C}\right)$} & \multirow{2}{*}{$\begin{array}{l}\text { Holder Material, } \\
\text { Design Diameter }\end{array}$} & \multirow{2}{*}{$\begin{array}{c}\text { Irradiation } \\
\text { Location, } \\
\text { Fill Gas }\end{array}$} & \multicolumn{3}{|c|}{$\begin{array}{c}\text { Specimen } \\
\text { Temperatures }\left({ }^{\circ} \mathrm{C}\right)\end{array}$} & \multicolumn{3}{|c|}{$\begin{array}{c}\text { Thermometry } \\
\text { Temperatures }\left({ }^{\circ} \mathrm{C}\right)\end{array}$} \\
\hline & & & Avg. & Min. & Max. & Avg. & Min. & Max. \\
\hline \multirow{3}{*}{200} & \multirow{3}{*}{$\begin{array}{l}\text { Al 6061-T6 } \\
9.410 \mathrm{~mm}\end{array}$} & \multirow{3}{*}{$\begin{array}{l}\text { PTP5, } \\
\text { Helium }\end{array}$} & 196 & 170 & 231 & \multirow{3}{*}{242} & \multirow{3}{*}{170} & \multirow{3}{*}{293} \\
\hline & & & 219 & 179 & 250 & & & \\
\hline & & & 231 & 176 & 261 & & & \\
\hline \multirow{3}{*}{330} & \multirow{3}{*}{$\begin{array}{l}\text { Al 6061-T6 } \\
9.230 \mathrm{~mm}\end{array}$} & \multirow{3}{*}{$\begin{array}{l}\text { PTP6, } \\
\text { Helium }\end{array}$} & 307 & 283 & 336 & \multirow{3}{*}{347} & \multirow{3}{*}{283} & \multirow{3}{*}{391} \\
\hline & & & 326 & 291 & 353 & & & \\
\hline & & & 337 & 293 & 362 & & & \\
\hline \multirow{2}{*}{550} & \multirow{2}{*}{$\begin{array}{l}\text { Molybdenum } \\
9.240 \mathrm{~mm}\end{array}$} & \multirow{2}{*}{$\begin{array}{l}\text { PTP5, } \\
\text { Helium }\end{array}$} & 530 & 504 & 557 & \multirow{2}{*}{568} & \multirow{2}{*}{506} & \multirow{2}{*}{613} \\
\hline & & & 548 & 510 & 573 & & & \\
\hline
\end{tabular}


a)

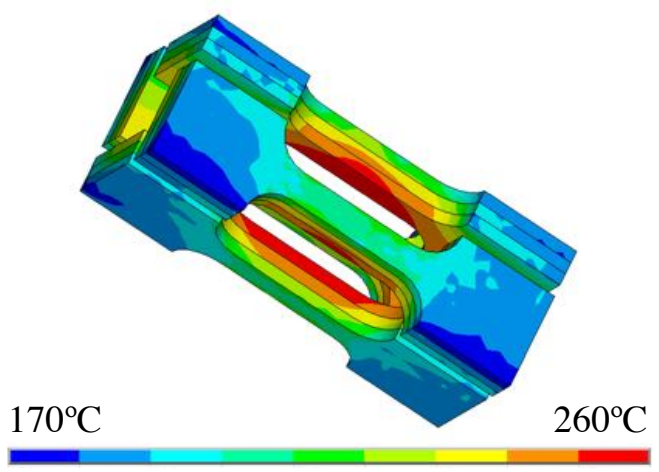

b)

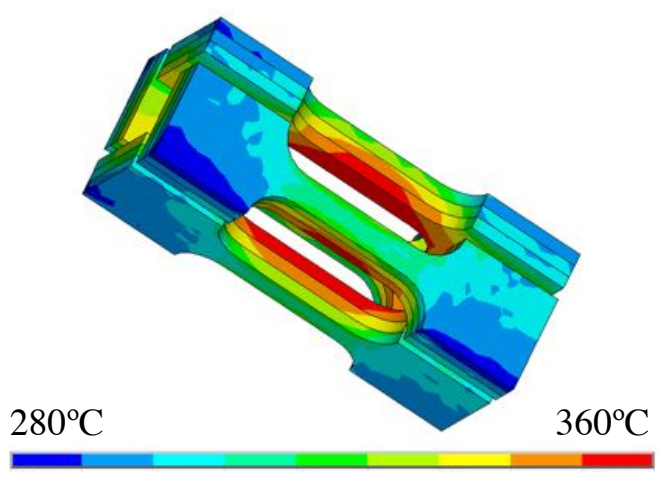

c)

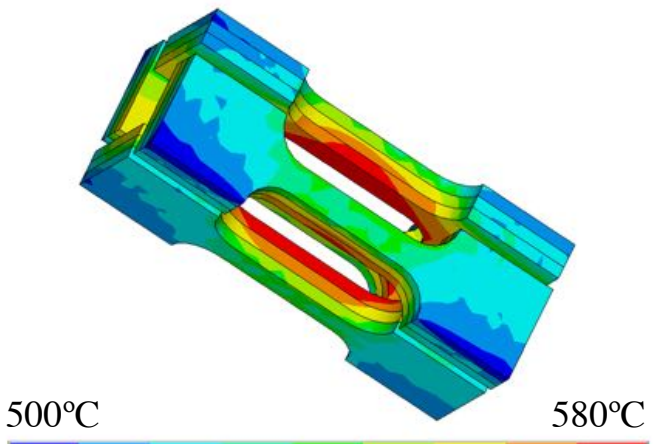

Figure 22: Specimen temperature contours for (a) $200^{\circ} \mathrm{C}$ PTT5 FCAT design, (b) $330^{\circ} \mathrm{C}$ PTT6 FCAT design, and (c) $550^{\circ} \mathrm{C}$ PTT5 FCAT design.

\subsection{Irradiation Test Matrix}

As discussed, the irradiation capsule allows for complete flexibility in the number of SS-2E and/or SS-J type tensile specimens to be loaded into a single capsule. For this program, a mixed design is selected with 27 SS-J type tensile specimens and 18 SS-2E tensile specimens per rabbit. This equates to 45 total specimens per irradiation capsule. As the SS-2E specimen is yet to be proven after irradiation, it was determined alloys and configuration (i.e. different composition and either welded or non-welded) tested with the SS-2E configuration must all also be tested in the SS-J type configuration. Furthermore, at least two specimens, if not more, are needed per specimen configuration and alloy/configuration. Thus, a limited number of alloys can be evaluated in a single rabbit. At the time of original reporting, it was determined that the C35M01TC, C35M10TC, and C36M alloy would not be irradiated within this program [23]. After evaluating the preliminary data in Reference [25], it was deemed that the C35M10TC would undergo irradiation but at the expense of the C35M03TC alloy. Several other experimental alloys 
from other programs are included in each test rabbit to provide a cross comparison of different alloy concepts. The program will have irradiated a total of nine different capsules. Three different temperatures, $200^{\circ} \mathrm{C}, 330^{\circ} \mathrm{C}$, and $550^{\circ} \mathrm{C}$ will be investigated to a total nominal average dose of $2 \mathrm{dpa}, 8 \mathrm{dpa}$, and 15 dpa. The dose and temperature regimes will allow for dose and temperature trends as well as composition trends to be established on both the mechanical response and microstructural response. PIE will be completed in a similar fashion to the following section. Table 7 summarizes the anticipated rabbit deployment within HFIR and the alloys of for each capsule.

Table 7: Irradiation test matrix and single rabbit loading list by alloy type, specimen type, and configuration. Alloys ODS FeCrAl (FCA-ODS) and C06M are FeCrAl alloys currently of interest in other irradiation programs.

\begin{tabular}{|c|c|c|c|c|c|c|}
\hline \multirow{2}{*}{$\begin{array}{l}\text { Capsule } \\
\text { ID }\end{array}$} & \multirow{2}{*}{$\begin{array}{l}\text { Target } \\
\text { Temp } \\
\left({ }^{\circ} \mathrm{C}\right) \\
\end{array}$} & \multirow{2}{*}{$\begin{array}{l}\text { Number } \\
\text { of HFIR } \\
\text { cycles }\end{array}$} & \multirow{2}{*}{$\begin{array}{l}\text { Average } \\
\text { Capsule } \\
\text { Dose } \\
\text { (dpa) } \\
\end{array}$} & \multicolumn{3}{|c|}{ Alloys } \\
\hline & & & & Material Code & \# SS-J/rabbit & \# SS-2E/rabbit \\
\hline FCAT-01 & 200 & 1 & 1.9 & \multirow{9}{*}{$\begin{array}{c}\text { C35M } \\
\text { C36M } \\
\text { C37M } \\
\text { C06M } \\
\text { FCA-ODS } \\
\text { C35MN } \\
\text { C35M10TC } \\
\text { C35M-welded } \\
\text { C37M-welded } \\
\text { C35MN-welded } \\
\text { C35M10TC-welded }\end{array}$} & \multirow{9}{*}{$\begin{array}{l}3 \\
3 \\
3 \\
3 \\
2 \\
2 \\
3 \\
2 \\
2 \\
2 \\
2\end{array}$} & \multirow{9}{*}{$\begin{array}{l}2 \\
3\end{array}$} \\
\hline FCAT-02 & 200 & 4 & 7.6 & & & \\
\hline FCAT -03 & 200 & 8 & 15.2 & & & \\
\hline FCAT-04 & 330 & 1 & 1.9 & & & \\
\hline FCAT-05 & 330 & 4 & 0.4 & & & \\
\hline FCAT-06 & 330 & 8 & 14.9 & & & \\
\hline FCAT-07 & 550 & 1 & 1.9 & & & \\
\hline FCAT-08 & 550 & 4 & 7.6 & & & \\
\hline FCAT-09 & 550 & 8 & 15.2 & & & \\
\hline
\end{tabular}

\section{AS-TESTED UNIRRADIATED MICROSTRUCTURES AND PROPERTIES}

\subsection{Thermal Aging Tests}

Small samples with a nominal size of $400 \mathrm{~mm} \times 400 \mathrm{~mm} \times 0.75 \mathrm{~mm}$ were fabricated from the final sheet product for each alloy in Table 1 to perform simple thermal aging tests. All specimens were laser engraved prior to thermal aging to provide specimen tracking throughout the experiment. Specimens were then thermally aged at either $400^{\circ} \mathrm{C}$ or $475^{\circ} \mathrm{C}$ for up to $\sim 1000 \mathrm{~h}$. At intermittent intervals of $1,4,8,24$, 100,500 and $\sim 1000 \mathrm{~h}$ samples were removed for analysis. All samples removed from the furnace were allowed to air cool and then metallographically polished to a final finish of 1200 grit or better. Surface grinding and polishing was used to remove the surface oxidation layer formed during either sample fabrication and/or thermal aging. Hardness testing was completed to evaluate any changes in materials properties after thermal aging. In particular, changes in hardening during thermal aging have been linked to the precipitation of the Cr-rich $\alpha^{\prime}$ phase (see Refs. $[11,12,14,17,18,38]$ and those within), the same phase that precipitates out under moderate temperature neutron irradiations $\left(<500^{\circ} \mathrm{C}\right)$. Hence, thermal aging provides a low-cost screening tool to evaluate the radiation tolerance of the candidate alloys. To date, only the C35M, C36M, and C37M alloys have been evaluated. 
Hardness testing was completed in accordance with ASTM E384: Standard Test Method for Knoop and Vickers Hardness of Materials using a Wilson VH3100 model microhardness indenter. A Vickers indenter tip was used with an indent load of $300 \mathrm{~g}$ with a dwell time of $10 \mathrm{~s}$. Fifteen indents were completed at random locations for each sample and condition, those that did not meet requirements of the ASTM E384 standard were removed from the dataset and the mean and standard deviation was recorded. Currently, the C35M01TC, C35M03TC, and C35M10TC have not been evaluated due to time restrictions but will be included in the final dataset.

Figure 23 shows the increase in hardness values $(\Delta \mathrm{HV})$ after thermal aging at $400^{\circ} \mathrm{C}$ and $475^{\circ} \mathrm{C}$ up to $1200 \mathrm{~h}$. The non-precipitate dispersion candidate alloys show an increase in hardness at and above $100 \mathrm{~h}$, which is within the agreement with studies on aged $\mathrm{FeCrAl}$ alloys at $475^{\circ} \mathrm{C}$ [11]. With increased aging time, the hardness increased as well with no apparent signs of saturation, although data points out to 5000h that are expected in February 2016 and will either confirm or deny this conclusion. Figure 23 also shows a clear composition effect where the higher Al content FeCrAl alloys (C36M and C37M) showed a lower rate of hardening increase compared to the lower $\mathrm{Al}$ base $\mathrm{C} 35 \mathrm{M}$ alloy, which is comparative to recent results presented in the literature. Finally, a temperature effect is also observed where at $400^{\circ} \mathrm{C}$ a larger hardening effect is observed for the $\mathrm{C} 35 \mathrm{M}$ alloy compared to the $475^{\circ} \mathrm{C}$ aging temperature.
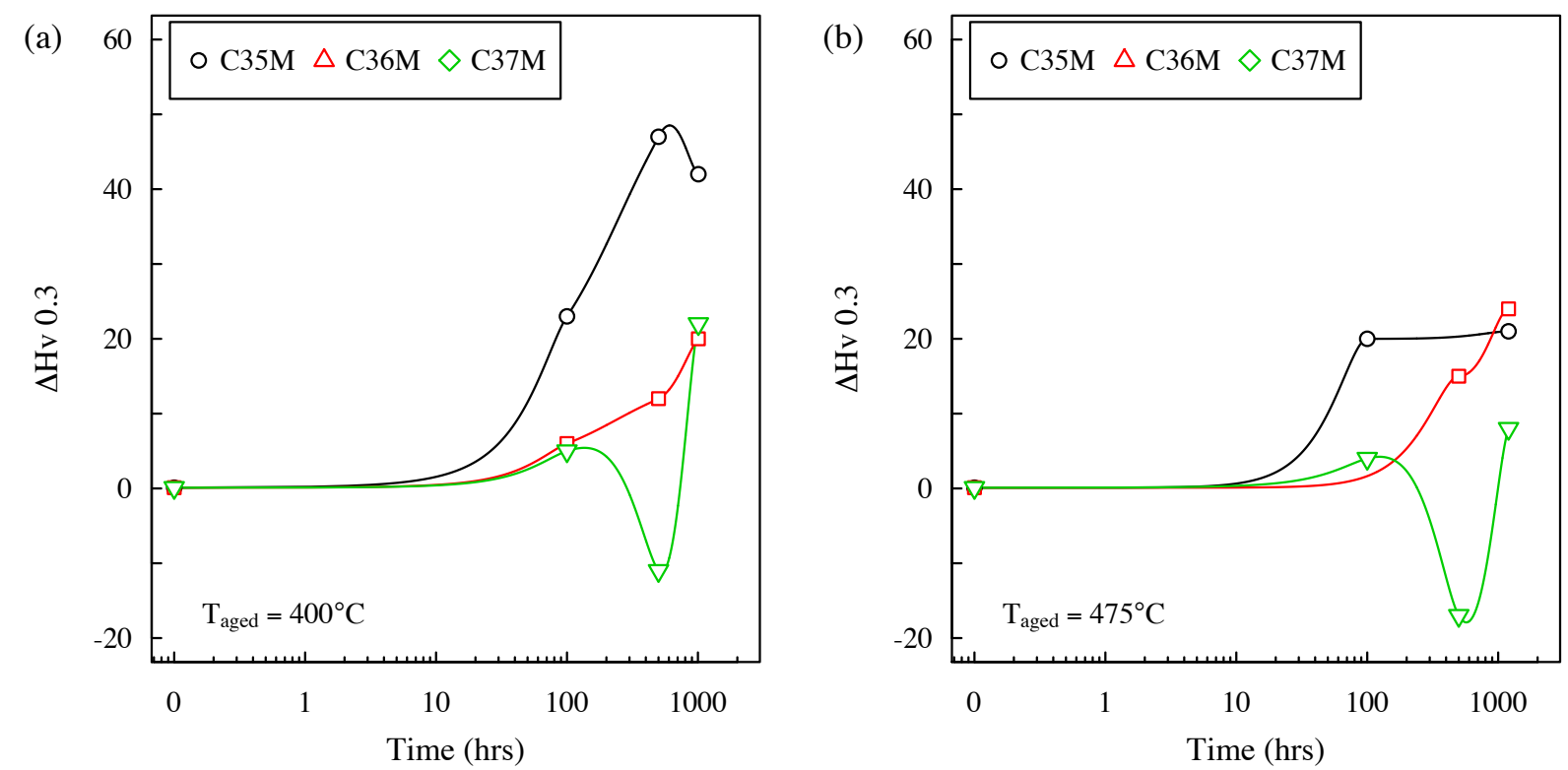

Figure 23: The effect of $\mathrm{Cr}$ and $\mathrm{Al}$ addition on the change in micro hardness in candidate $\mathrm{FeCrAl}$ as a function of time at (a) $400^{\circ} \mathrm{C}$ and (b) $475^{\circ} \mathrm{C}$. Data points are based on averaging greater than 5 individual measurements, standard deviations were on average 4-5 HV 0.3.

The different observed effects (composition, temperature, and time) can be rationalized based on the phase diagram proposed by Kobayashi and Takasugi [11] where a FeCrAl ternary phase diagram was developed by thermally aging a range of compositions at $475^{\circ} \mathrm{C}$. This phase diagram is reproduced in Figure 24, and shows that $\mathrm{Al}$ in solid solution can lead to a shift in the $\alpha-\alpha^{\prime}$ phase boundary where larger amounts of $\mathrm{Cr}$ can exist in solid solution without a phase instability. Thus, it would be expected that as the closer the composition reaches the phase boundary, such as the C36M and C37M alloys, a reduced volume fraction of the Cr-rich $\alpha^{\prime}$ phase would precipitate out leading to a reduced hardening response as seen in our study. A similar composition effect was proposed by Williams [39] where a $\sim 4 \mathrm{wt} . \%$ increase in $\mathrm{Al}$ shifted the $\alpha-\alpha^{\prime}$ phase boundary to higher $\mathrm{Cr}$ contents, but also showed the temperature dependence where the general shape of the phase boundary remained constant with this boundary shift. 
This result would suggest that the alloys observed with Al contents between 5-7 wt.\% would also be closer to the phase boundary at $475^{\circ} \mathrm{C}$ than at $400^{\circ} \mathrm{C}$, hence the observed temperature effects in Figure 23 .

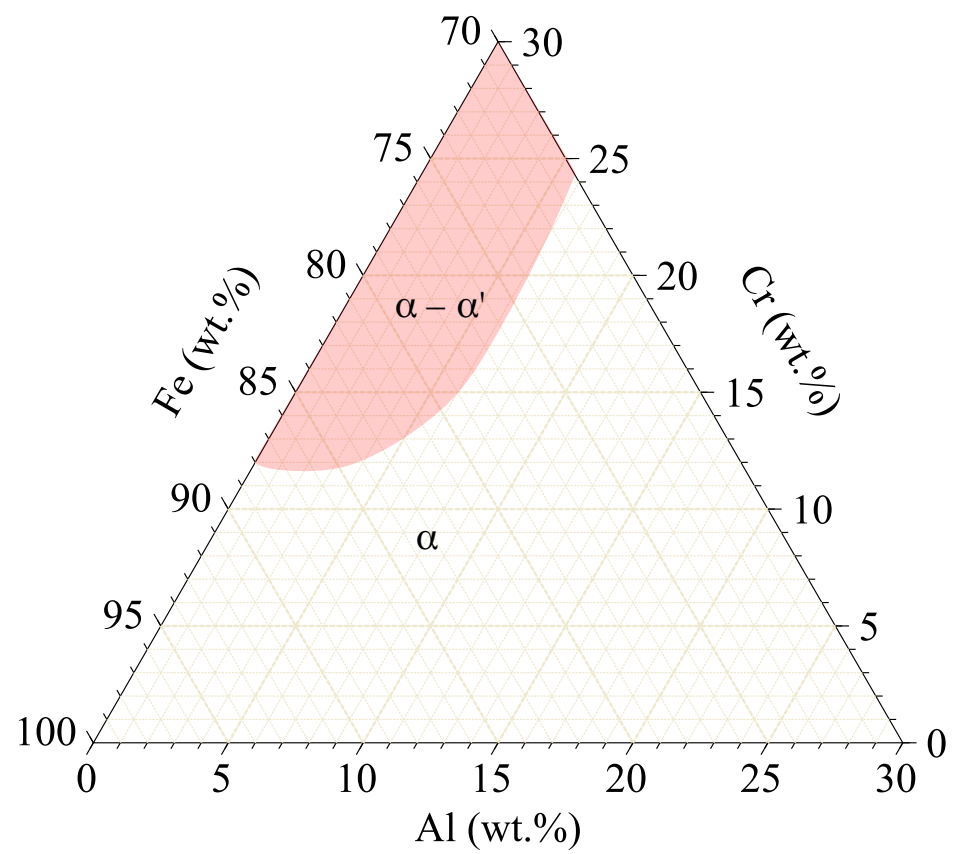

Figure 24: Proposed FeCrAl phase diagram at $475^{\circ} \mathrm{C}$. Adapted for use from Ref. [11].

The preliminary thermal aging results provide an initial insight into the radiation tolerance of the observed candidate alloys. If the phase instability observed via thermal aging remains similar for alloys undergoing neutron irradiation it can be expected that all the observed effects (composition, temperature, and time or irradiation dose) will also play a significant role in the phase stability and hence radiation tolerance of the $\mathrm{FeCrAl}$ alloys.

\subsection{Hydrogen Charging Tests}

Preliminary tests have indicated that cathodic hydrogen charging is the most repeatable and efficient method to introduce hydrogen into the candidate samples and evaluate their susceptibility to hydrogen ingress [25]. Cathodic charging is completed in a solution of $0.1 \mathrm{M}$ sulfuric acid, containing $0.25 \mathrm{~g} / \mathrm{L}$ sodium arsenite powder which is readily soluble in sulfuric acid and acts as a hydrogen recombination inhibitor. Pt wires were spot welded onto the surface of the test specimens and as well as a Pt mesh. The $\mathrm{Pt}$ mesh was used as the anodes. Pt wires were then connected to a DC power supply. Charging current density was maintained at $50-200 \mathrm{~mA} / \mathrm{cm}^{2}$ for the duration of the tests. A LECO ${ }^{\circledR} \mathrm{OH} 836$ oxygen and hydrogen analyzer was used to determine the hydrogen content after cathodic charging. The measurement limits for the hydrogen and oxygen content within the alloys is $0.1 \mathrm{ppm}$ to $2500 \mathrm{ppm}$ and $0.05 \mathrm{ppm}$ to $5 \%$ for a $1 \mathrm{~g}$, respectively. Details on the operation of the LECO ${ }^{\circledR} \mathrm{OH} 836$ oxygen and hydrogen analyzer can be found in Ref. [25]. To limit hydrogen loss during sample transfers between the charging and analyzing system, a small Dewar filled with liquid nitrogen was used. Preliminary trials were completed on small samples of C35M, C36M, and C37M. A total charging time of $48 \mathrm{~h}$ was used at room temperature. Table 3 summarizes the resulting data generated from the test. No significant impact on sample chemistry was observed and all samples exhibited about an order of magnitude higher hydrogen content in the samples undergoing charging compared to the as-received condition. 
Table 8: Oxygen and hydrogen contents after cathodic charging. The oxygen and hydrogen of asreceived samples are also listed for comparison.

\begin{tabular}{c|ccc|ccc}
\hline \multirow{2}{*}{$\begin{array}{c}\text { Sample } \\
\text { ID }\end{array}$} & \multicolumn{3}{|c|}{ As-received } & \multicolumn{3}{c}{$\begin{array}{c}\text { Cathodic H charging } \\
\left(\mathbf{2 0 0 m A} / \mathbf{c m}^{2}, \mathbf{4 8 h}\right)\end{array}$} \\
\cline { 2 - 7 } & Mass & $\mathbf{O}$ & $\mathbf{H}$ & Mass & O (wppm) & H (wppm) \\
\hline \hline C35M & 0.118 & 110 & 1.39 & 0.135 & 116 & 24.5 \\
C36M & 0.104 & 151 & 3.98 & 0.137 & 130 & 21.3 \\
C37M & 0.103 & 171 & 3.72 & 0.144 & 111 & 25 \\
\hline
\end{tabular}

Based on the preliminary results, a set of SS-J type (thickness of $0.5 \mathrm{~mm}$ ) from the C37M alloy was selected for hydrogen charging followed by tensile testing to examine the effect of hydrogen ingress on the mechanical properties of the candidate FeCrAl alloys. Hydrogen loading was performed by using the cathodic hydrogen charging system with an electrical current of $120 \mathrm{~mA} / \mathrm{cm}^{2}$. Two charging durations, $22 \mathrm{~h}$ and $70 \mathrm{~h}$, were conducted to generate two different hydrogen loading contents. Following the hydrogen loading, tensile testing was performed. Then the two broken tabs were used to determine the hydrogen contents by the use of the LECO analyzer.

Figure 25 shows the comparison of the tensile stress-strain curves for as-received, low hydrogen concentration, and high hydrogen concentration specimens with a strain rate of $1 \times 10^{-3} \mathrm{~s}^{-1}$. Table 9 summarizes the mechanical properties and the hydrogen loading conditions of the studied samples. Small variations of the yield stress and ultimate stress were observed. A significant change was observed following hydrogen loading where the reduction of the total elongation, indicating significant changes in the ductility of the alloy due to hydrogen. Higher hydrogen content leads to more significant decrease of the elongation. This is in good agreement with the literature data where the presence of hydrogen always accompanied a reduction of ductility, despite the contradictory effects of hydrogen on yield and tensile strengths of steels $[40,41]$. Different from the tensile behavior of the as-received samples, no obvious necking process was observed for those hydrogen loading samples. The fracture surfaces of the specimens are being investigated and will help to understand the observed mechanical property changes. Note that the hydrogen concentration in these samples is in a low level and the effect of high hydrogen concentration $(>100 \mathrm{wppm})$ on the mechanical properties needs to be addressed.

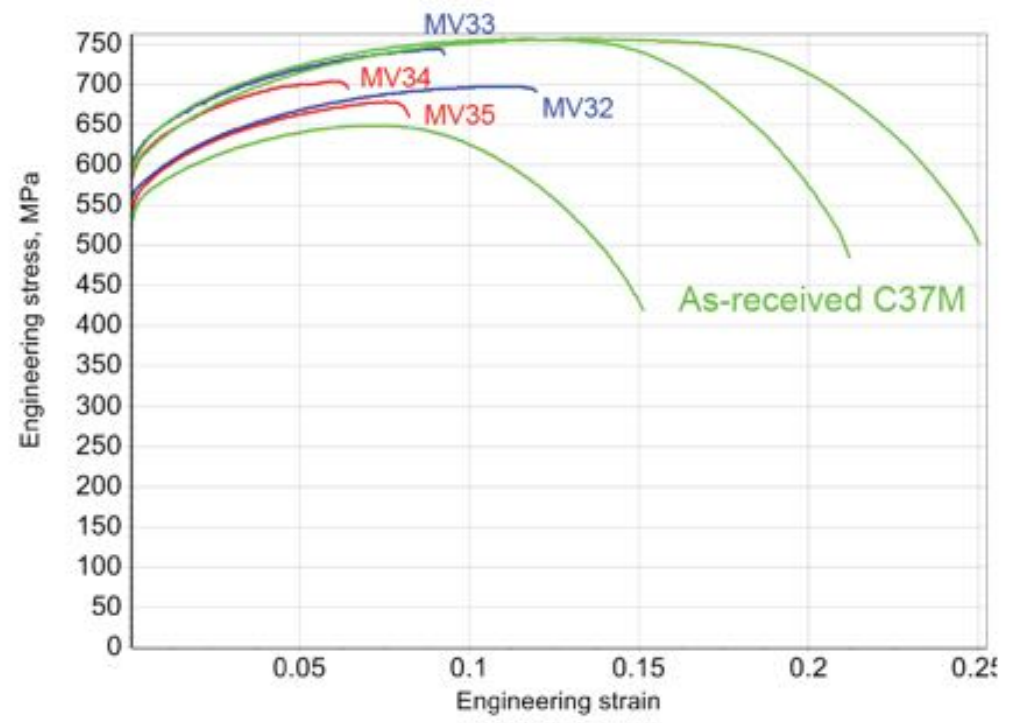

Figure 25: Comparison of tensile testing results for as-received C37M (green), low hydrogen loading sample (blue), and high hydrogen loading sample (red). 
Table 9: Summary of the tensile properties for C37M with different hydrogen contents.

\begin{tabular}{c|cccccc}
\hline \multirow{2}{*}{ Materials } & Conditions & $\begin{array}{c}\text { H content } \\
\text { (wppm) }\end{array}$ & $\begin{array}{c}\text { Yield } \\
\text { stress } \\
(\mathbf{M P a})\end{array}$ & $\begin{array}{c}\text { Ultimate } \\
\text { stress } \\
(\mathbf{M P a})\end{array}$ & $\begin{array}{c}\text { Uniform } \\
\text { elongation (\%) }\end{array}$ & $\begin{array}{c}\text { Total } \\
\text { elongation } \\
\text { (\%) }\end{array}$ \\
\hline \multirow{3}{*}{ C37M } & As-received & 2 & 587.2 & 720.9 & 10.8 & 20.4 \\
\cline { 2 - 7 } & $\begin{array}{c}\text { H loading } \\
(22 \mathrm{~h})\end{array}$ & 22 & 592.4 & 720.8 & 9.9 & 10.8 \\
\cline { 2 - 7 } & $\begin{array}{c}\text { H loading } \\
(70 \mathrm{~h})\end{array}$ & 39 & 579.7 & 691.4 & 6.8 & 7.3 \\
\hline
\end{tabular}

\subsection{Fusion-Based Welding Tests}

Full details on the preliminary and optimized welding trials can be found in previous reports of this program $[23,25]$. Here, only details on the optimized welding trials will be provided. Optimized welding trials were completed on all alloys listed in Table 1 using autogenous, bead-on-plate welding along the traverse rolling direction. A pulsed laser-welding machine was used to perform the welding. No preheating of the parts was used. Full penetration welds were found to occur using a $7 \mathrm{~ms}$ pulse length, 7 pulses $/ \mathrm{s}$ and a $2.12 \mathrm{~mm} / \mathrm{s}$ welding speed. Lamp energy was maintained near 100 Watts for the duration of the welding. Due to the slightly thicker plate product for the C35MN alloys, slightly elevated welding parameters were needed. All welds were completed in an inert argon cover gas. Welded specimens were used for both microstructural characterization and mechanical evaluation as well as the generation of test specimens for the irradiation trials discussed previously. As such, both SS-J type specimens and SS-2E specimens were fabricated from the welded specimens using EDM techniques. An example of the welded C37M part and extraction map can be found in Figure 26. As shown in Figure 26, specimen types (SS-J and SS-2E) were staggered to prevent overlapping HAZs in the specimens. Similar configurations were used for all alloys in Table 1.
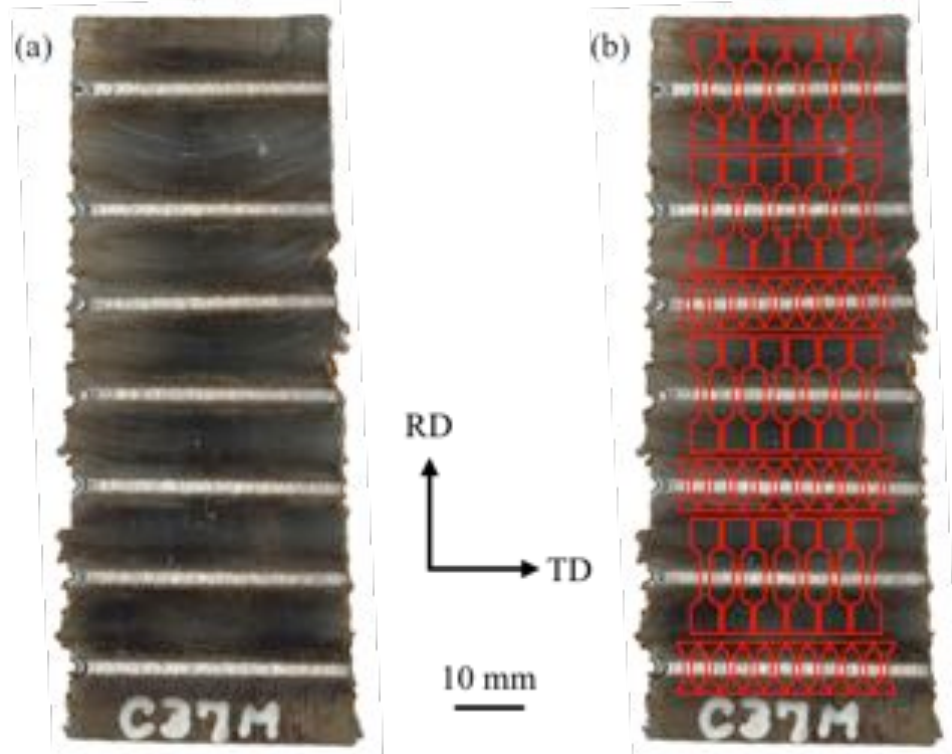

Figure 26: Image of cross-welds performed using laser welding techniques on the C37M alloy; (a) as imaged, (b) with overlays of SS-J type and SS-2E sample geometries to show where samples were fabricated from. 
Cross-sections of optimized welded specimens were metallographically prepared for SEM-EBSD observations. Identical conditions for SEM-EBSD were used for the welded and as-received specimens. Due to the large size of the primary feature, the fusion zone, several SEM-EBSD maps were generated and then manually stitched to provide a full field-of-view of the weldment. Figure 27 shows the stitched image of each weldment investigated to date. For most alloys (C35M, C37M, C35M01TC, and C35M03TC), welding led to the formation of relatively large grains of irregular shapes near the weldment centerline. This feature was complemented by elongated or columnar grains which appeared roughly 300$400 \mu \mathrm{m}$ away from the centerline. The width of the columnar grain area was on the order of $300 \mu \mathrm{m}$. Nearly $1 \mathrm{~mm}$ away from the centerline a distinct area of course grained, yet round shaped grains were observed. It is believed this region is the HAZ where melting did not occur, but the specimen temperature was well above the recrystallization temperature for the materials. The $\mathrm{C} 37 \mathrm{M}$ alloy showed a manufacturing defect, Figure 27b, that was cured by welding as it did not appear within the fusion zone of the weldment. All other alloys were defect free and showed no signs of cracking and deposits.

The C35M10TC had a distinctly different microstructure in the fusion zone compared to the other observed alloys. The grain size of the fusion zone was significantly reduced on the order of 3-5 times smaller. The columnar grain area was also smaller and appeared more elongated. The grains were also different with more torturous boundaries dominating the weldment. Based on the observed microstructures in Figure 27c-e, the addition of TiC appeared to increase the fraction of grain boundaries pinned during the melt and solidification process. When the nominal TiC addition increases up to $1 \mathrm{wt} \%$, the TiC pinned a significant fraction of the grain boundaries leading to limited grain growth resulting in a reduced grain size. This pinning effect can observed by the increased fraction of torturous grain boundaries in the C35M10TC specimen. This mechanism appeared to only occur in the fusion zone, where base metal melting occurred, but areas where the temperature did not exceed the melting point, such as in the elongated grain region and coarse-grained region, the addition of $\mathrm{TiC}$ did not have a significant effect on the grain morphology. 
a)

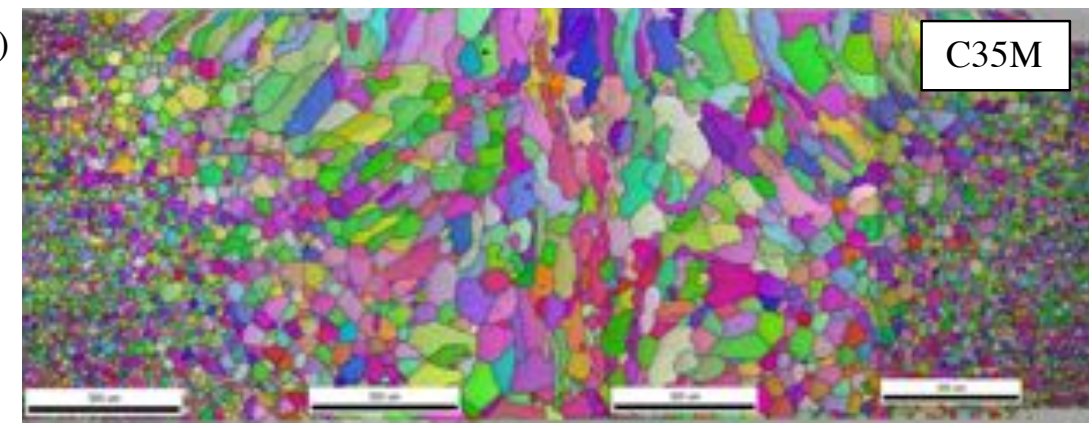

b)

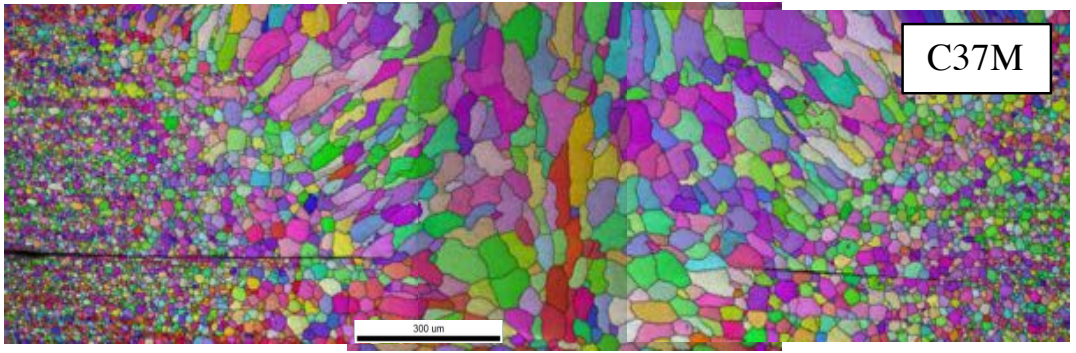

c)

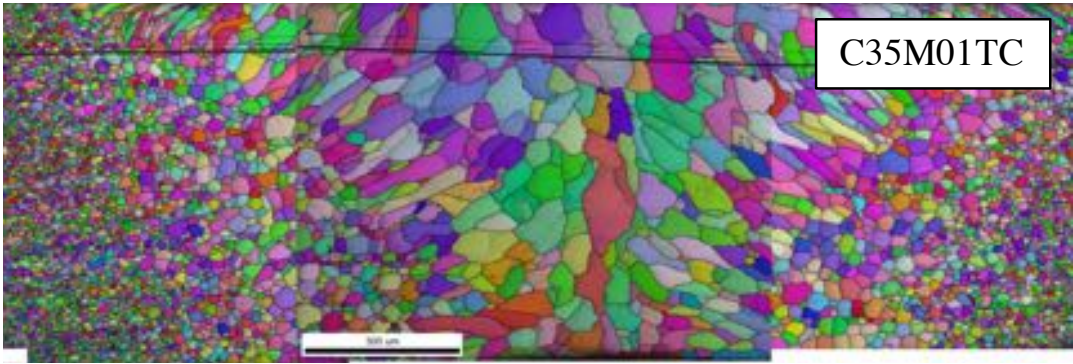

d)

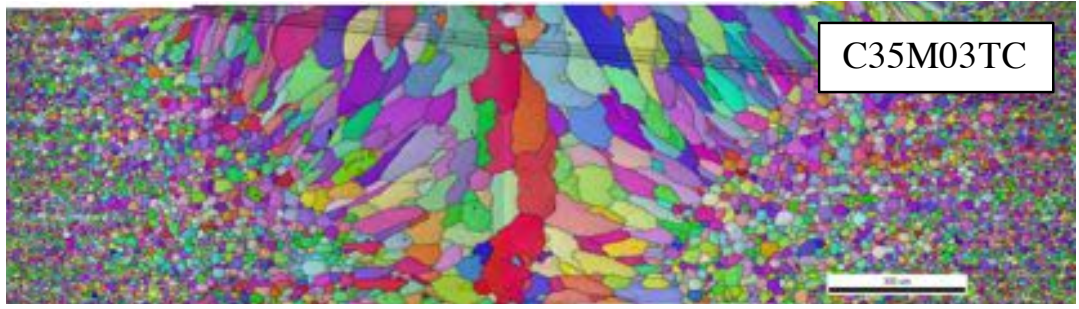

e)

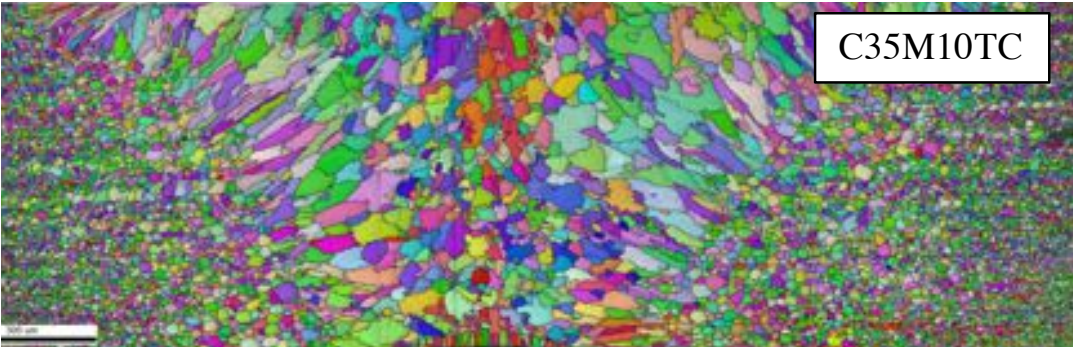

Figure 27: SEM-EBSD determined IPF maps showing weldment structure in the (a) C35M, (b) C37M, (c) C35M01 TC, (d) C35M03TC, and (e) C35M10TC candidate alloys. 
The C35M, C37M, C35M01TC, and C35M03TC weldments in Figure 27 where evaluated using microhardness mapping using the same parameters in Section 5.1 but with a $100 \mu \mathrm{m}$ spacing, Figure 28. Microhardness mapping was used to determine the confluences between the observed microstructure and mechanical properties. All investigated alloys showed a decrease in hardness corresponding to the fusion zone, columnar grain region, and grain growth regions. The alloys with $\mathrm{TiC}$ additions showed distinct drops in hardness in the columnar grain growth region while the fusion zone reached hardness values closer to the values of the base metal. In Figure 28d, the heterogeneity in the as-rolled structure of the alloy can be observed far from the weldment where the central thickness of the specimen showed higher hardness values. The lower hardness in the weldment over the base alloy suggests that under tensile testing the localized necking and final failure is most likely to occur in the weldment based on the results of Field et al. [34].

a)

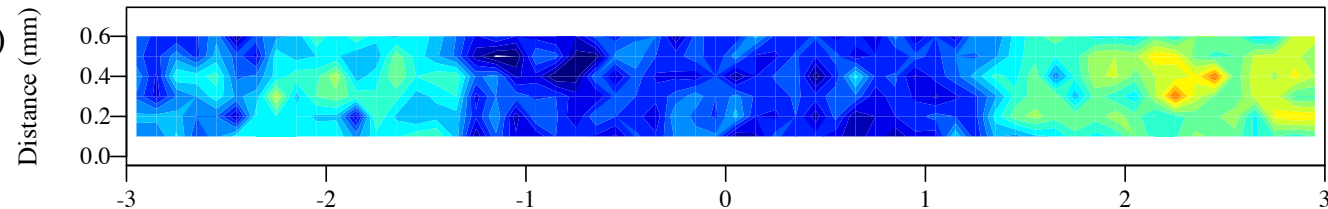

b)

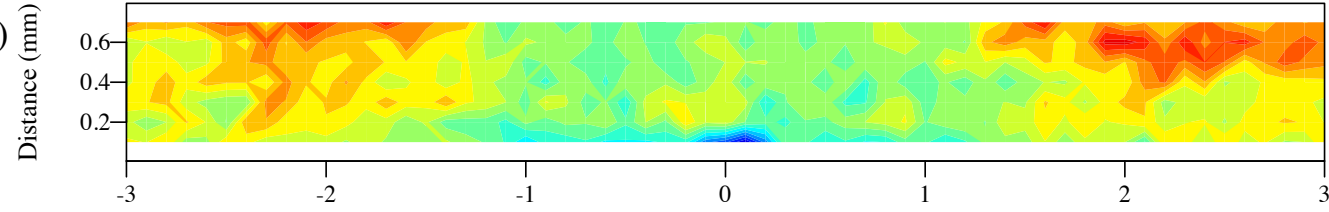

c)

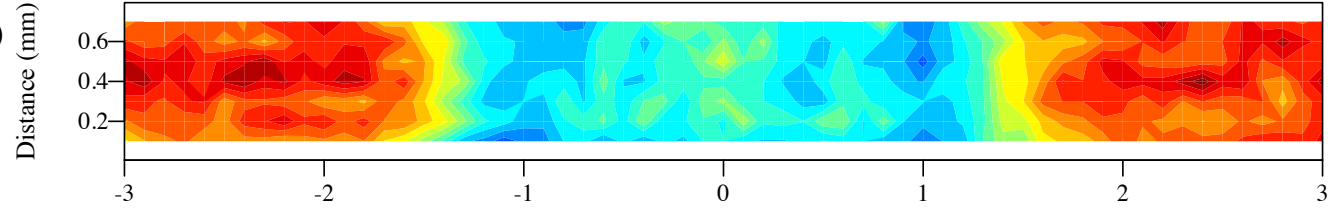

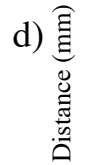

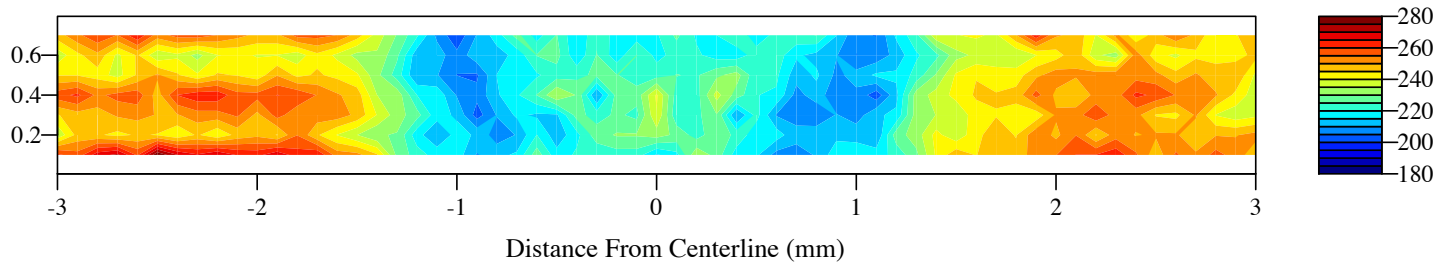

Figure 28: Cross weld hardness maps (Hv 0.3) taken at $100 \mu \mathrm{m}$ x $100 \mu \mathrm{m}$ spacing of (a) C35M, (b) C37M, (c) C35M01TC, and (d) C35M03TC. Color scale is the same for each map.

At the moment, the mechanical testing of the welded specimens is in progress; limited data for comparison with the as-received materials are available and will be discussed below. Table 10 shows the mechanical properties of the same alloys before and after welding. The engineering mechanical properties, calculated from the tensile curves, showed some softening (yield stress decreased at $\sim 12-15 \%$ ) and strong decrease in the specimen ductility (see also tensile curves in Figure 29). However, it may be speculated that the formal ductility decrease is not an issue; local ductility and neck formation might be more important for the material performance. The FeCrAl alloys are usually sensitive to the weldinginduced embrittlement, and there was a risk to get an unpredictable, brittle fracture for the welded specimens. However, the tensile curves (Figure 29) demonstrated well-developed neck and smooth localized deformation without visible signs of embrittlement. 
Table 10: Mechanical properties of the welded specimens in comparison with the as-received material.

\begin{tabular}{|c|c|c|c|c|c|}
\hline \multirow{2}{*}{ Alloy } & Condition & $\begin{array}{c}\text { Yield } \\
\text { stress, } \\
\text { MPa }\end{array}$ & $\begin{array}{c}\text { Ultimate } \\
\text { stress, MPa }\end{array}$ & $\begin{array}{c}\text { Uniform } \\
\text { elongation, } \\
\text { \% }\end{array}$ & $\begin{array}{c}\text { Total } \\
\text { elongation, \% }\end{array}$ \\
\hline \hline \multirow{2}{*}{ C37M } & As-received & 587.2 & 720.9 & 10.8 & 20.4 \\
\cline { 2 - 6 } & Welded & 514.0 & 629.0 & 4.5 & 4.5 \\
\hline \multirow{2}{*}{ C35MT10 } & As-received & 581.6 & 707.5 & 14.6 & 23.0 \\
\cline { 2 - 6 } & Welded & 518.8 & 683.4 & 6.8 & 12.0 \\
\hline
\end{tabular}

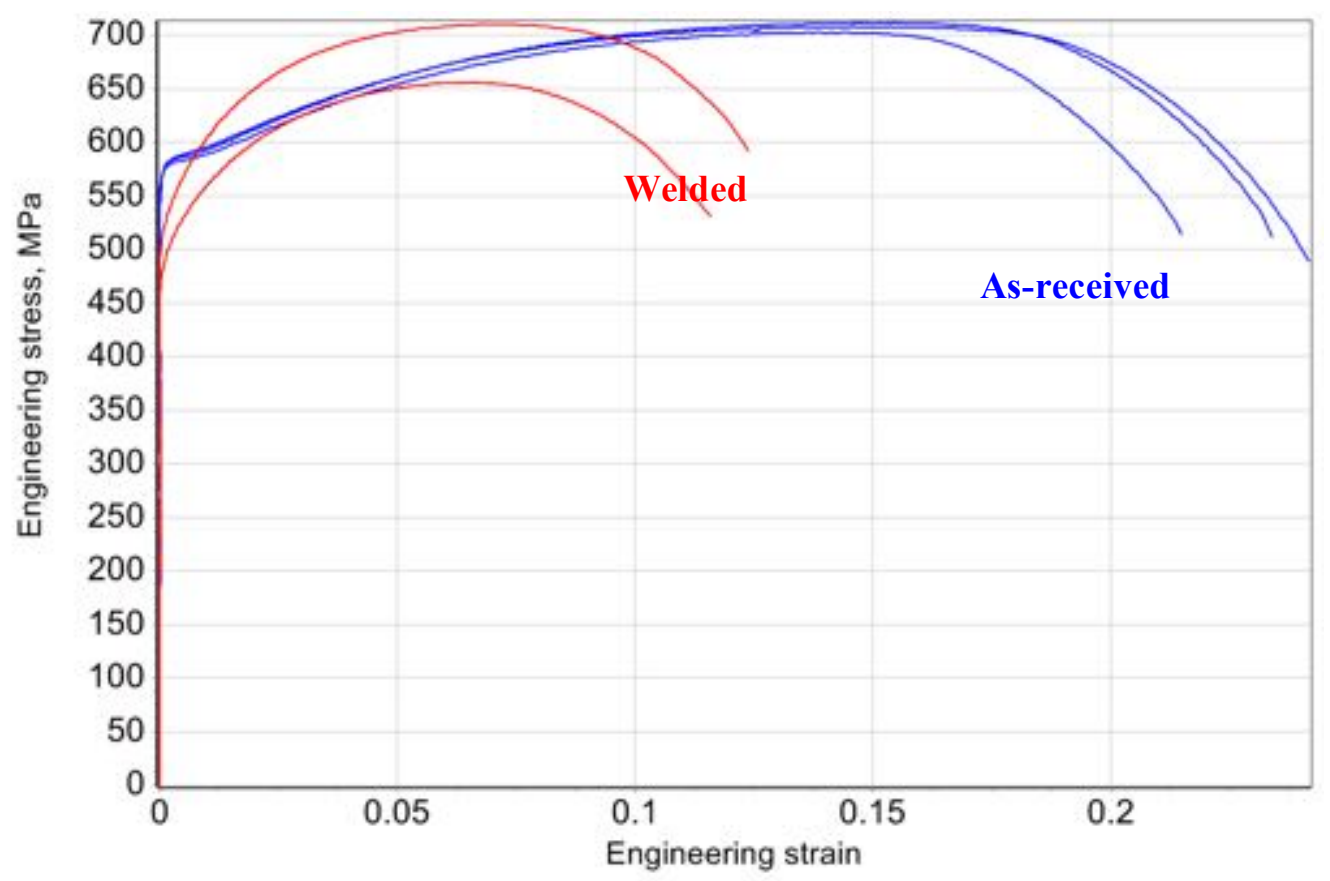

Figure 29: Engineering tensile curves for the C35M10TC alloy before and after welding.

It is worth to note the following. Since the weldment size is much smaller than the gauge length, the welded specimens contain multiple areas: the weldment itself, heat-affected zones (HAZs) and parent material. The conventional tensile test may guarantee the minimal carrying capacity of the object (specimen with weldment) and provide the yield stress value for the weakest area (in most cases, weldment), but there is a limited capacity to retrieve the true mechanical behavior for different areas using usual tensile data. Therefore, the tensile testing in the present project is accompanying by optic strain measurements (DIC). Some preliminary DIC results for the welded specimen are shown in Figure 30 and Figure 31. First, DIC testing demonstrated differences in local yield stress and local plastic strain distribution, Figure 30, as expected from the hardness maps in Figure 1. Weldment is not necessarily the weakest area (see the complex strain patterns for Frames \#40 and \#50), but the largest plastic strains and fracture were usually observed in the weldment. Second, the local mechanical behavior of the weldment region, Figure 31, revealed high ductility of the welded alloy with ultimate stress value close to the parent, non-welded material. 

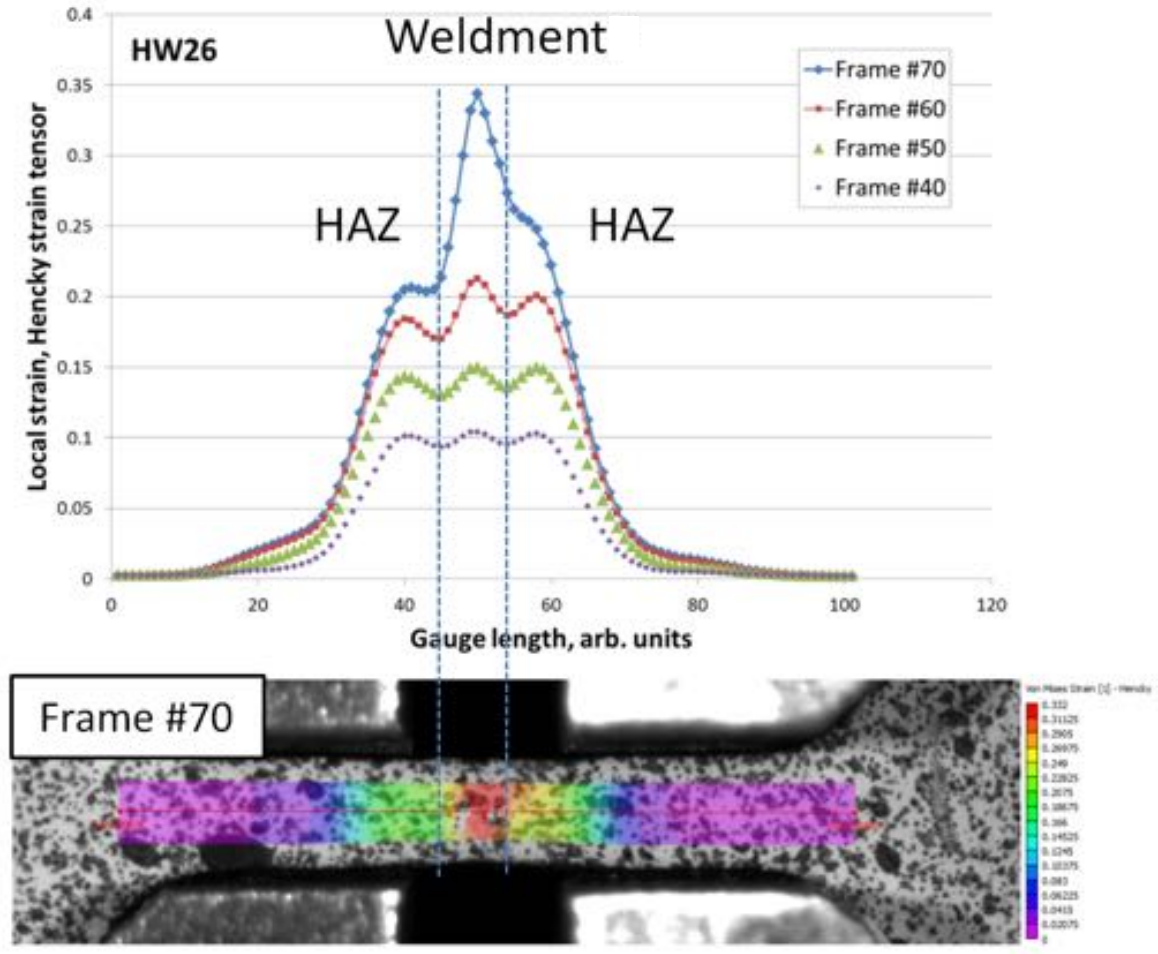

Figure 30: Strain distribution at the surface of the C35M10TC welded specimen.

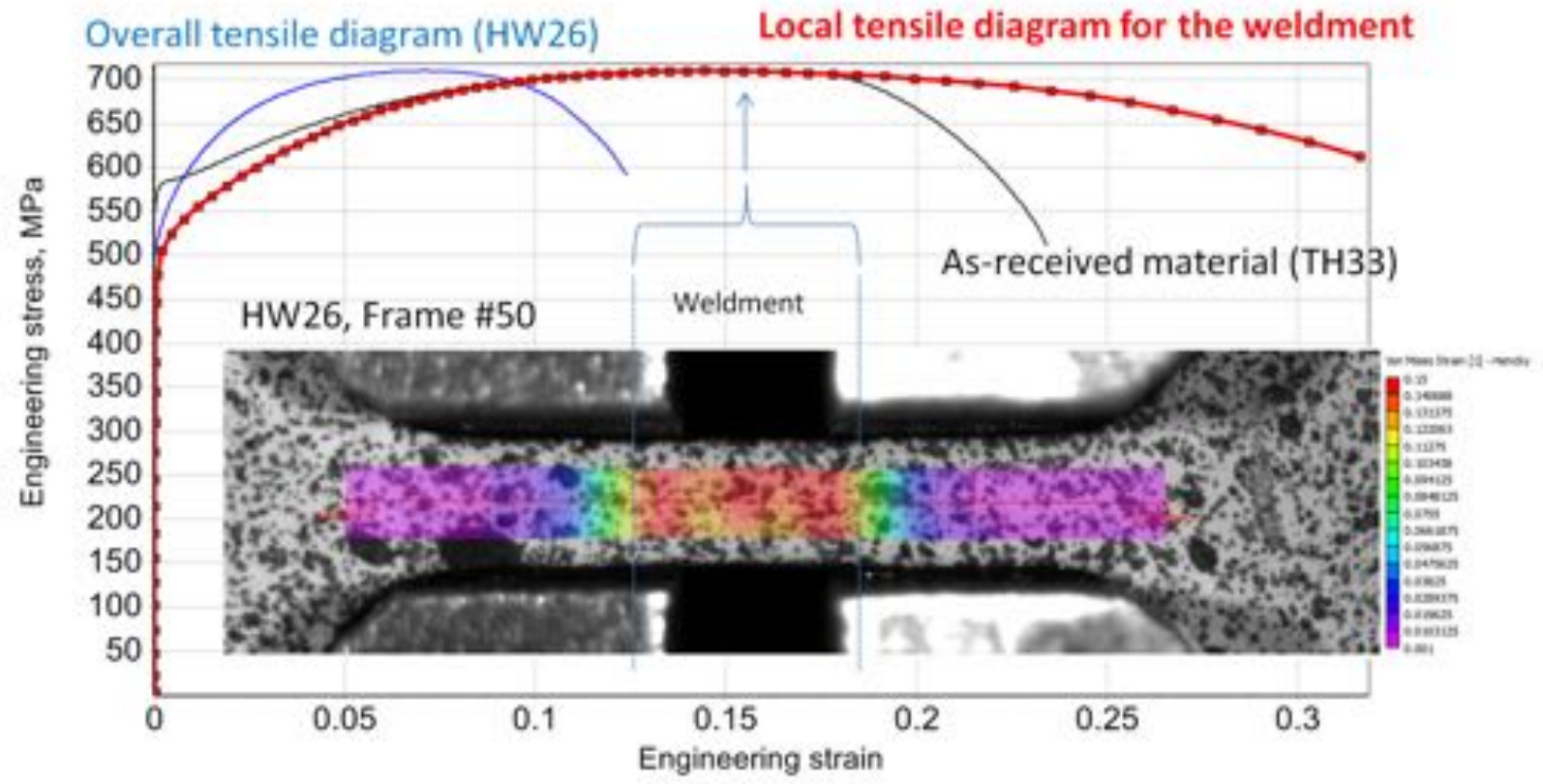

Figure 31: The local mechanical behavior of the weldment (C35M10TC alloy).

Although no brittle fracture was observed in the tensile tests performed at the moment, and the specimens demonstrated acceptable ductility and good necking behavior, the SEM analysis revealed significant changes in the fracture mechanisms compared to unwelded test specimens. After welding, the 
investigated materials demonstrated a strong shift from pure ductile fracture mode to a mixed, ductile plus cleavage fracture, Figure 32 and Figure 33. Most often, dimples and cleavage areas co-existed for the same specimen.

The change in fracture mechanisms raises a question on more quantitative analysis of the fracture. It was decided to estimate the normal fracture stress (the ratio of acting load to the cross-section) for the tested specimens, and this work is in progress.

a)

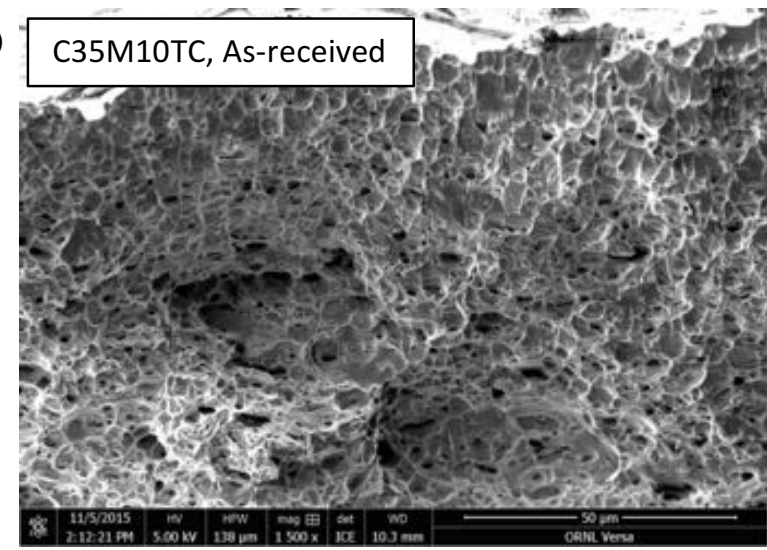

c)

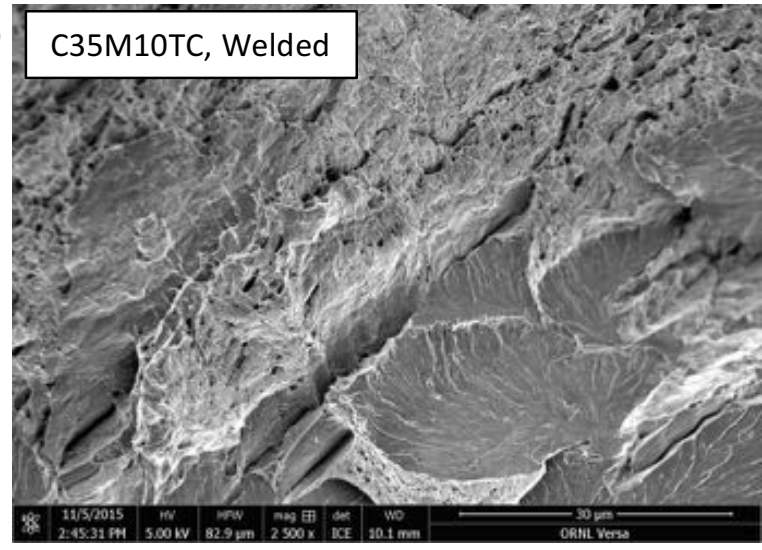

b)

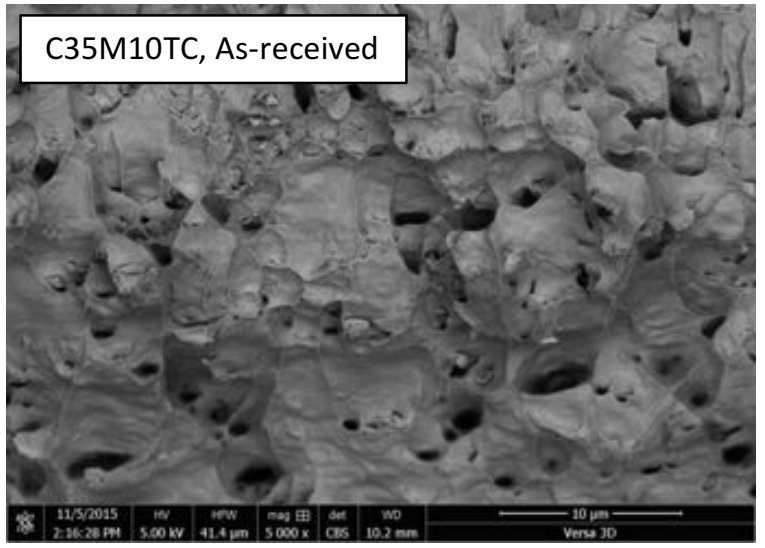

d)

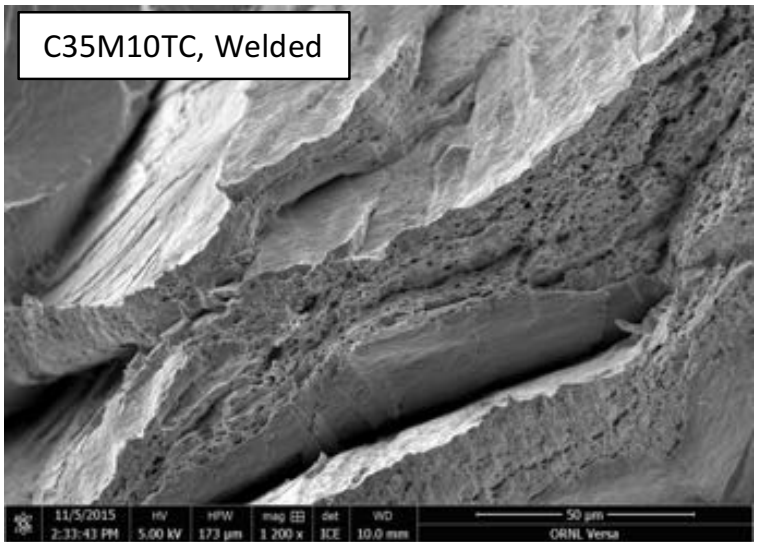

Figure 32: The impact of the laser welding on the C35M10TC alloy fracture mechanism, c) lower magnification image and d) higher magnification image. The fracture surface of the as-received specimen, a) lower magnification image and d) higher magnification image, is shown to underline the degree of changes. 
a)

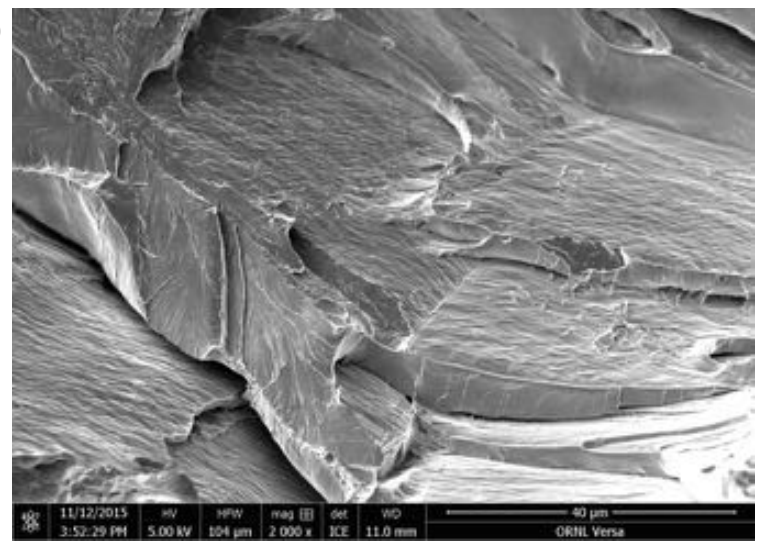

b)

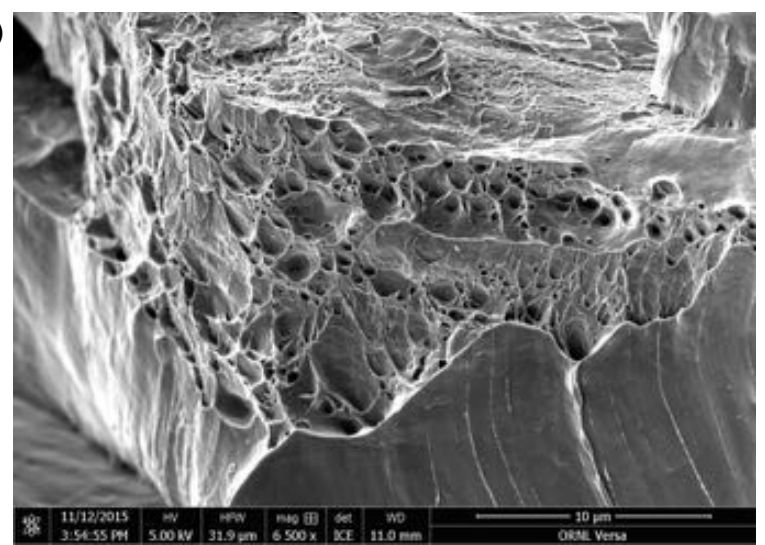

Figure 33: The typical fracture surface in the fusion zone of the welded C35M01TC alloy specimen, a) high magnification and b) low magnification images.

The ratio between ductile and cleavage, brittle fracture varied among the studied materials. The most drastic changes (almost pure cleavage) were observed for the C37M alloy, Figure 34. 
a)

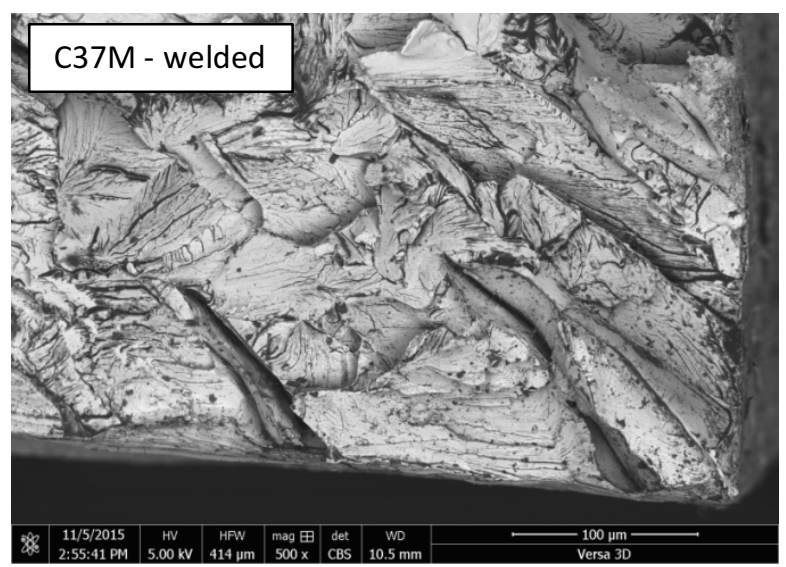

b)

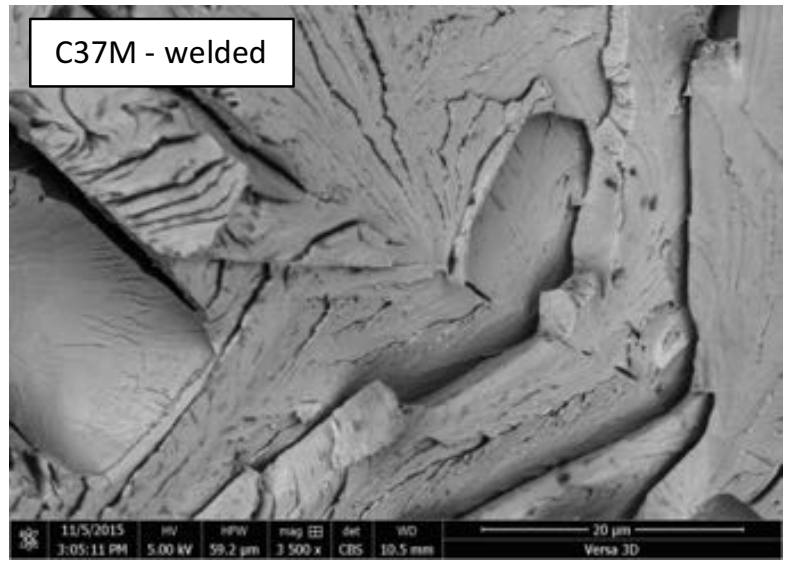

c)

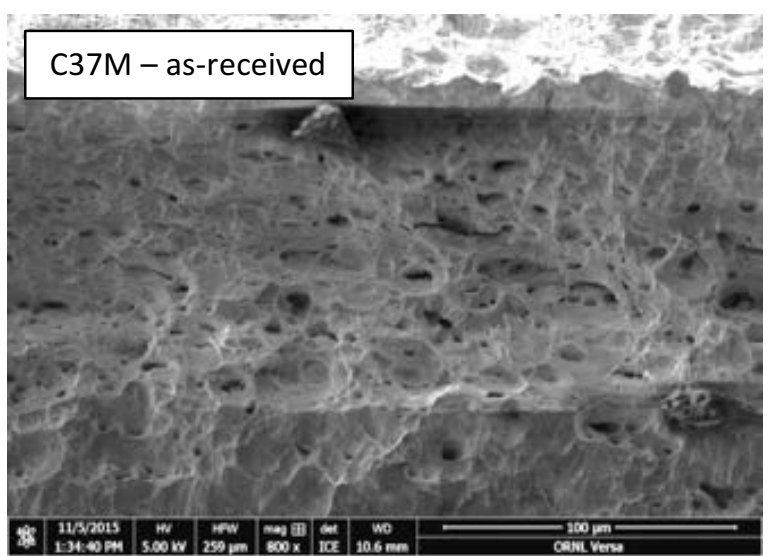

Figure 34: The impact of the laser welding on the C37M alloy fracture mechanism, a) lower magnification image and $b$ ) higher magnification image. The fracture surface of the as-received (c) specimen is shown at the bottom to underline the degree of changes.

The mechanical testing results (hardness mapping and tensile testing) indicates that the specimen strengths decreased after welding. The engineering ductility decreased as well but the tensile necking behavior did not reveal critical embrittlement. The material in the weldment remained ductile with the ability to undergo strain-induced hardening. For the welded specimens, the SEM fractography analysis revealed changes from pure ductile to mixed (dimples + cleavage) fracture mode. Further analysis is needed to quantify the changes. 


\section{CONCLUSIONS}

The results and discussion provided in the present report provides the foundational understanding on the alloy development efforts towards a $\mathrm{FeCrAl}$ alloy class specifically designed to have enhanced weldability and radiation tolerance for nuclear power production applications. Key activities leading to this foundation include the fabrication of seven candidate FeCrAl alloys with well controlled chemistry and microstructure, the microstructural characterization of these alloys using standardized and advanced techniques, mechanical properties testing and evaluation of base alloys, the completion of welding trails and production of weldments for subsequent testing, the design of novel tensile specimen geometry to increase the number of samples that can be irradiated in a single capsule and also shorten the time of their assessment after irradiation, the development of testing procedures for controlled hydrogen ingress studies, and a detailed mechanical and microstructural assessment of weldments prior to irradiation or hydrogen charging. Although significant strides have been made by these activities, more development into advanced $\mathrm{FeCrAl}$ alloys are needed before full commercialization of this alloy class can be realized.

\section{REFERENCES}

[1] K.A. Terrani, S.J. Zinkle, L.L. Snead, Advanced oxidation-resistant iron-based alloys for LWR fuel cladding, J. Nucl. Mater. 448 (2013) 420-435. doi:10.1016/j.jnucmat.2013.06.041.

[2] K.A. Terrani, Y.J. Kim, B.A. Pint, Uniform Corrosion of Model FeCrAl Alloys in LWR Coolants, 2015 Am. Nucl. Soc. Annu. Meet. (2015).

[3] B.A. Pint, S. Dryepondt, K.A. Unocic, D.T. Hoelzer, Development of ODS FeCrAl for compatibility in fusion and fission energy applications, Jom. 66 (2014) 2458-2466.

doi:10.1007/s11837-014-1200-z.

[4] B.A. Pint, K.A. Terrani, M.P. Brady, T. Cheng, J.R. Keiser, High temperature oxidation of fuel cladding candidate materials in steam-hydrogen environments, J. Nucl. Mater. 440 (2013) 420 427. doi:10.1016/j.jnucmat.2013.05.047.

[5] J. Tusek, A. Kosmac, U. Nartnik, A. Dejan, Welding of heat-resistant $20 \% \mathrm{Cr}-5 \% \mathrm{Al}$ steels, Z. Met. 93 (2002) 310-314.

[6] H. El Kadiri, Y. Bienvenu, K. Solanki, M.F. Horstemeyer, P.T. Wang, Creep and tensile behaviors of $\mathrm{Fe}-\mathrm{Cr}-\mathrm{Al}$ foils and laser microwelds at high temperature, Mater. Sci. Eng. A. 421 (2006) 168181. doi:10.1016/j.msea.2005.11.048.

[7] J.N. Dupont, J.R. Regina, K. Adams, Improving the weldability of fecral weld overlay coatings, Foss. Energy Mater. Conf. (2007) 131-137.

[8] J.R. Regina, J.N. Dupont, A.R. Marder, The effect of chromium on the weldability and microstructure of Fe-Cr-Al weld cladding, Weld. J. 86 (2007) 170-178.

[9] T.R.G. Kutty, C. Ganguly, Identation creep of Zircaloy-2 welds of nuclear fuel pins, J. Nucl. Mater. 207 (1993) 345-349.

[10] M. Ahmad, J.I. Akhter, M.A. Shaikh, M. Akhtar, M. Iqbal, M.A. Chaudhry, Hardness and microstructural studies of electron beam welded joints of Zircaloy-4 and stainless steel, J. Nucl. Mater. 301 (2002) 118-121. 
[11] S. Kobayashi, T. Takasugi, Mapping of $475^{\circ} \mathrm{C}$ embrittlement in ferritic Fe-Cr-Al alloys, Scr. Mater. 63 (2010) 1104-1107. doi:10.1016/j.scriptamat.2010.08.015.

[12] J.J. Heger, 885F embrittlement of the ferritic chromium-iron alloys, Met. Prog. (1951) 55-61.

[13] C. Capdevila, M.K. Miller, G. Pimentel, J. Chao, Influence of recrystallization on phase separation kinetics of oxide dispersion strengthened Fe-Cr-Al alloy, Scr. Mater. 66 (2012) 254-257. doi:10.1016/j.scriptamat.2011.11.003.

[14] M. Courtnall, F. Pickering, The effect of alloying on 485 C embrittlement, Met. Sci. 10 (1976) 273-276.

[15] E.A. Little, Neutron-irradiation hardening in irons and ferritic steels, Int. Met. Rev. 21 (1976) 2559.

[16] M. Bachhav, G. Robert Odette, E.A. Marquis, $\alpha^{\prime}$ precipitation in neutron-irradiated Fe-Cr alloys, Scr. Mater. 74 (2014) 48-51. doi:10.1016/j.scriptamat.2013.10.001.

[17] K.G. Field, X. Hu, K.C. Littrell, Y. Yamamoto, L.L. Snead, Radiation tolerance of neutronirradiated model Fe-Cr-Al alloys, J. Nucl. Mater. 465 (2015) 746-755. doi:10.1016/j.jnucmat.2015.06.023.

[18] F. Bergner, C. Pareige, M. Hernández-Mayoral, L. Malerba, C. Heintze, Application of a threefeature dispersed-barrier hardening model to neutron-irradiated $\mathrm{Fe}-\mathrm{Cr}$ model alloys, J. Nucl. Mater. 448 (2014) 96-102. doi:10.1016/j.jnucmat.2014.01.024.

[19] S. Messoloras, B.C. Pike, R.J. Stewart, C.G. Windsor, Precipitation in iron-chromium-aluminium alloys, Met. Sci. 18 (1984) 311-321.

[20] L.E. Steele, J.R. Hawthorne, H.E. Watson, Irradiation Effects on Reactor Structural Materials, Washington, D.C., 1965.

[21] H.S. Edwards, K.M. Bohlander, Physico-chemical studies of Fe-Cr-Al-clad fuel systems, General Electric, 1968.

[22] High-Temperature Materials Program Progess Report No. 59, Part A, General Electric, Cincinnati, Ohio, 1966.

[23] K.G. Field, R.H. Howard, Y. Yamamoto, Design of Experiment for Irradiation of Welded Candidate Fe-Cr-Al Alloys, Oak Ridge National Laboratory, Oak Ridge, TN, 2015.

[24] K.G. Field, M.N. Gussev, Y. Yamamoto, X. Hu, R.H. Howard, Preliminary Studies on the Fabrication and Characterization of Fe-Cr-Al Alloys Designed to Have Enhanced Weldability and Radiation Tolerance, Oak Ridge National Laboratory, Oak Ridge, TN, 2015.

[25] K.G. Field, M.N. Gussev, X. Hu, Y. Yamamoto, Preliminary Results on FeCrAl Alloys in the Asreceived and Welded State Designed to Have Enhanced Weldability and Radiation Tolerance, Oak Ridge, TN, 2015.

[26] Y. Yamamoto, B.A. Pint, K.A. Terrani, K.G. Field, L.L. Snead, Development and property evaluation of nuclear grade wrought FeCrAl fuel cladding for light water reactors, Accept. - J. Nucl. Mater. (2015). 
[27] M.A. Sutton, J.J. Orteu, H. Schreier, Image Correlation for Shape, Motion and Deformation Measurements: Basic Concepts, Theory and Applications, Springer Science \& Business Media, 2009. https://books.google.com/books?hl=en\&lr=\&id=AlkqMxpQMLsC\&pgis=1 (accessed December 22, 2015).

[28] T. CONNOLLEY, P.E. MCHUGH, M. BRUZZI, A review of deformation and fatigue of metals at small size scales, Fract. Eng. Mater. Struct. 28 (2005) 1119-1152. doi:10.1111/j.14602695.2005.00951.x.

[29] Y. Kohno, A. Kohyama, M.L. Hamilton, T. Hirose, Y. Katoh, F.A. Garner, Specimen size effects on the tensile properties of JPCA and JFMS, J. Nucl. Mater. 283-287 (2000) 1014-1017. doi:10.1016/S0022-3115(00)00245-2.

[30] P. Hosemann, C. Shin, D. Kiener, Small scale mechanical testing of irradiated materials, J. Mater. Res. 30 (2015) 1-15. doi:10.1557/jmr.2015.26.

[31] G.S. Was, J.T. Busby, T.R. Allen, E.A. Kenik, A. Jenssen, S.M. Bruemmer, et al., Emulation of neutron irradiation effects with protons; validation of principle, J. Nucl. Mater. 300 (2002) 198216.

[32] M.N. Gussev, J.T. Busby, K.G. Field, M.A. Sokolov, S.E. Gray, Role of Scale Factor During Tensile Testing of Small Specimens, (2014) 1-19. doi:10.1520/stp157620140013.

[33] R.L. Klueh, Miniature tensile test specimens for fusion reactor irradiation studies, Nucl. Eng. Des. Fusion. 2 (1985) 407-416. doi:10.1016/0167-899X(85)90028-X.

[34] K.G. Field, M.N. Gussev, Y. Yamamoto, L.L. Snead, Deformation behavior of laser welds in high temperature oxidation resistant $\mathrm{Fe}-\mathrm{Cr}-\mathrm{Al}$ alloys for fuel cladding applications, J. Nucl. Mater. 454 (2014) 352-358. doi:10.1016/j.jnucmat.2014.08.013.

[35] E. Wakai, S. Nogami, R. Kasada, A. Kimura, H. Kurishita, M. Saito, et al., Small specimen test technology and methodology of IFMIF/EVEDA and the further subjects, J. Nucl. Mater. 417 (2011) 1325-1330. doi:10.1016/j.jnucmat.2011.02.011.

[36] O.N. Pierron, D.A. Koss, A.T. Motta, Tensile specimen geometry and the constitutive behavior of Zircaloy-4, J. Nucl. Mater. 312 (2003) 257-261. doi:10.1016/S0022-3115(02)01554-4.

[37] J. Džugan, P. Konopik, M. Rund, R. Prochazka, Determination of Local Tensile and Fatigue Properties With the Use of Sub-Sized Specimens, in: Vol. 1A Codes Stand., ASME, 2015: p. V01AT01A066. doi:10.1115/PVP2015-45958.

[38] P.J. Grobner, The 885F (475C) embrittlement of ferritic stainless steels, Metall. Trans. 4 (1973) 251-260.

[39] R.O. Williams, Further studies of the iron-chromum system, Trans. Met. Soc. AIME. 212 (1958) 497-502.

[40] G. V. Karpenko, N.Y. Yarmchenko, M.M. Shved, Effect of hydrogen on the strength of iron, Sov. Mater. Sci. 7 (1973) 304-306. doi:10.1007/BF00723599.

[41] Y. Murakami, T. Kanezaki, Y. Mine, Hydrogen Effect against Hydrogen Embrittlement, Metall. Mater. Trans. a-Physical Metall. Mater. Sci. 41A (2010) 2548-2562. doi:10.1007/s11661-0100275-6. 